\title{
ANALYSIS OF PARTICLES THOROUGH THE AORTIC ARCH DURING TRANSCATHETER AORTIC VALVE REPLACEMENT
}

\author{
A Thesis \\ Presented to \\ the Faculty of California Polytechnic State University, \\ San Luis Obispo
}

In Partial Fulfillment

of the Requirements for the Degree

Master of Science in Biomedical Engineering

By,

Andrew Joseph Janicki

June 2015 
(C)2015

Andrew Joseph Janicki

ALL RIGHTS RESERVED 


\section{COMMITTEE MEMBERSHIP}

TITLE:

AUTHOR:

DATE SUBMITTED:

COMMITTEE CHAIR:

COMMITTEE MEMBER:

COMMITTEE MEMBER:
Analysis of Particles Thorough the Aortic Arch During Transcatheter Aortic Valve Replacement Andrew Joseph Janicki

June 2015

Associate Professor David Clague, Ph.D., Department of Biomedical \& General Engineering

Cameron Purcell, MS., R\&D Engineer II at Claret Medical

Professor Dan Walsh, Ph.D., Department of Biomedical \& General Engineering 


\begin{abstract}
Analysis of Particles Thorough the Aortic Arch During Transcatheter Aortic Valve Replacement

Andrew Joseph Janicki

Ischemia caused by particles becoming dislodged during transcatheter aortic valve replacement (TAVR) is a possible complication of TAVR. The particles that become dislodged can travel out of the aortic valve, into the aortic arch, and then into either the brachiocephalic artery, the left common carotid artery, the left subclavian artery or continue into the descending aorta. If the particles continue into the descending aorta it poses no risk of causing ischemia however if it travels into the other arteries then it increases the possibility of the particle causing an ischemic event. The goal of this study is to determine what parameters cause the particle to enter one artery over another. The parameters analyzed are the particle diameter, the particle density, the blood pressure, and the diameter of the catheter used in the surgery. This was done by creating a finite element model in COMSOL Multiphysics ${ }^{\circledR}$ to track the particles flowing through a scan of an actual aortic arch. It was determined that the particle diameter, particle density, and the blood pressure affect which artery the particles take to exit the aortic arch. However the diameter of the surgical catheter used in a transaortic approach is not statistically significant when determining which artery the particles will exit. The study shows that larger diameter particle would lead to a higher transmissions probability into the brachiocephalic artery, the left common carotid artery, and the left subclavian artery while a smaller diameter particle would have a higher transmission probability for the descending aorta. Averaging all particle diameters, densities and blood pressure found that $54.95 \pm 13.66 \%$ of the particles released will travel into the cerebral circulatory system.
\end{abstract}




\section{TABLE OF CONTENTS}

LIST OF TABLES.................................................................................................................

LIST OF FIGURES ............................................................................................................ii

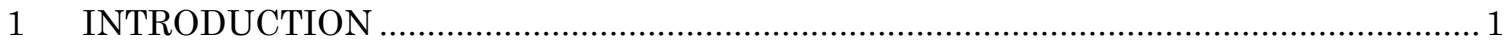

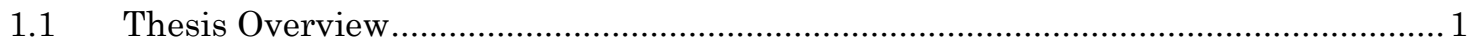

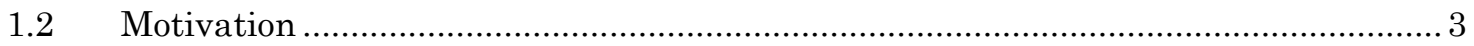

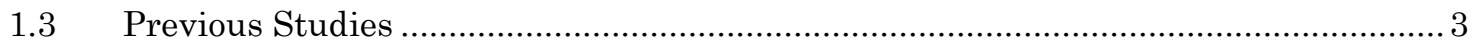

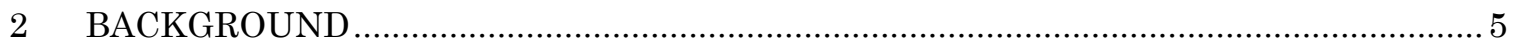

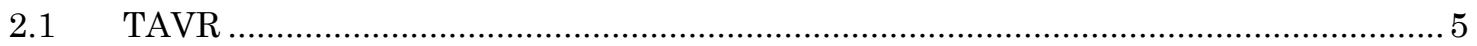

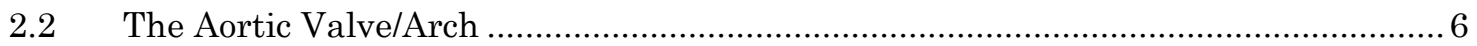

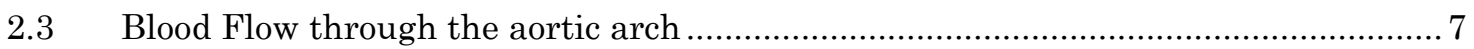

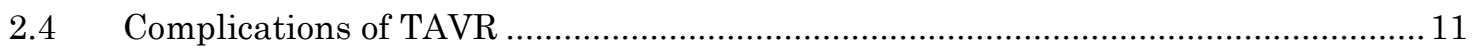

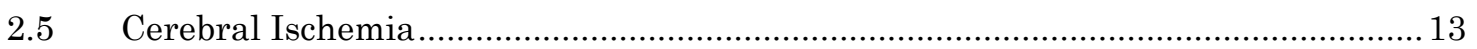

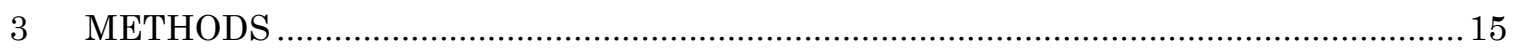

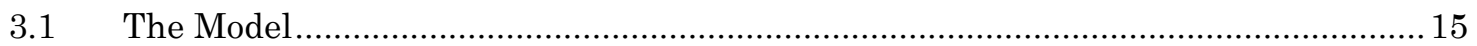

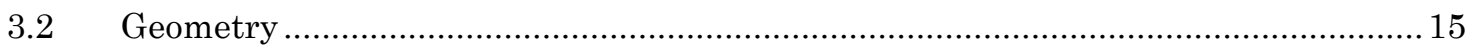

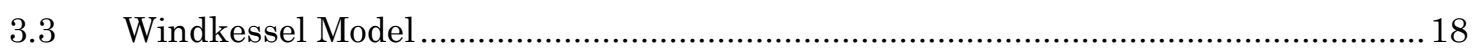

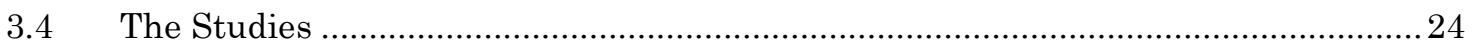

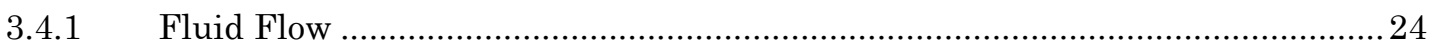

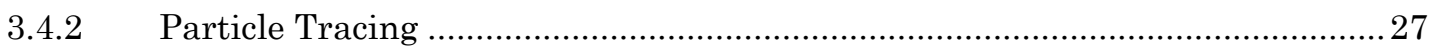

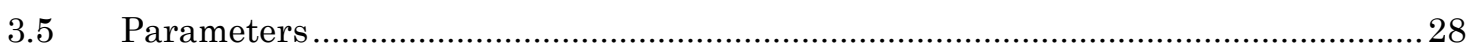

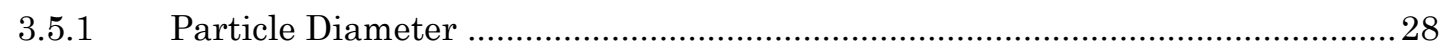

3.5.2 Number of Particles .......................................................................................

3.5.3 Density of the particles ................................................................................

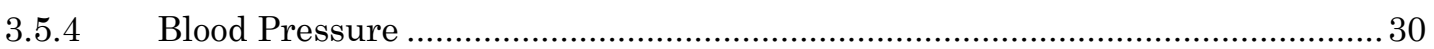

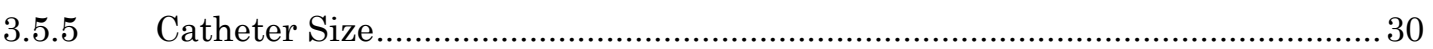

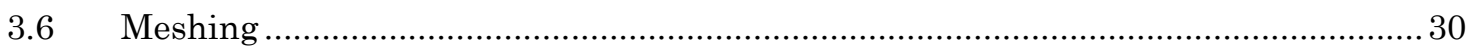

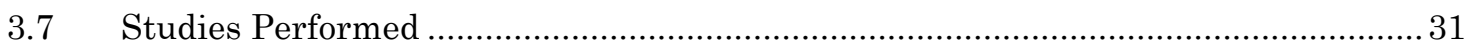

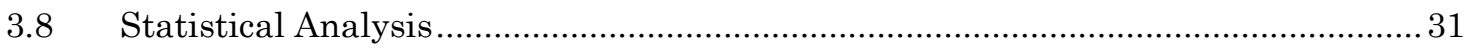

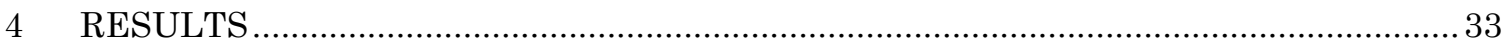

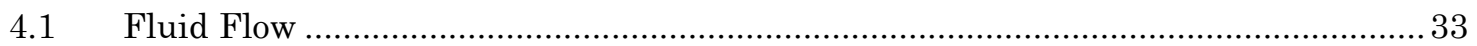

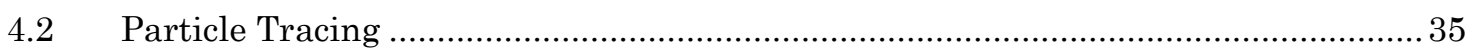

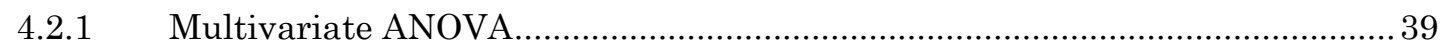

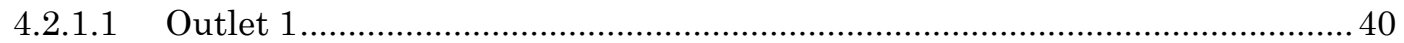




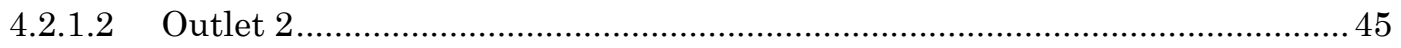

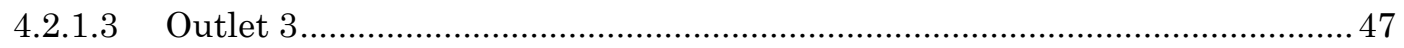

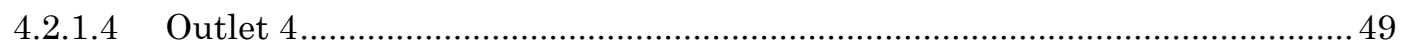

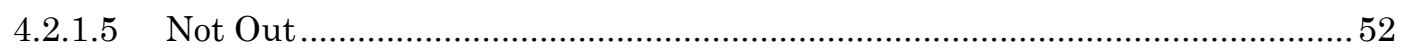

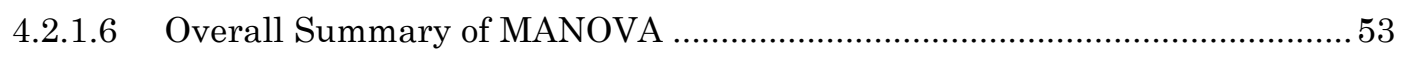

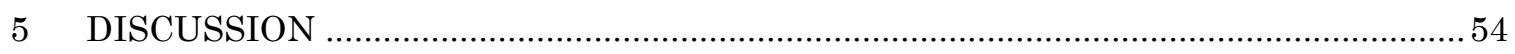

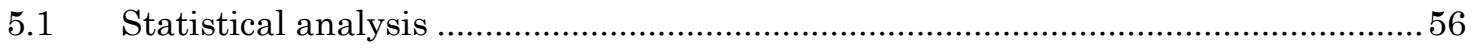

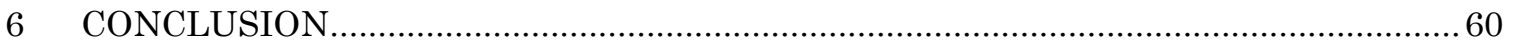

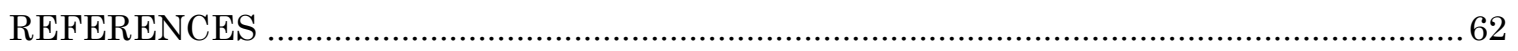

APPENDICES

A: CONVERTING CT SCAN INTO COMSOL MULTIPHYSICS $®$.................................... 67

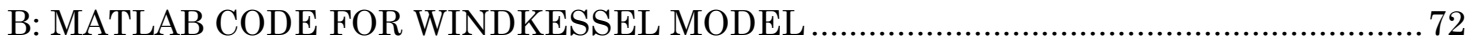

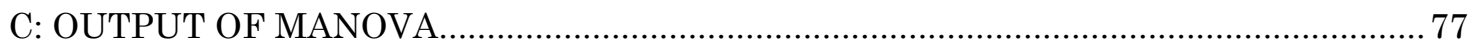




\section{LIST OF TABLES}

Table 1: Different settings for the Windkessel model .22

Table 2: Transmission probability of particles leaving each outlet with $3 \mathrm{~mm}$ included and excluded. .36

Table 3: Outlet 1 interaction of blood pressure and particle diameter. ................................... 40

Table 4: Outlet 1 interaction of blood pressure and particle density...................................... 42

Table 5: Outlet 2 interaction of blood pressure and particle diameter. ................................... 45

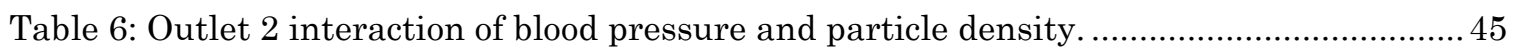

Table 7: Outlet 3 interaction of particle diameter and particle density. .................................. 47

Table 8: Outlet 3 interaction of particle diameter and blood pressure. .................................. 48

Table 9: Outlet 4 interaction of particle diameter and particle density. ................................... 49

Table 10: Outlet 4 interaction of particle diameter and blood pressure. .................................50

Table 11: Outlet 4 interaction of blood pressure and particle density.....................................51

Table 12: Not Out interaction of particle diameter and blood pressure. …..............................52 


\section{LIST OF FIGURES}

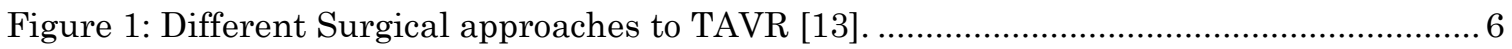

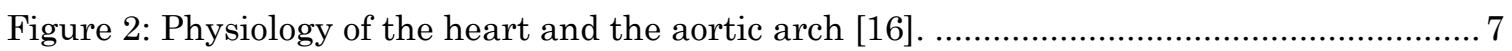

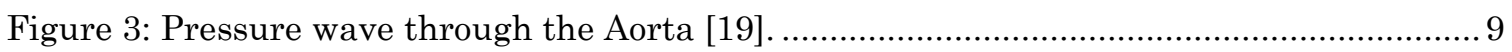

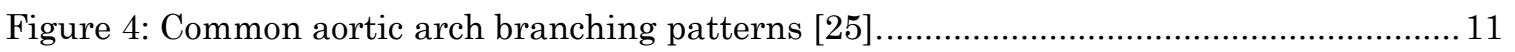

Figure 5: Original file G1-07-HH arch_001.stl opened in MeshLab. .....................................16

Figure 6: Simplified G1-070HH arch _001.stl opened in MeshLab......................................... 17

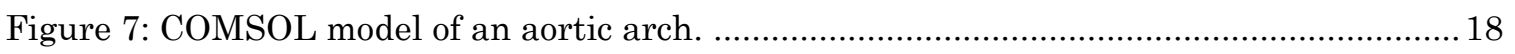

Figure 8: Electrical circuit of the four element Windkessel model [37]..................................20

Figure 9: Arterial pressure for three Windkessel Models: a - measured pressure (solid line, black dots), b - 4 Element Model (dashed line, red dots), c - 3WM (dot line, blue

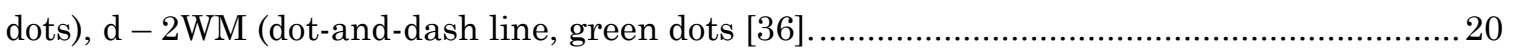

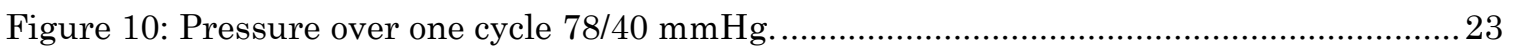

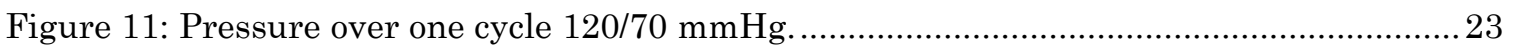

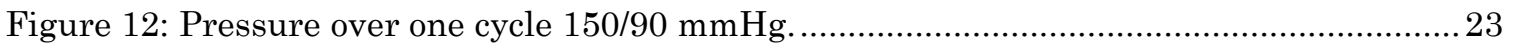

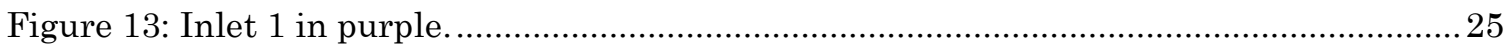

Figure 14: Fluid Outlets: Panel A shows brachiocephalic (1), left common carotid (2), and left subclavian arteries (3). Panel B shows the descending aorta (4). .............................26

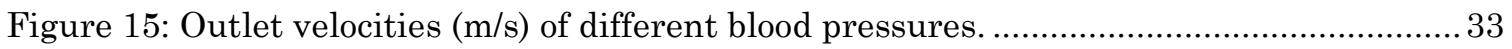

Figure 16: Velocity magnitude $(\mathrm{m} / \mathrm{s})$ with a catheter diameter of $8.667 \mathrm{~mm}$ and a blood pressure $150 / 90 \mathrm{mmHg}$ at different time intervals. Panel 'A' at 0 seconds, panel 'B' at 2.6 seconds, panel 'C' at 5.2 seconds, panel 'D' at 7.8 seconds, panel 'E' at 10.4 seconds, and panel ' $\mathrm{F}$ ' at 13 seconds.

Figure 17: Particle tracing catheter diameter $7.33 \mathrm{~mm}$, blood pressure 150/90 $\mathrm{mmHg}$, particle diameter $0.25 \mathrm{~mm}$, particle density $0.8 \mathrm{~g} / \mathrm{cm}^{3}$, Panel 'A' at 0.5 seconds, panel 'B' at 3.5 seconds, panel 'C' at 6.5 seconds, panel 'D' at 9.5 seconds and panel 'E' at 13 seconds.....

Figure 18: Particle tracing catheter diameter $7.33 \mathrm{~mm}$, blood pressure 150/90 $\mathrm{mmHg}$, particle diameter $3 \mathrm{~mm}$, and particle density $0.8 \mathrm{~g} / \mathrm{cm}^{3}$. Panel 'A' at 0.5 seconds, panel 'B' at 3.5 seconds, panel 'C' at 6.5 seconds, panel 'D' at 9.5 seconds and panel 'E' at 13 seconds.

Figure 19: LS Means Plot for outlet 1 interaction of blood pressure and particle

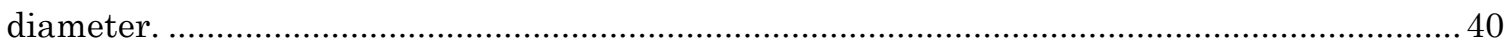

Figure 20: LS Means Plot for outlet 1 interaction of blood pressure and particle density ...... 42 Figure 21: LS Means Plot for outlet 2 interaction of blood pressure and particle

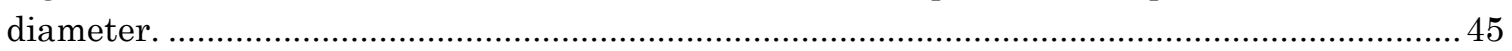

Figure 22: LS Means Plot for outlet 2 interaction of blood pressure and particle density...... 46 Figure 23: LS Means Plot for outlet 3 interaction of particle diameter and particle density. .47

Figure 24: LS Means Plot for outlet 3 interaction of particle diameter and blood pressure.

Figure 25: LS Means Plot for outlet 4 interaction of particle diameter and particle density.

Figure 26: LS Means Plot for outlet 4 interaction of particle diameter and blood pressure. 
Figure 27: LS Means Plot for outlet 4 interaction of blood pressure and particle density. .....51 Figure 28: LS Means Plot for not out interaction of particle diameter and blood

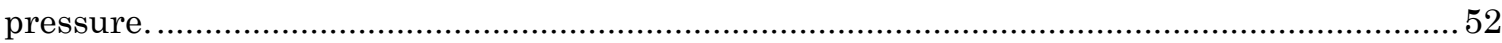

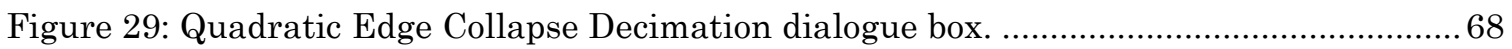

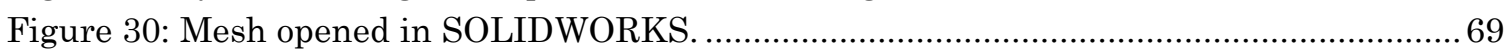

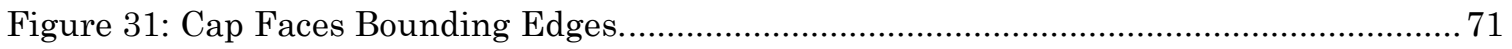




\section{INTRODUCTION}

\subsection{Thesis Overview}

Currently there is no reliable way to predict if a person will have an ischemic event after Transcatheter Aortic Valve Replacement (TAVR). Many studies have been done on what causes ischemia and how TAVR patients have a high risk of ischemia, but none have analyzed more than the effects of particle size on ischemia. This thesis expands upon studies performed by Ian A. Carr and Shawn Shadden, in which they analyzed the effect of particle size and the path of travel in the aortic arch using computational fluid dynamic models [1] [2].

During TAVR, tissue fragments are released and can cause ischemia. These tissue fragments or particles come from various tissues and can vary in size and density. This leads to one of the questions that this thesis is trying to answer: do the physical properties of the particle affect the artery out of which the particles travel. The second question is related to the patient and how the surgery is performed. These questions are the backbone of this thesis and inspired the following two hypotheses.

1. The first hypothesis is that the size and/or the density of the particles affect which branch the particles will take to exit the aortic arch. 
2. The second hypothesis is that the blood pressure of the patient and/or the catheter size used during the surgery impacts which branch the particles will take to exit the aortic arch.

Overall the goal of this thesis is to analyze the effect of different parameters: particle size, particle density, blood pressure, and catheter size on the particles and to see if they exit the aortic arch via the Brachiocephalic artery, the left common carotid artery, the left subclavian artery or continue into the descending aorta. This was done using a finite element model to simulate blood flow and particle tracking through an aortic arch.

Additionally, this thesis will lay the foundation for future TAVR models for Cal Poly Biofluidics Laboratory.

Background research of previous TAVR and particle tracking studies, physiology and morphology of the aortic arch, properties of blood, flow rates, boundary conditions, and properties of particles was performed. To test the effect of these parameters, COMSOL Multiphysics ${ }^{\circledR}$ was used to perform finite element analysis (FEA) using the creeping flow module to simulate blood flow through the aortic arch and the particle tracing module to track the particles through the arch. Nine simulations were run with the fluid and particles flowing through the simulations for 13 seconds. The effect of the parameters on the transmission probabilities of the particles was analyzed using multivariate analysis of variance (MANOVA) in JMP Pro 11 statistical software. 


\subsection{Motivation}

According to the American Heart Association more than five million Americans are diagnosed each year with heart valve disease. Heart valve disease can occur in any of the heart valves but is most common in the aortic valves accounting for $43 \%$ of all patients having heart disease [3]. Disease of the aortic valve is called aortic stenosis and in the United States around 1.5 million people suffer from aortic stenosis [4]. If the aortic valve is not replaced in people who suffer aortic stenosis $44 \%$ will not survive more than an average of 2 years after the onset of symptoms [5]. The main reason a valve would not be replaced is a high operative risk [6]. In a study of patients who were not considered suitable candidates for aortic value replacement TAVR was performed and the patient had a $20 \%$ lower rate of death versus standard therapy. However the study found that after TAVR there was a higher incidence of major stroke [7]. About $87 \%$ of all strokes are ischemic strokes where blood flow to the brain is blocked [8]. Embolism is the most common mechanism for stroke accounting for $40 \%$ of cases with the majority of embolisms having a cardiac or arterial origin [9]. Any way to reduce the number of embolisms released during TAVR could potentially save many lives.

\subsection{Previous Studies}

Previous studies have been performed on the effects of TAVR and particle tracking in the aortic arch. One such study by Ian A. Carr analyzed 
the effect of the particle size and the aortic anatomy on the cardiogenic embolic transport. In this study, Mr. Carr analyzed 10 computed tomography (CT) angiography of patients' aorta and branch. The scans were converted into a computational mesh and finite element analysis software was run to simulate fluid flow and particle tracking. The study tested particle diameter ranging from 0 to $4 \mathrm{~mm}$, in increments of $250 \mu \mathrm{m}$. The results showed peak particle transport to the branch arteries occurred for $1.275 \pm 0.25 \mathrm{~mm}$ diameter particles, and the total percentage of released embolic particles that entered the branch arteries was $60 \pm 13 \%$ [1].

Another study took a different approach and examined in vivo data of embolic debris during TAVR. This study, performed by Nicolas M. Van Mieghem, MD, looked at 40 patients who underwent TAVR with a dual filter based embolic protection device. In $75 \%$ of the patients they captured material ranging in sizes from $0.15 \mathrm{~mm}$ to $4.0 \mathrm{~mm}$ that was traveling into the branch arteries. The debris consisted of fibrin, or amorphous calcium and connective tissue derived most likely from either the native aortic valve leaflets or aortic wall [10]. 


\section{BACKGROUND}

\subsection{TAVR}

Transcatheter Aortic Valve Replacement (TAVR also known as Transcatheter Aortic Valve Implantation or TAVI) is a therapy that treats aortic stenosis. Aortic stenosis is the narrowing of the aortic valve which blocks blood flow from your heart into the aortic arch. During TAVR a new valve is wedged into the damaged valve's place. In this surgery the original aortic valve is not removed instead the valve leaflets are pushed out of the way and the new valve is placed. The new valve is delivered using a catheter allowing TAVR to be a minimally invasive procedure. The catheter is most likely inserted between the sixth or the fifth intercostal space using 2 to 4 inch incisions without opening the entire chest [11] [12].

There are three different approaches to inserting the catheter as shown in Figure 1. First is the transfemoral approach where the valve is delivered via a catheter through the femoral artery shown in panel A. The second approach shown in panel $\mathrm{B}$, is the transapical approach where the valve is delivered via a catheter through the apex of the heart. Finally there is the transaortic approach where the valve is delivered via a catheter through the ascending aorta, panel C [13]. 


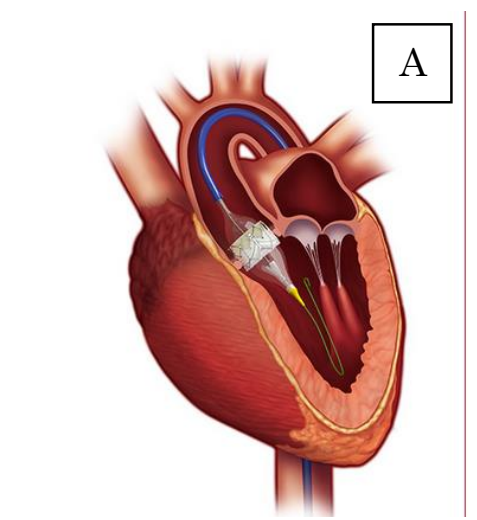

Transfemoral Approach

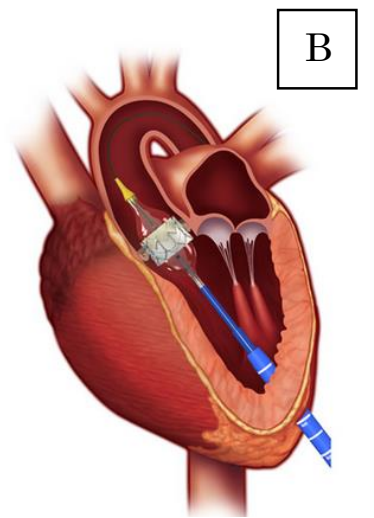

Transapical Approach

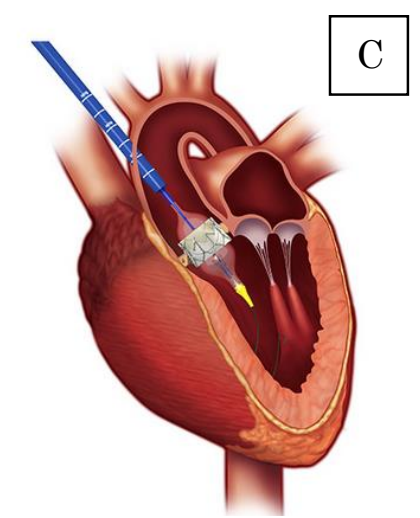

Transaortic Approach

Figure 1: Different Surgical approaches to TAVR [13].

In the past to replace the aortic valve, surgeons had to perform open heart surgery where they would make a 6 - to 8 -inch incision down the center of the sternum [12]. This surgery, surgical aortic valve replacement, is significantly more invasive for the patients and leaves a large scar. Obviously it is much preferred to us the noninvasive TAVR approach. However there are certain patients that are advised against TAVR due to disease and patient related factors. In addition one of the disadvantages with TAVR is it can cause more frequent neurological complications [14].

\subsection{The Aortic Valve/Arch}

The aortic valve is located between the left ventricle and the largest artery in the body, the aorta (Figure 2). The function of the aortic valve is to maintain one-way blood flow out of the heart and into the aortic arch. Blood leaves the heart through the aortic valve and passes into the ascending aorta, from there it can either flow up into three smaller arteries or down into the 
descending aorta. If the blood travels into the descending aorta then it will flow to the lower half of the body. If the blood travels through the ascending aorta it can exit the aortic arch through three outlets: Brachiocephalic artery, the left common carotid artery, the left subclavian artery shown in Figure 2. The Brachiocephalic trunk bifurcates into Right Common Carotid and Right Subclavian. The Right Subclavian flows into the arm and the Right Common Carotid flows in the cerebral circulatory system. The Left Common Carotid artery leads directly into the cerebral circulatory system (CCS). The Left Subclavian Artery bifurcates into the Vertebral Artery and the Left Subclavian Artery. The Vertebral Artery leads into the CCS and the Left Subclavian does not [15].
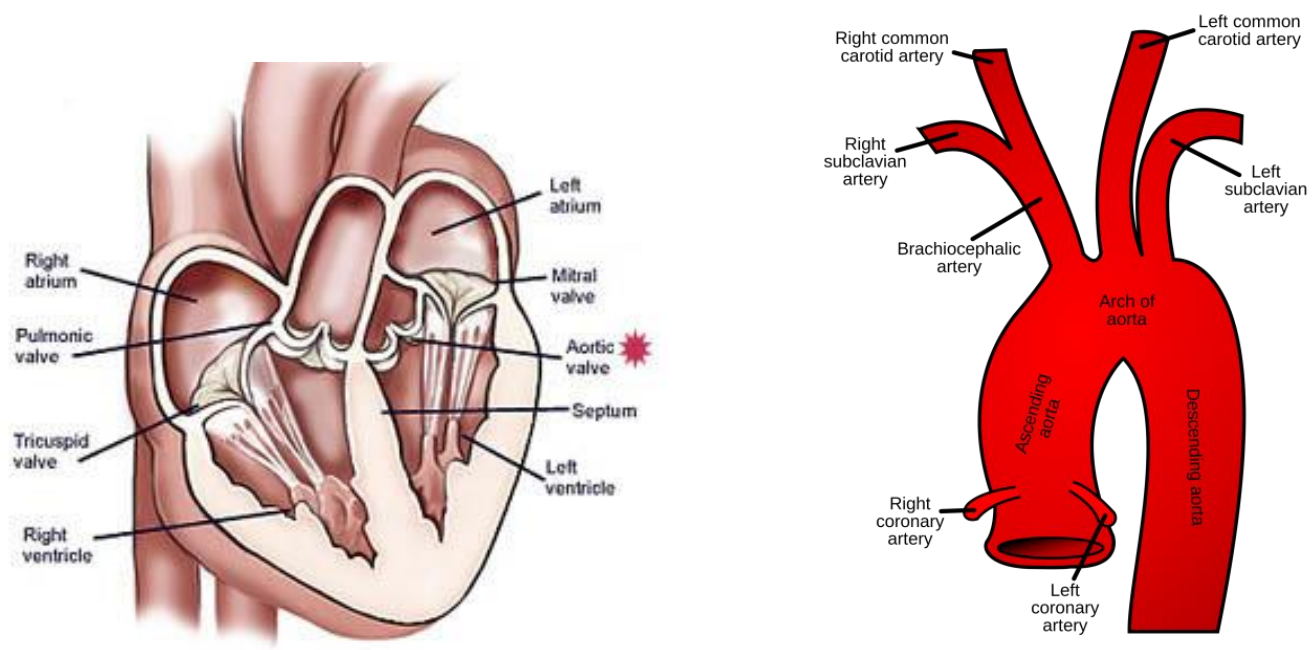

Figure 2: Physiology of the heart and the aortic arch [16].

2.3 Blood Flow through the aortic arch

The flow of fluid through the aortic arch is pressure driven flow based on the contracting of the cardiac muscles. The blood pressure in the aortic 
arch is determined by three major factors: the total peripheral resistance, the blood viscosity and the cardiac output [17]. A typical persons' peripheral resistance is dictated by the geometries of their circulatory system and does not change over short periods of time and, thus, can be considered constant during a surgery. The viscosity of blood can also be considered constant during a surgery. The only factor that influences blood pressure during a surgery is the cardiac output. Cardiac output is how much blood is pumped out of the heart each minute. Cardiac output is determined by two factors: heart rate and stroke volume. The heart rate can increase or decrease based on the amount of activity a person is doing or stress level. The stroke volume of an individual is fairly constant but can fluctuate during exercise.

Typically the blood pressure is measured using two numbers, systolic pressure and diastolic pressure. A person with average blood pressure, for example, should have a systolic pressure of around $120 \mathrm{mmHg}$ and a diastolic pressure of around $80 \mathrm{mmHg}$, or 120 over $80 \mathrm{mmHg}(120 / 80 \mathrm{mmHg})$. Systolic pressure measures the pressure in the arteries when the heart is fully contracted. Diastolic pressure is the pressure between heart beats when the cardiac muscles are relaxed [18]. However these two numbers don't tell the whole story when it comes to blood pressure. In reality the typical aortic pressure over one cycle is not constant and changes over time as shown in Figure 3. 


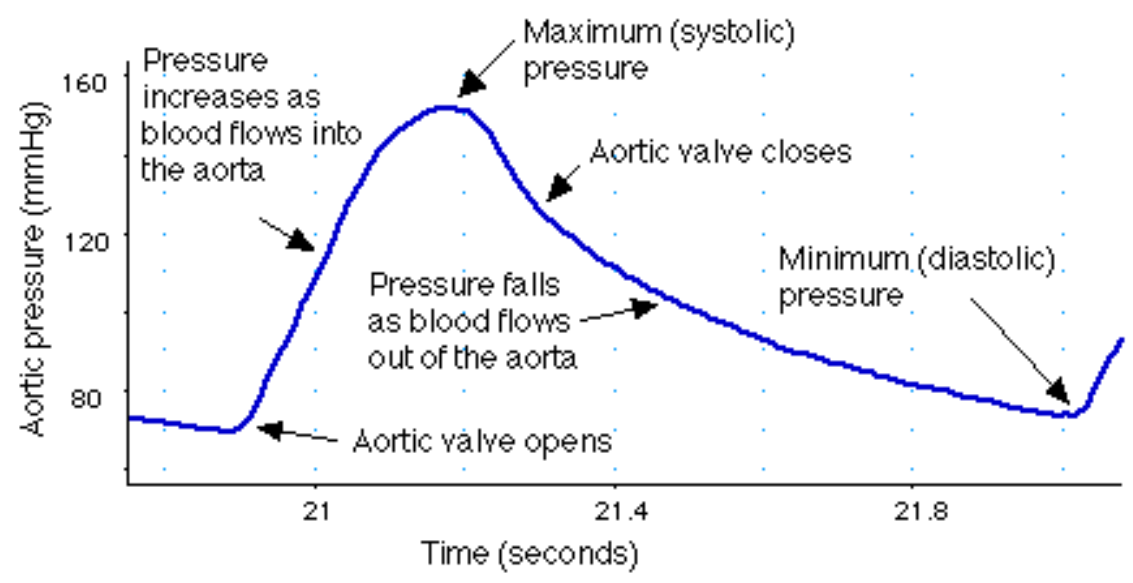

Figure 3: Pressure wave through the Aorta [19].

The pressure wave as shown in Figure 3 changes due to a large variety of factors. The factors that change the pressure wave are heart rate, age, high or low blood pressure, and medications that the patient is taking. As the heart rate increases the pressure wave becomes compact and has a shorter cycle time. Increased age can result in higher systolic and diastolic blood pressures [20]. Depending on what medications a patient is on dictates how the pressure wave will change. For example if the patient is on B-blocker the heart will beat more slowly leading to a longer cycle time. In addition the heart may not be contracting as forcefully leading to lower blood pressure. All of these factors affect the blood pressure and in turn affect the blood flow through the aortic arch.

Another factor that affects the fluid flow through the aortic arch is the geometry of the arch. Like a snowflake each person's aortic arch is different. The changes in the aortic arch's size are based on the age and sex of the person, the amount the person exercises, and the workload of the heart [21]. 
Both the length and the diameter of the aortic arch change with age [22]. The diameter of the arch is different between the sexes but when averaging both men and women the mean diameter for the ascending arch is $33.2 \pm 4.1 \mathrm{~mm}$ and $24.6 \pm 3.0 \mathrm{~mm}$ for the descending aorta [23]. An increase in exercise and the workload of the heart can lead to a larger aortic diameter.

In addition to the size variability, the normal anatomy of the aortic arch is subject to considerable variation [24]. Aortic Arch morphologies are differentiated by looking at the relationship between the brachiocephalic artery and the aortic arch. Figure 4 shows the three common aortic morphologies. The most common geometry is the classic picture shown in panel A of Figure 4 which has separate origins for the brachiocephalic (innominate in Figure 4), left common carotid, and left subclavian arteries. Panel B depicts the second most common pattern of aortic arch branching where the left common carotid artery has the same origin as brachiocephalic artery. Panel $\mathrm{C}$ shows the common carotid has its origin on the brachiocephalic artery [25]. The morphologies in panels B and C are 
commonly referred to as bovine aortic arches; however this anatomy is not generally found in cattle so the name is a misnomer [26].

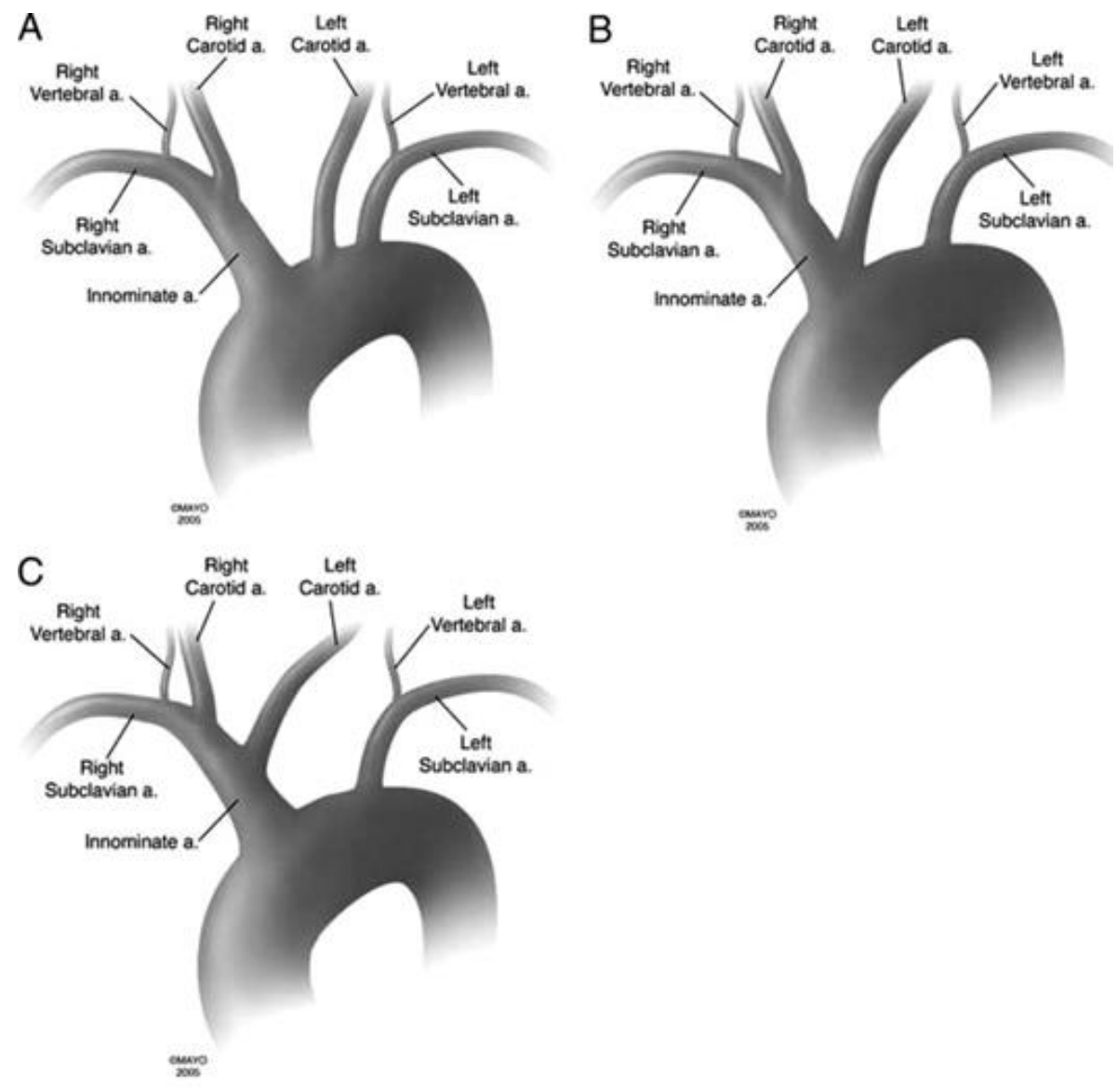

Figure 4: Common aortic arch branching patterns [25].

\subsection{Complications of TAVR}

Research and studies are still being done on the long term complications of TAVR. In a study comparing 5,024 TAVR and 3,512 surgical aortic valve replacement patients there was no statistical difference between the 30 day and 1 year mortality rate of the two different surgical methods. However the study found that TAVR subjects had greater baseline renal impairment $(\mathrm{P}<$ 0.001), a higher incidence of prior myocardial infarction $(\mathrm{P}=0.032)$ and 
respiratory disease $(\mathrm{P}=0.005)$ and a higher logistic EuroSCORE $(\mathrm{P}=0.039)$ [27] . European System for Cardiac Operative Risk Evaluation (EuroSCORE) is a risk model which allows the calculation of the risk of death after a heart operation. The EuroSCORE model uses 17 pieces of information about the patient and fits the data to a logistic regression to calculate the risks [28].

In another study 699 high-risk patients with severe aortic stenosis had either a surgical aortic-valve replacement or a TAVR. The patients were followed for two years and had assessment of clinical outcomes and echocardiographic evaluation. This study also concluded that there was no difference in the mortality rate between the two surgeries. The study did find that at 30 days, strokes were more frequent with TAVR than with surgical replacement ( $4.6 \%$ vs. $2.4 \%, \mathrm{P}=0.12)$ [29].

Similarly to the other studies, a large multicenter study collected mortality and stroke data on TAVR patients. This study also looked at diffusion-weighted cerebral magnetic imaging studies and found that clinically silent ischemic brain lesions are relatively common after TAVR [30]. A small study was performed in Germany focusing on the issue of clinically silent ischemic brain lesions formed after TAVR and found that lesions were formed in $84 \%$ of patients compared to $48 \%$ after open surgery [31]. 


\subsection{Cerebral Ischemia}

Cerebral ischemia occurs when there is not enough blood flow to the brain to meet the metabolic demand which can lead to cerebral hypoxia, cerebral legions or ischemic stroke. There are many symptoms that would alert the patient that they are having a stroke such as blindness in one eye, weakness in a side of the body, difficulty speaking and vertigo [32]. In certain cases of ischemia called silent ischemic brain lesions there are no symptoms and therefore are very difficult to monitor for. In 1998 there were around 770,000 strokes in the US, during that same time period is was estimated that there were around 9 million silent cerebral infarctions [33]. The only way to detect these silent strokes is to use some type of imaging of the brain to detect these legions, the most common way to do this is using Magnetic Resonance Imaging (MRI).

How can a surgery dealing with the aortic valve cause ischemia in the brain?

If a particle is dislodged during the aortic valve surgery and flows into the brachiocephalic artery, the left common carotid artery, or the left subclavian artery then it has a possibility of traveling into the cerebral circulatory system. If a particle travels into cerebral circulatory system then it has the possibility to cause ischemia in the brain. 
The purpose of this thesis is to track the particles and see if they enter the brachiocephalic artery, the left common carotid artery, the left subclavian artery, or the descending aorta. The following section of this thesis discusses how a model was built to mimic a real aortic arch and how particles would flow through the model. Section 3.5 goes into detail on how the parameters were picked to be physiologically relevant. In section 4 the results of the study are shown and in section 5 the results are interpreted and discussed. 


\section{METHODS}

\subsection{The Model}

The simulations were run on COMSOL Multiphysics ${ }^{\circledR} 4.4$ educational edition. The simulation is broken into three major categories: the model's geometry, the fluid flow, and the particle tracing.

\subsection{Geometry}

The geometry was generated by using a CT scan supplied by Claret Medical. The CT scan for the aortic arch was supplied in a stl format. In order for the geometry to be used in COMSOL, the file had to be modified and converted into different file formats. A full description of this conversion process can be found in APPENDIX A. First the file was opened in MeshLab. MeshLab is an open source free 3D mesh processing software that was used to simplify the original mesh. The mesh was simplified in order to get rid of the excess detail in the model. This was done by limiting the number of faces in the model. The original file G1-070HH arch_001.stl can be seen in Figure 5 with 61,543 faces. 


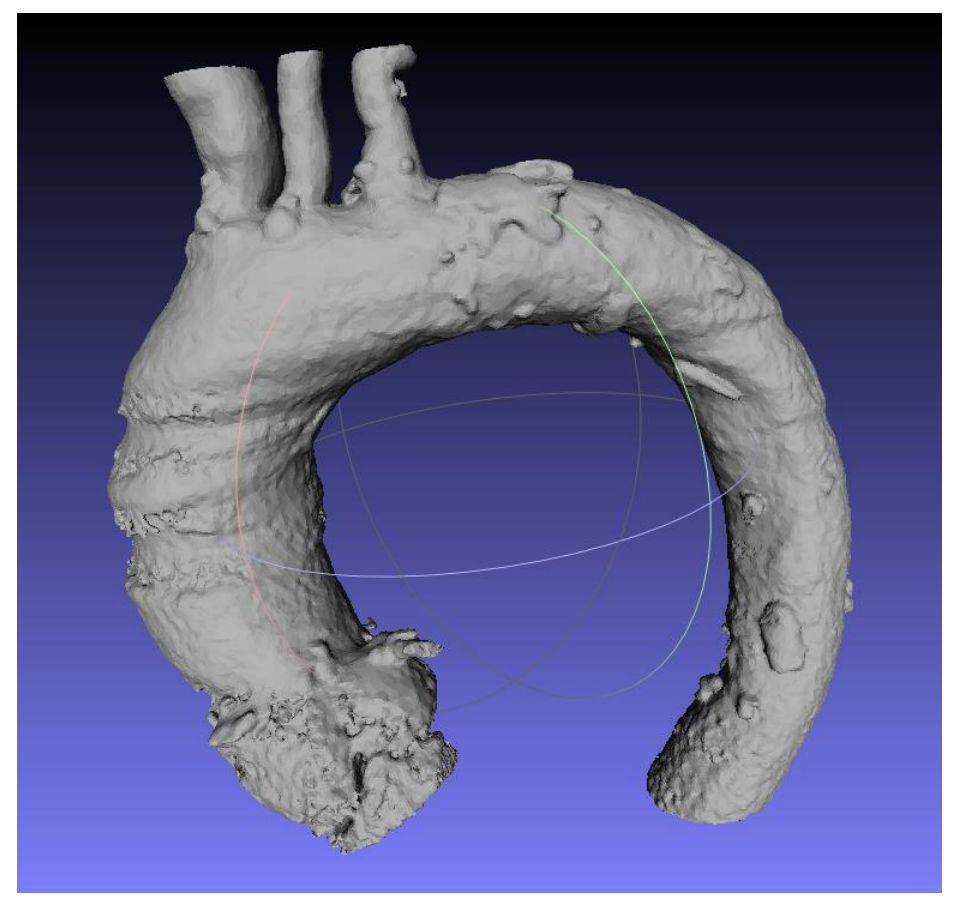

Figure 5: Original file G1-07-HH arch_001.stl opened in MeshLab.

After reducing the number of faces the model now had 251 faces and can be seen in Figure 6. Reducing the number of faces was important to do because the model would be too complicated to import into SOLIDWORKS because SOLIDWORKS places a limit on how many faces you can import. When reducing the number of faces special care was taken to make sure that the general shape of the arch would remain intact. The simplification of the geometry had the added benefit of reducing the computational time. 


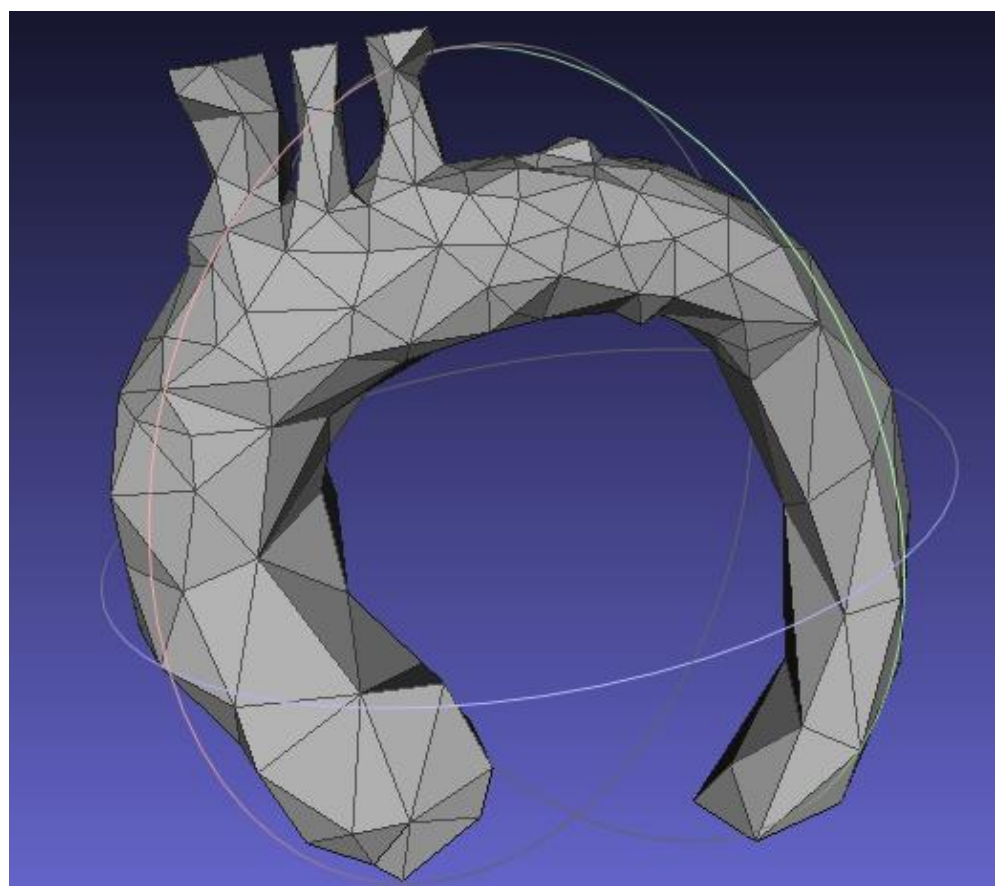

Figure 6: Simplified G1-070HH arch_001.stl opened in MeshLab.

The geometries were then imported into SOLIDWORKS for the purpose of converting the file type from STL file to a SOLIDWORKS Part Document. After this conversion the model was imported into COMSOL using LiveLink.

After the model was imported into COMSOL additional changes had to be made to allow for flow through the model. Each inlet/ outlet as shown in Figure 7 had to be created by making a work plane and differencing the ends in order to create flat inlets/outlets. After the inlets/outlets were created the model had to be made solid. This was done by using the Cap Faces function built into COMSOL. With the model now solid, fluid was now able flow 
through the model. The fluid flow is a pressure drive fluid. The pressure used for the flow was generated using a Windkessel model.

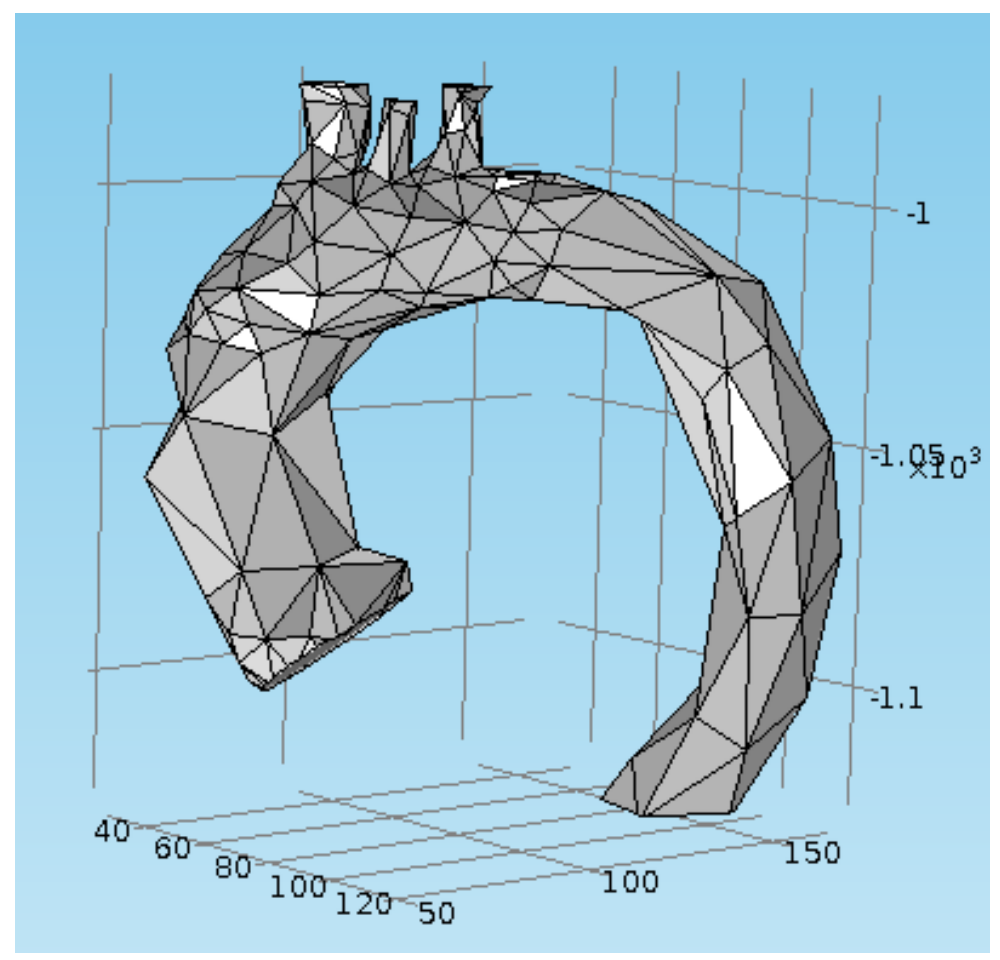

Figure 7: COMSOL model of an aortic arch.

\subsection{Windkessel Model}

The Windkessel was developed in the 1900s and is currently one of the best ways to model the cardiovascular system. The Windkessel model was created by mimicking the cardiac system as an electrical circuit. The cardiovascular system was found to be described by Equation 1.

$$
Q_{\text {in }}=\frac{d V}{d t}+Q_{\text {out }}
$$

In this model ' $Q$ ' is the flow rate in to and out of the blood vessel and 'V' is the volume of blood stored in the blood vessel due to the blood vessels' 
compliance. Compliance is the tendency of the vessel to yield elastically and stretch allowing more blood to fill the vessel. Each vessel has a different compliance based on the amount of elastin and other structural proteins [34]. Another factor that affects the flow of blood is the resistance the flow encounters due to the arterioles and capillaries. Both resistance ' $R$ ' in $\mathrm{mmHg}{ }^{*} \mathrm{~s} / \mathrm{ml}$ and compliance of the vessel ' $\mathrm{C}$ ' in $\mathrm{ml} / \mathrm{mmHg}$ are modeled in the simplest Windkessel models known as the 2 element model as seen in equation 2 below [35].

$$
Q_{i n}=C \frac{d P}{d T}+\frac{P}{R}
$$

The 2-element model is generally not used anymore since it is only a rough approximation of the real system. The 3 -element model is more accurate because another variable is added to simulate the resistance to blood flow due to the aortic valve, this is done by adding an additional resistor to the simulation [36]. The four element model adds more complexity and accuracy to the model by adding an inductor. This full electrical circuit model can be seen in Figure 8 and the four element model can be seen in equation 3. 


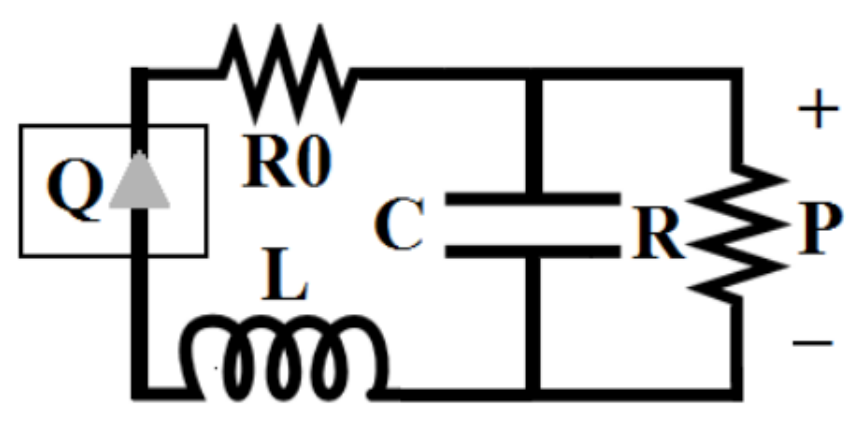

Figure 8: Electrical circuit of the four element Windkessel model [37].

$$
\left(1+\frac{R_{0}}{R}\right) Q+\left(C R_{0}+\frac{L}{R}\right) \frac{d Q}{d t}+L C \frac{d^{2} Q}{d t^{2}}=C \frac{d P}{d t}+\frac{P}{R}
$$

Figure 9 shows a comparison of the 2, 3 and 4 element models in comparison to a measured pressure value [36].

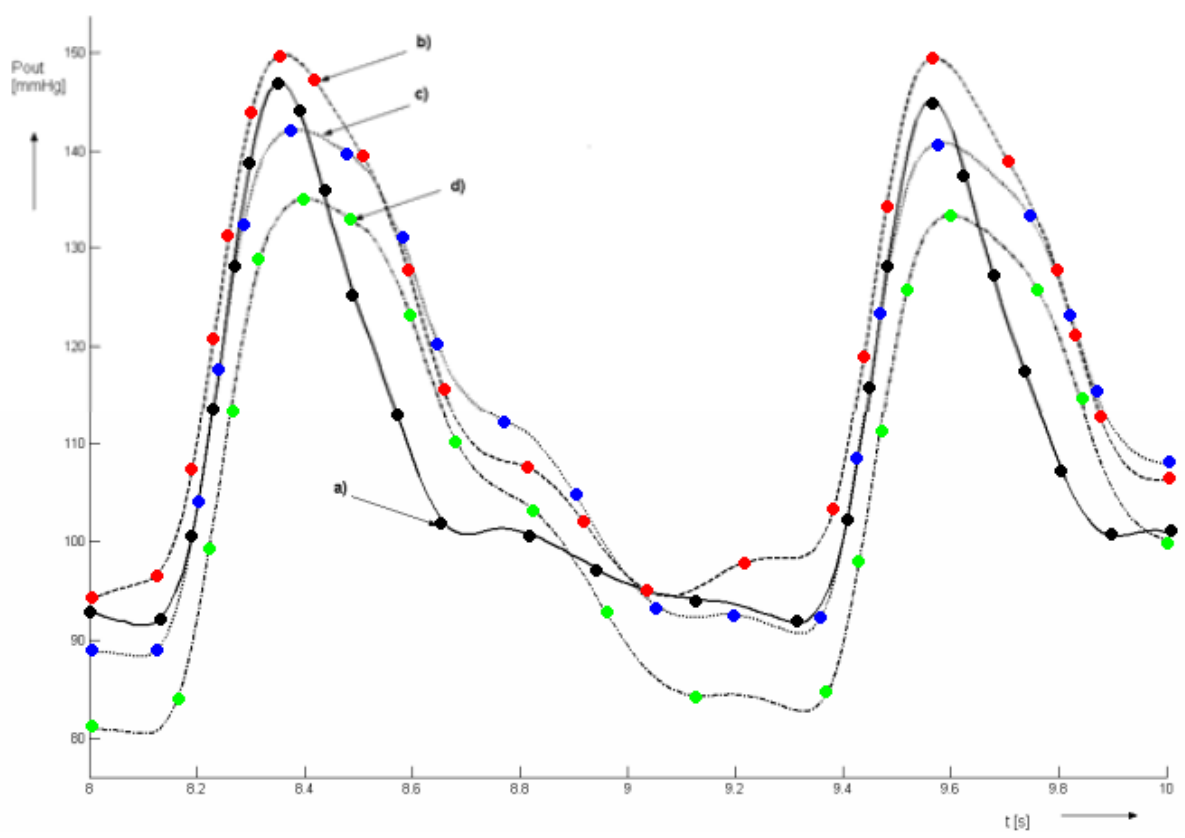

Figure 9: Arterial pressure for three Windkessel Models: a - measured pressure (solid line, black dots), b - 4 Element Model (dashed line, red dots), c - 3WM (dot line, blue dots), d 2WM (dot-and-dash line, green dots [36].

As Figure 9 shows by increasing the complexity of the model by adding additional elements, the simulation moves closer to the measured pressures. 
The three element model does a good job approximating the waveform but has issues when transitioning between systole and diastole [38].

For this project the MATLAB code created by Garry Howe was used to simulate the pressure and flow rate waveforms through the aortic arch using 2, 3, and 4-element models. Mr. Howe's code used the 4-element Windkessel model to solve for the pressure waveform in the aorta, given the flow rate and vasculature properties. Howe's code split the Windkessel into two different equations, one for systole and one for diastole. His code used equation 4 to solve for the systole portion of the cardiac cycle [37].

$$
\left(1+\frac{R_{0}}{0}\right) Q+\left(C R_{0}+\frac{L}{R}\right) \frac{d Q}{d t}+L C \frac{d^{2} Q}{d t^{2}}=C \frac{d P}{d t}+\frac{P}{R}
$$

' $\mathrm{R}_{0}$ ' is the proximal resistance of conducting arteries, ' $\mathrm{R}$ ' is the peripheral resistance of the capillary and veins, ' $\mathrm{C}$ ' is the capacitance of the blood vessel, and ' $L$ ' is the inductance. After systole, the heart valve closes and the flow rate and its derivatives become zero. Solving the new circuit gives equation 5 that models the pressure during diastole [37].

$$
P(t)=P\left(t_{D}\right) e^{\frac{t-t_{D}}{R C}} t_{D}<t<T
$$

' $\mathrm{t}^{\prime}$ ' is the time when diastole starts, while ' $\mathrm{R}$ ' and ' $\mathrm{C}$ ' are the same as in systole. This exponential decay starts at the same pressure as the end of systole and then drops back to the starting pressure of the cardiac cycle.

Using Mr. Howe's model 3 pressure waveforms were produced with systolic/systolic pressures 78/40 mmHg (Figure 10), 120/70 mmHg (Figure 11), and 150/90 $\mathrm{mmHg}$ (Figure 12) respectively. Each waveform was 
generating using 72 beats per minute which is within the normal range for resting heart rate in adults [39]. The settings used in the model were as follows: a systemic peripheral resistance of $0.9000 \mathrm{mmHg} / \mathrm{cm}^{3} / \mathrm{sec}$, a systemic arterial compliance of $1.0666 \mathrm{~cm}^{3} / \mathrm{mmHg}, \mathrm{R}_{0}=0.05$, the time the heart valve was open was 0.4 seconds [37]. Different waveforms were created by changing the initial pressure and the fluid output per cycle. The different settings used can be seen in Table 1 . The settings were chosen using trial and error to get blood pressure that simulates different kinds of people, as discussed further in section 3.5.4. The full MATLAB code used to create these pressure waves can be seen in APPENDIX B.

Table 1: Different settings for the Windkessel model

\begin{tabular}{|l|l|l|l|}
\hline $\begin{array}{l}\text { Blood Pressure } \\
(\mathrm{mmHg})\end{array}$ & $\begin{array}{l}\text { Initial } \\
\text { Pressure (torr) }\end{array}$ & $\begin{array}{l}\text { Fluid Output per } \\
\text { Cycle (cm } 3 / \text { cycle) }\end{array}$ & Figure \\
\hline $78 / 40$ & 40 & 65 & Figure 10 \\
\hline $120 / 70$ & 70 & 91 & Figure 11 \\
\hline $150 / 90$ & 90 & 120 & Figure 12 \\
\hline
\end{tabular}




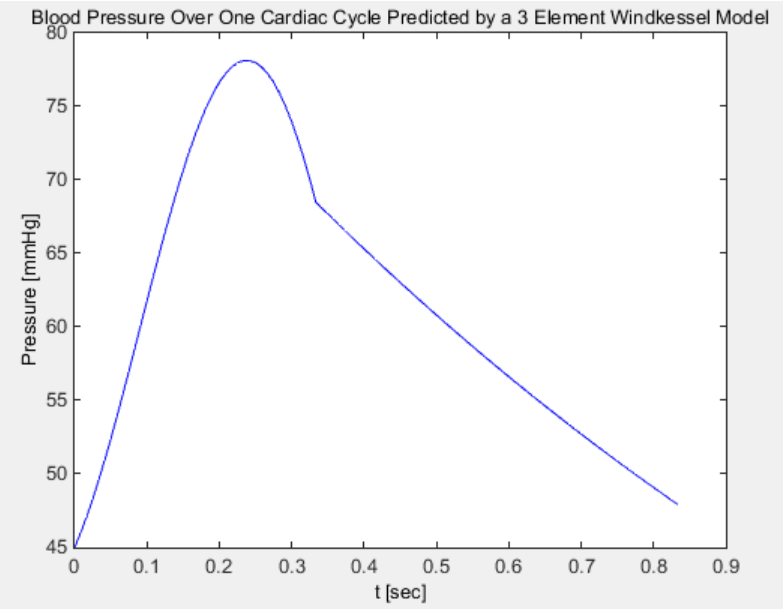

Figure 10: Pressure over one cycle 78/40 mmHg.

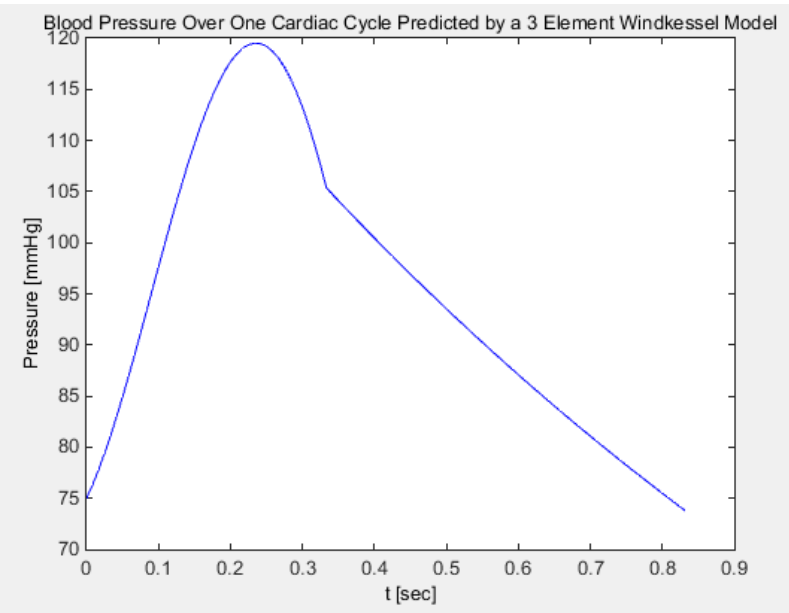

Figure 11: Pressure over one cycle 120/70 mmHg.

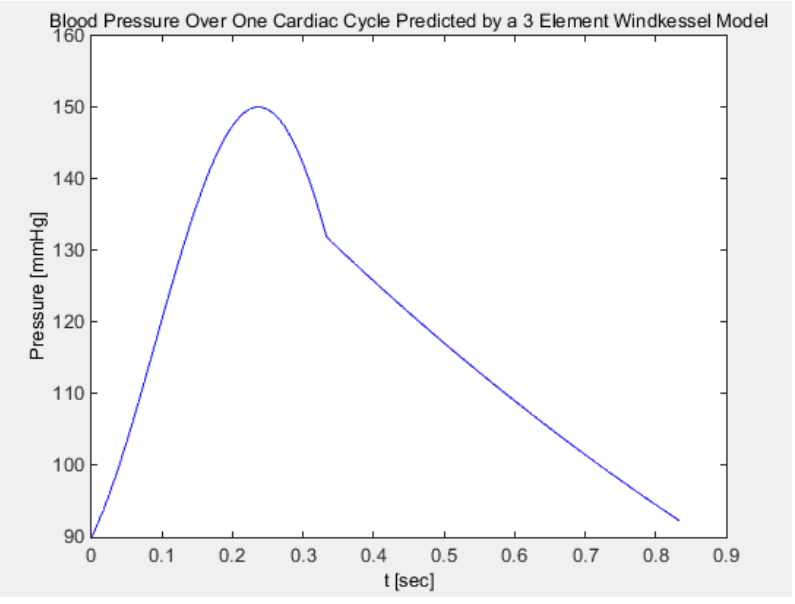

Figure 12: Pressure over one cycle 150/90 mmHg. 


\subsection{The Studies}

There are two time dependent studies used in this model, study 1: Fluid Flow, study 2: Particle Tracing. Two studies were used in order to isolate the flow physics to reduce the number of time the fluid flow would have to be recalculated. After the fluid flow was run once it would not need to be continually recalculated when doing analysis on the particle tracing. Each study was run for 13 seconds with time steps every 0.05 seconds.

\subsubsection{Fluid Flow}

The fluid flow through the aortic arch was modeled using the creeping flow module generated by COMSOL MULTIPHYSICS $®$. The fluid flowing through the artery was modeled as incompressible with a density of 1060 $\mathrm{kg} / \mathrm{m}^{3}$ and a dynamic viscosity of $0.005 \mathrm{pa}^{*}$ seconds [40] [41]. The flow through the artery is governed by equations 6 and 7 .

$$
\begin{gathered}
\rho \nabla \cdot u=0 \\
\rho \frac{d u}{d t}=\nabla \cdot\left[-p I+\mu\left(\nabla \mathrm{v}+(\nabla \mathrm{v})^{T}\right)\right]+F
\end{gathered}
$$

Equation 6 represents the constraint that the fluid is incompressible. Equation 7 describes the Navier-Strokes fluid flow. In equation 7 ' $\rho$ ' represents the fluid density, ' $\mu$ ' represents the dynamic viscosity of the fluid, 'v' represents the velocity field vector, 'I' is the identity tensor, ' $\nabla$ ' is the gradient operator, ' $\mathrm{T}$ ' is the transpose of a matrix, and ' $\mathrm{F}$ ' is the force action on the fluid. 
The walls of the artery have a no slip boundary condition which means the fluid velocity as the wall is zero. At the inlet a pressure is applied $\mathrm{P}_{-}$in $(\mathrm{t})$ this pressure was generated using the Windkessel model discussed in section 6.3 with respect to different time points. The inlet is governed by the equation 8.

$$
p=p_{0}, \quad\left[\mu\left(\nabla v+(\nabla \mathrm{v})^{T}\right)\right] n=0
$$

In equation 8 ' $n$ ' is the boundary normal pointing out of the domain, ' $p_{o}$ ' is the pressure at the inlet boundary and ' $p$ ' is the fluid pressure.

The pressure is applied at the inlet shown in purple in Figure 13. The circle in the middle of inlet one is the bottom of the catheter. There is no flow applied through the catheter and it is treated as a wall.

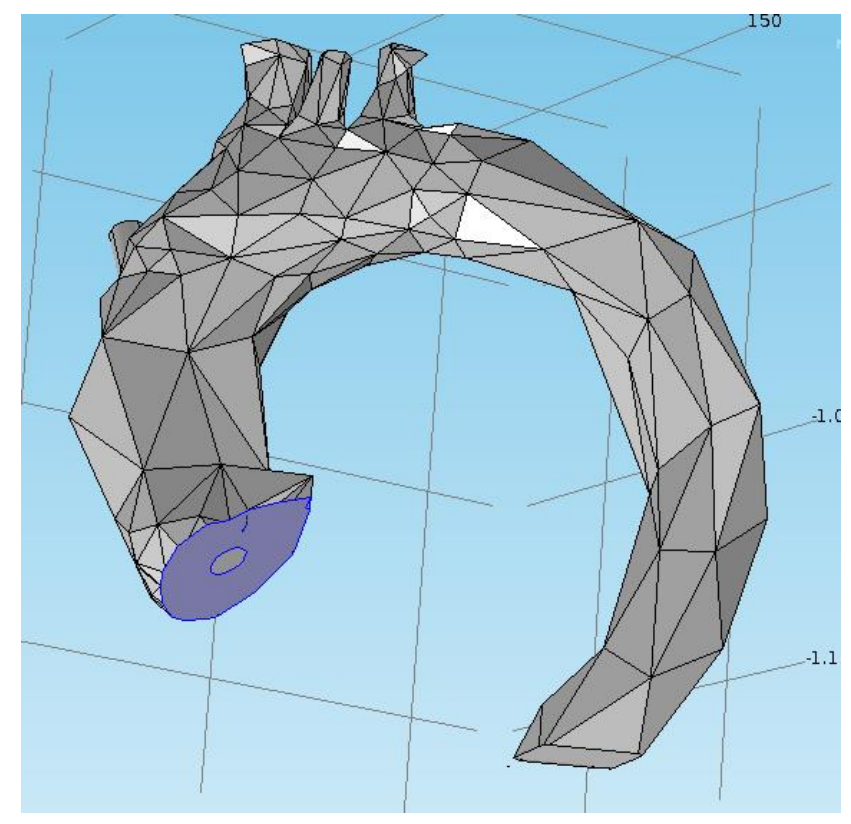

Figure 13: Inlet 1 in purple. 
The fluid flows through the model and has four outlets. Three on the top as shown in panel A of Figure 14 shows the brachiocephalic (1), left common carotid (2), and left subclavian arteries (3). Panel B shows the descending aorta (4).
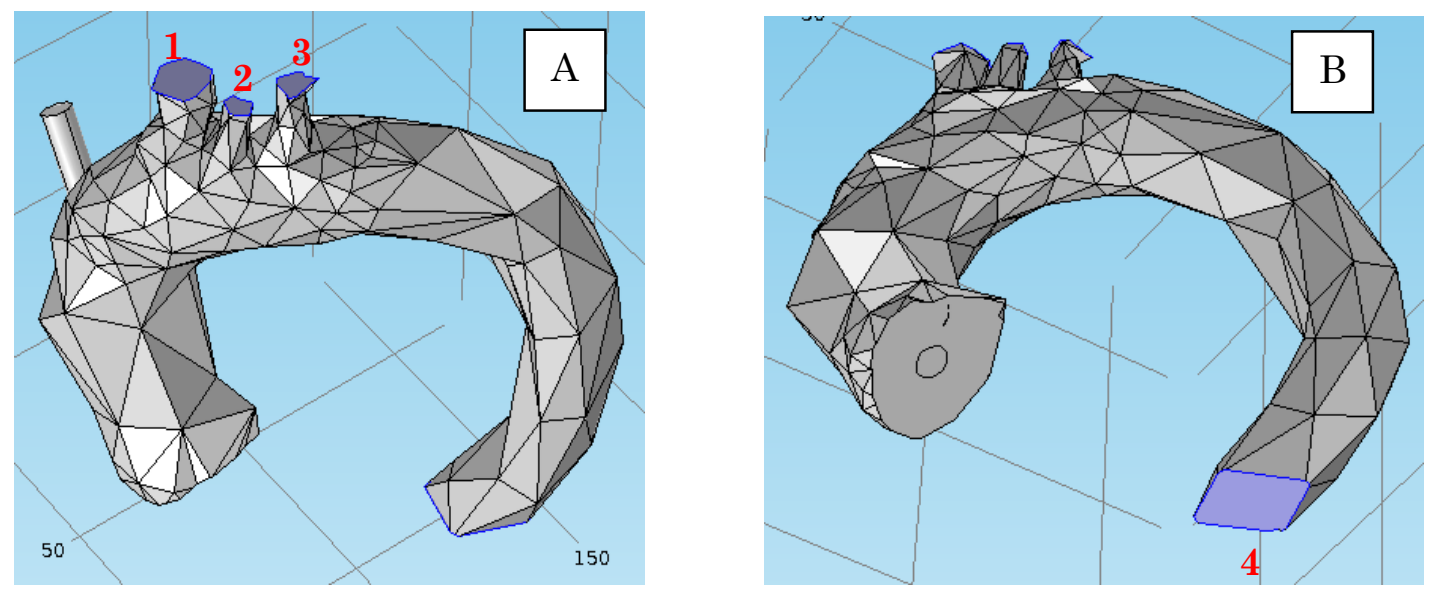

Figure 14: Fluid Outlets: Panel A shows brachiocephalic (1), left common carotid (2), and left subclavian arteries (3). Panel B shows the descending aorta (4).

The outlets have a pressure of $.992 * \mathrm{P} \_$in(t). 0.992 was chosen by looking at the pressure drop in a similar COSMOL model [38]. The outlets are governed by the equation 9 .

$$
\hat{p}_{0} \leq p_{0}, \quad\left[-p I+\mu\left(\nabla v+(\nabla v)^{T}\right) n\right]=-\hat{p}_{0} n
$$

The backflow is suppressed to simulate the fluid in the artery continuing to flow. 


\subsubsection{Particle Tracing}

Particle tracing was done by using the particle tracing module for fluid flow built into COMSOL MULTIPHYSICS®. Particle tracing used time dependent equation 10 .

$$
\frac{d\left(m_{p} v\right)}{d t}=F_{t}
$$

In equation 10 ' $\mathrm{m}_{\mathrm{p}}$ ' is the mass of the particle, ' $\mathrm{v}$ ' is the velocity of the particle and ' $\mathrm{F}_{\mathrm{t}}$ ' is the force on the particle. The particle properties were the diameter of the particles and the density of the particles these parameters are discussed fully in sections 3.5.1 and 3.5.3 respectively.

Drag was simulated on the particles released using Stokes Drag Law shown in equations 11 and 12 below.

$$
\begin{aligned}
& F=\frac{1}{t_{p}} m_{p}(u-v) \\
& t_{p}=\frac{\rho_{p} d_{p}^{2}}{18 \mu}
\end{aligned}
$$

In equation 11, ' $F$ ' is the drag force, 'u' is the velocity field, 'tp' is the particle velocity response time. In equation 12 , 'pd' is the particle density 'dp' is the particle diameter, ' $\mu$ ' is the fluid viscosity.

The particles were released from inlet one as seen in Figure 13. The particles released were in a plane grid and the number of particles released is discussed in section 3.5.2. The particles were all released at the same time at 
the beginning of each simulation. The initial velocity of the particles was predicted by the velocity field generated by the fluid flow. After the particles were released they traveled through the simulation and exited the model through one of the four outlets depicted in Figure 14. The parameters on the walls of the model were that the velocity of the particle hitting the wall is equal to the velocity of the particle leaving the wall.

\subsection{Parameters}

Five different parameters were chosen to be analyzed for this paper. Each parameter has different categories that were chosen by looking at how the surgery is performed in the real world and how different categories would affect the statistical significance of the results. The five different parameters are as follows.

1. Particle diameter

2. The number of particles released

3. The density of the particles released

4. The blood pressure

5. Catheter diameter

\subsubsection{Particle Diameter}

Four different sizes were chosen for particle diameter, $3 \mathrm{~mm}, 1 \mathrm{~mm}$, $0.5 \mathrm{~mm}$, and $0.25 \mathrm{~mm}$. These particle sizes were chosen by looking at studies 
that examined the size of the particles released in TAVR. These studies found the particles sizes to range between 0.15 and $4.0 \mathrm{~mm}$ [10] [1].

\subsubsection{Number of Particles}

The number of particles released was chosen to be 1,000 because that is a sufficient number for statistical analysis. There is no interaction between the particles in the simulation so a large number can be chosen without affecting the outcomes of the study.

\subsubsection{Density of the particles}

Four different densities of particles were chosen: $1.45 \mathrm{~g} / \mathrm{cm}^{3}, 1.22$ $\mathrm{g} / \mathrm{cm}^{3}, 1.066 \mathrm{~g} / \mathrm{cm}^{3}$, and $0.8 \mathrm{~g} / \mathrm{cm}^{3}$. Densities $1.45 \mathrm{~g} / \mathrm{cm}^{3}$ and $1.22 \mathrm{~g} / \mathrm{cm}^{3}$ were chosen by looking at the average density of calcified (class VII) atherosclerotic plaque and non-calcified (non-class VII) atherosclerotic plaque [42]. Density $1.066 \mathrm{~g} / \mathrm{cm}^{3}$ was chosen by looking at the average density of muscle [43]. The density $\mathrm{g} / \mathrm{cm}^{3}$ was chosen to be a low end of the densities and provide statistical significance if a particle was released with a density between 0.8 $1.066 \mathrm{~g} / \mathrm{cm}^{3}$. This range of particles was chosen because a study analyzing the particles released after TAVR the particles are $17 \%$ calcified material, $27 \%$ collagen and elastic fibers, $43 \%$ collagenous material from the vessel wall and $30 \%$ thrombotic material $\left(0.79-1.41 \mathrm{~g} / \mathrm{cm}^{3}\right)$ [44] [10]. 


\subsubsection{Blood Pressure}

Three different blood pressures were chosen 78/45 mmHg (low blood pressure), 95/55 $\mathrm{mmHg}$ (Stage 1 hypertension), and 150/90 $\mathrm{mmHg}$ (Stage 2 hypertension) [18]. These were chosen to provide a range of blood pressures that would allow for statistical analysis of a large range of blood pressures. The blood pressure was generated using a Windkessel model as described in section 3.3.

\subsubsection{Catheter Size}

Three different sizes were chosen for the catheter diameter: 22 French (Fr), $24 \mathrm{Fr}$ and $26 \mathrm{Fr}$ catheters. A French is the unit of measurement that is used when measuring catheters. For example, a $3 \mathrm{Fr}$ catheter has an external

diameter $1 \mathrm{~mm}$. Therefore the sizes chosen for the catheters external diameter was $7.33,8.0$, and $8.667 \mathrm{~mm}$. These sizes were determined by looking at the size of the sheath of the Edwards SAPIEN valve [45].

\subsection{Meshing}

A single mesh was design was used for all of the simulations. The mesh was a physics controlled mesh created by COMSOL using the normal mesh setting. The mesh contained 111,958 tetrahedral elements, 114 pyramid elements, 13,449 prism elements, 16,656 triangular elements, 297 quadrilateral elements, 3,739 edge elements, and 285 vertex elements. The total number of elements was 125,521 with a minimum element quality of $3.197 * 10^{-4}$ and an average element quality of 0.6626 . These mesh setting 
were chosen because they are the finest mesh able to be run without crashing the computer.

\subsection{Studies Performed}

Nine different simulations were run to figure out the significance of different parameters discussed in section 3.5. Nine different simulations were run to have every possible combination of the different categories in the parameters. For example a simulation was run with a catheter diameter of $7.33 \mathrm{~mm}$, a blood pressure of $120 / 70 \mathrm{mmHg}$, and every iteration of the particle parameters. Every iteration of the particle parameters was run using a parametric study. The parametric study allowed me to do a sweep of all the combinations of the particle parameters while only having to run the particle tracing study once.

Each of the nine simulations used a mesh with settings discussed in section 3.6. Each simulation was either run on the Microfluidics group's server or the group's lab computers. The simulations took between 36-40 hours to run, consisting of 12-15 hours to run the fluid flow study and 22-24 hours to run the particle tracing study.

\subsection{Statistical Analysis}

A multivariate analysis of variance (MANOVA) was performed using JMP 11 pro. A MANOVA allows for multiple parameter (independent variables) to be tested on their effect on the transmission probability 
(dependent variable). Using a MANOVA allows the following questions to be answered:

1. Do changes in the parameters (particle diameter, particle size, catheter size, and blood pressure) have significant effects on the particular outlets transmission probability?

2. What are the relationships between the parameters variables? 


\section{RESULTS}

\subsection{Fluid Flow}

After Study 1, described in section 3.4.1, was run the data was visually analyzed to ensure that the fluid was flowing through the aortic arch properly. Figure 17 shows the velocity magnitude of a study with a catheter diameter of $8.66 \mathrm{~mm}$ and a blood pressure of $150 / 90 \mathrm{mmHg}$. The different panels show different time points during the simulation and the color change indicates that the fluid velocity is different. Blue shows a very low velocity and red show a higher velocity. This velocity profile is fairly typical among differing catheter sizes and blood pressures. The average surface velocity at 13 seconds was measured as each outlet. The average surface velocity across each blood pressure can be seen in Figure 15.

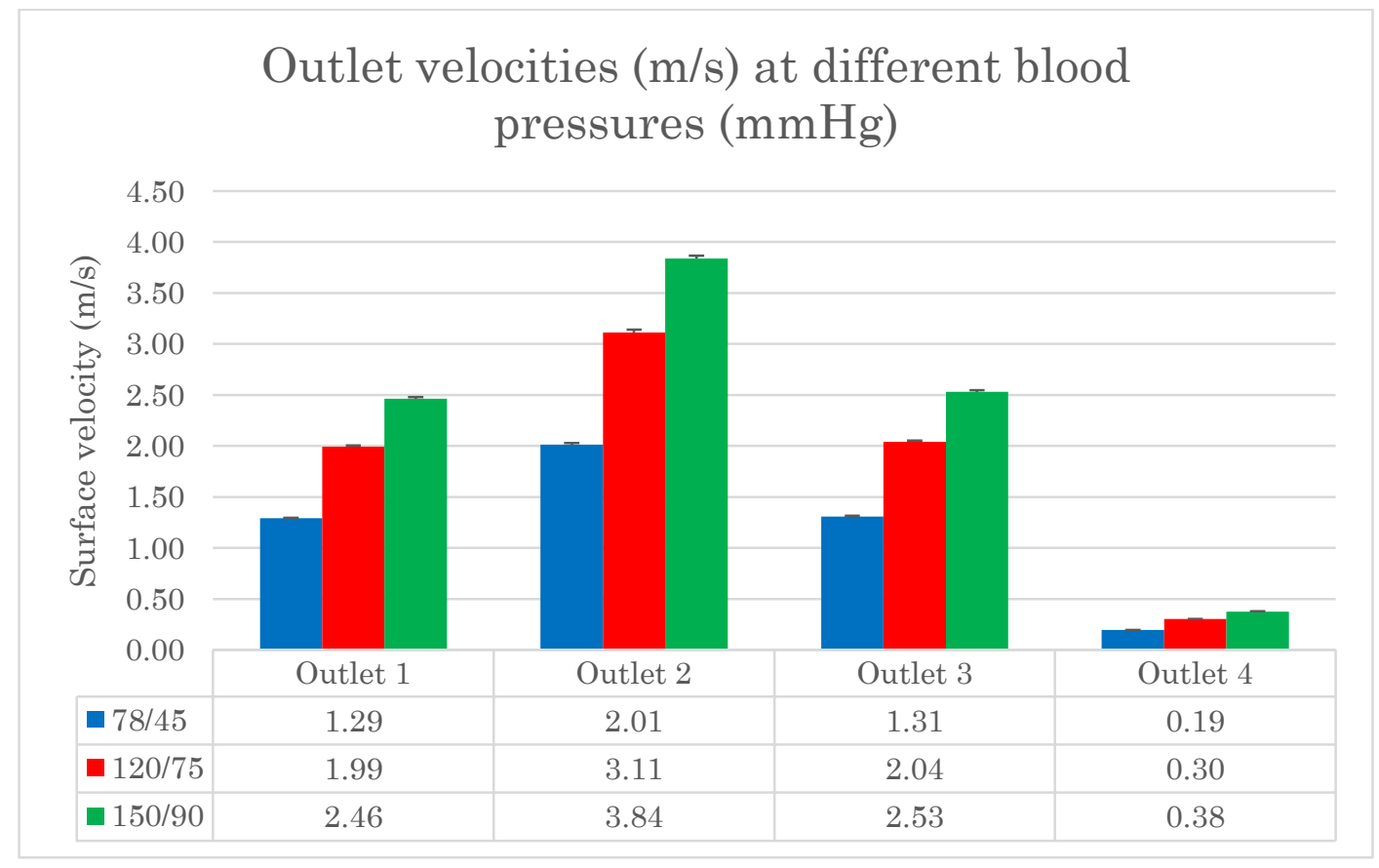

Figure 15: Outlet velocities $(\mathrm{m} / \mathrm{s})$ of different blood pressures. 

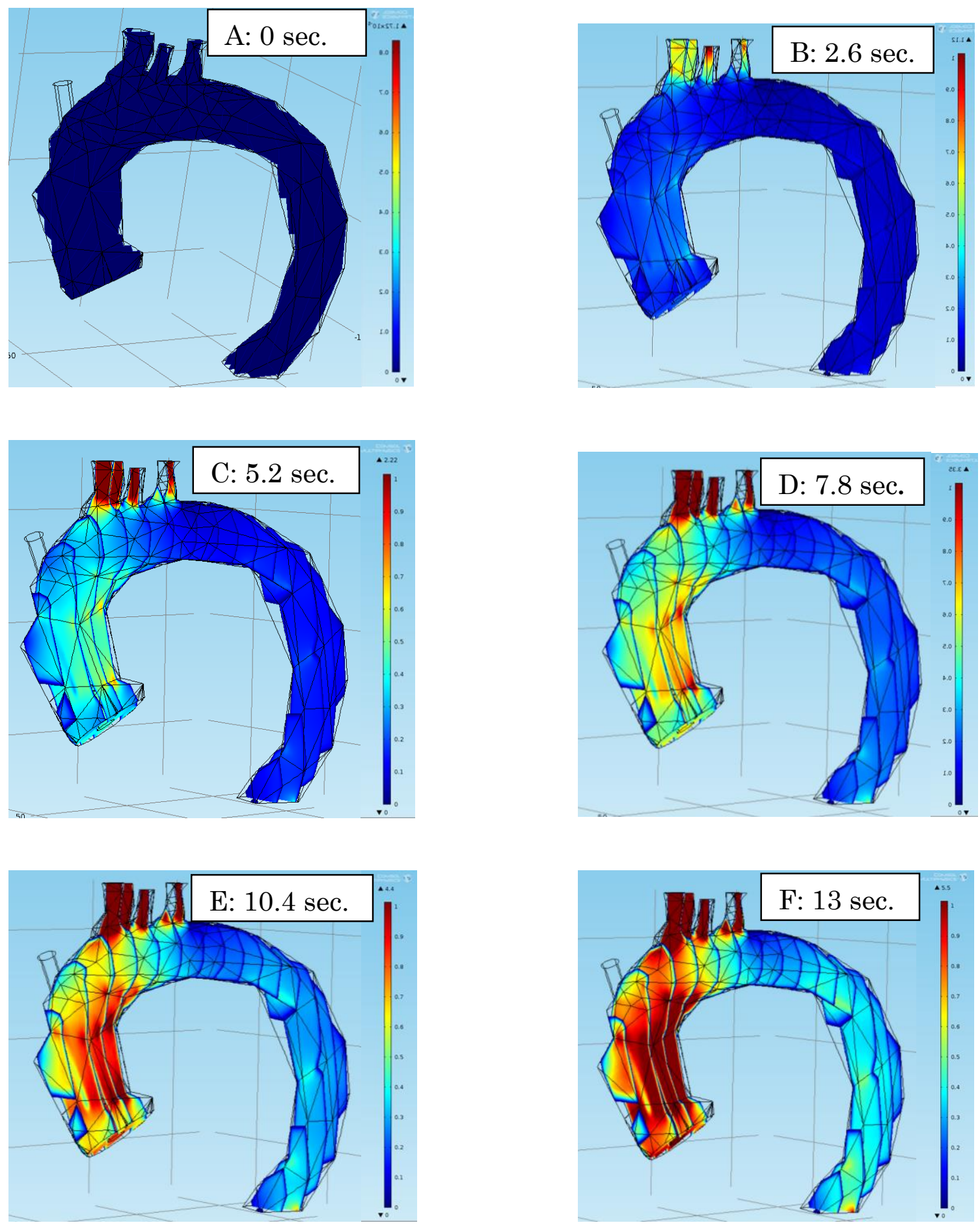

Figure 16: Velocity magnitude $(\mathrm{m} / \mathrm{s})$ with a catheter diameter of $8.667 \mathrm{~mm}$ and a blood pressure 150/90 mmHg at different time intervals. Panel 'A' at 0 seconds, panel 'B' at 2.6 seconds, panel 'C' at 5.2 seconds, panel 'D' at 7.8 seconds, panel 'E' at 10.4 seconds, and panel 'F' at 13 seconds. 


\subsection{Particle Tracing}

After the particle tracing study was run, described in section 3.4.2, the data was analyzed both visually and by using the statistical software JMP Pro 11. A visual analysis was done first to make sure that the particles appeared to be flowing through the system correctly and not getting stuck in the simulation.

After looking at animations of the results an issue was found when a particle diameter of $3 \mathrm{~mm}$ was analyzed. Figure 17 shows the particle tracking of a study with a catheter diameter of $7.33 \mathrm{~mm}$, blood pressure $150 / 90 \mathrm{mmHg}$, particle diameter $0.25 \mathrm{~mm}$, and particle density $0.8 \mathrm{~g} / \mathrm{cm}^{3}$. The different panels show different time points during the simulation and the particles can be seen flowing through the aortic arch. However Figure 18 shows the particle tracking of the same study with the particle diameter changed to be $3 \mathrm{~mm}$.

The difference between these two results is dramatic. Panel 'A' looks nearly identical in both Figures 17 and 18 however the particles in in panel 'B' in Figure 18 appear to get stuck against the wall and not continue through the simulation. This is demonstrated quantitatively by looking at the transmission probability of the different studies and then calculating what percentage of the particles did not exit the simulation. On average the probability of a particle not exiting the simulation when the diameter was $3 \mathrm{~mm}$ was $49.6 \pm 13.95 \%$ and the probability for all other diameters was 3.94 
$\pm 2.09 \%$. The full difference in the transmission probabilities between including $3 \mathrm{~mm}$ and excluding $3 \mathrm{~mm}$ can be seen in Table 2 .

Table 2: Transmission probability of particles leaving each outlet with $3 \mathrm{~mm}$ included and excluded.

\begin{tabular}{|c|c|c|c|c|c|}
\hline Particle & Outlet 1 & Outlet 2 & Outlet 3 & Outlet 4 & Not Out \\
\hline $\begin{array}{c}\text { Excluding } \\
3 \mathrm{~mm}\end{array}$ & $46.35 \pm 3.76 \%$ & $16.32 \pm 7.88 \%$ & $17.75 \pm 8.34 \%$ & $15.64 \pm 8.02 \%$ & $3.94 \pm 2.09 \%$ \\
\hline $3 \mathrm{~mm}$ & $41.18 \pm 4.54 \%$ & $6.49 \pm 8.17 \%$ & $1.91 \pm 3.17 \%$ & $0.03 \pm 0.12 \%$ & $49.60 \pm 13.95 \%$ \\
\hline
\end{tabular}

When the statistical analysis was preformed particles having a diameter of $3 \mathrm{~mm}$ was left out of the analysis. The reasons for this are discussed in section 5 . 

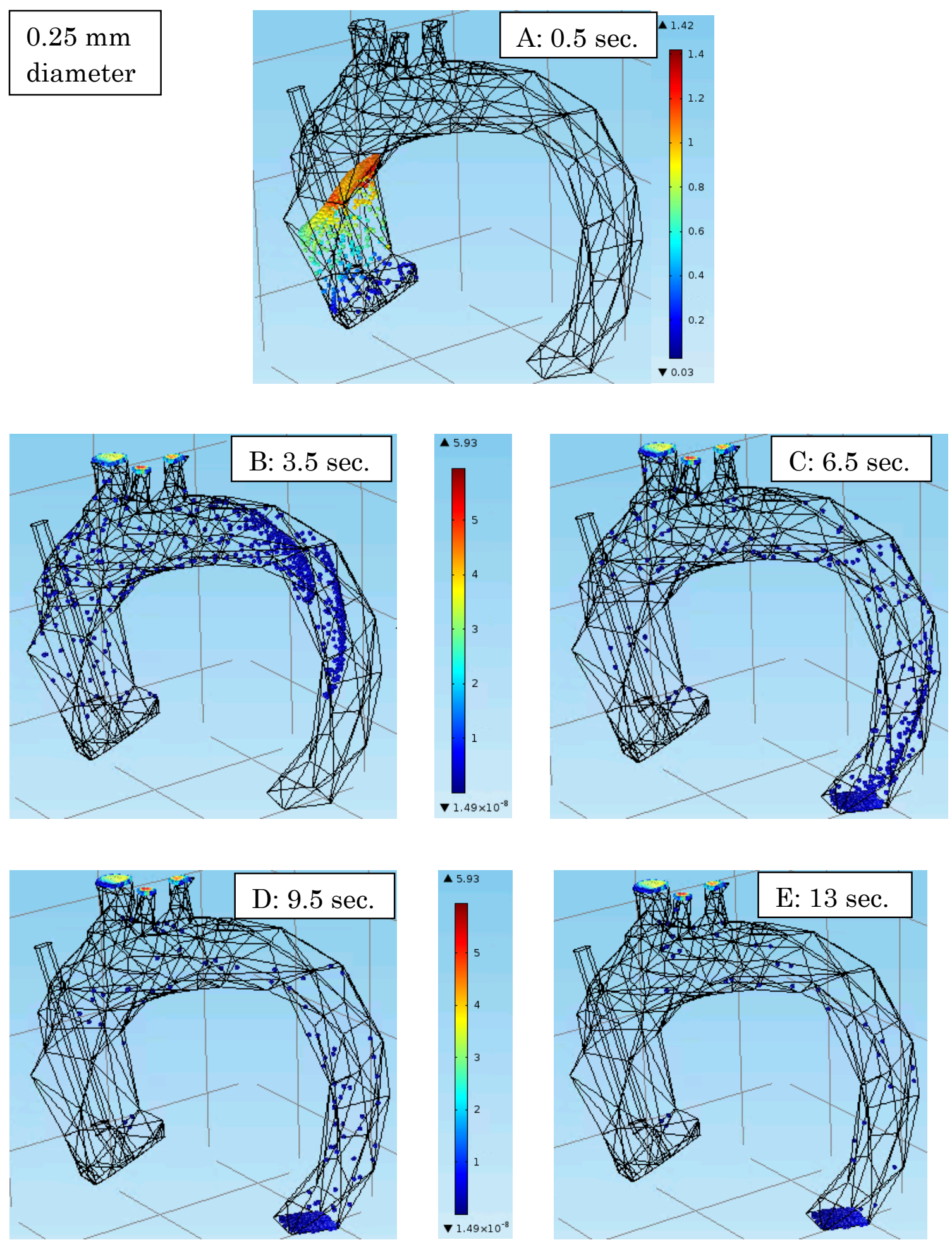

Figure 17: Particle tracing catheter diameter $7.33 \mathrm{~mm}$, blood pressure 150/90 mmHg, particle diameter $0.25 \mathrm{~mm}$, particle density $0.8 \mathrm{~g} / \mathrm{cm}^{3}$, Panel 'A' at 0.5 seconds, panel 'B' at 3.5 seconds, panel 'C' at 6.5 seconds, panel 'D' at 9.5 seconds and panel 'E' at 13 seconds. 

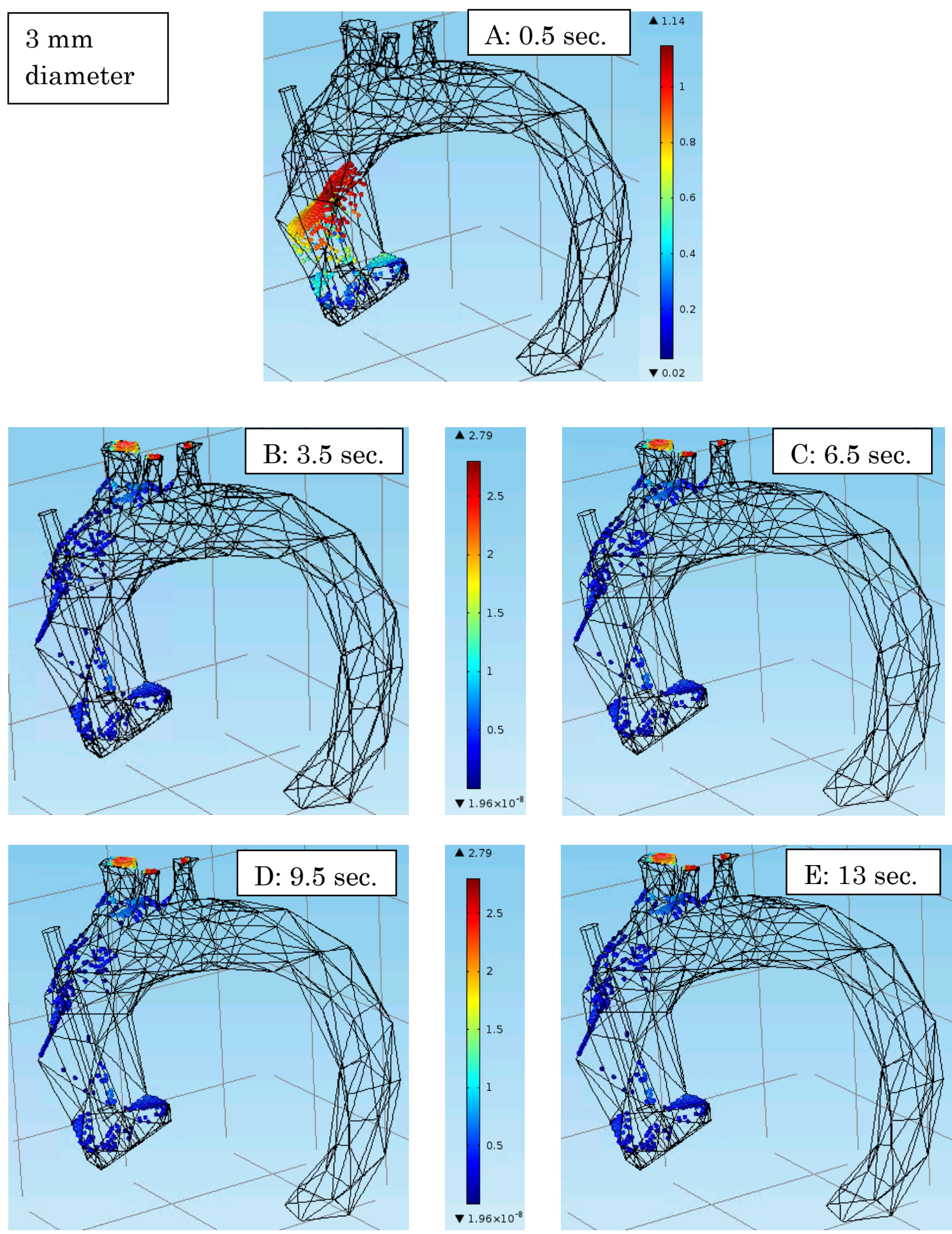

Figure 18: Particle tracing catheter diameter $7.33 \mathrm{~mm}$, blood pressure 150/90 mmHg, particle diameter $3 \mathrm{~mm}$, and particle density $0.8 \mathrm{~g} / \mathrm{cm}^{3}$. Panel 'A' at 0.5 seconds, panel 'B' at 3.5 seconds, panel 'C' at 6.5 seconds, panel 'D' at 9.5 seconds and panel 'E' at 13 seconds. 


\subsubsection{Multivariate ANOVA}

A multivariate ANOVA was performed using JMP 11 pro. Each table below represents an interaction that was deemed to be significant using a MANOVA with a significance level of $1 \%$. A full output of the analysis can be found in APPENDIX C.

In all of these tables showing the results, the word "Higher" is used to mean that this setting has a statistically significantly higher proportion of particles exiting through that outlet than the text of the same color that is labeled "Lower". The range of percentages next to "Higher" represent a 99\% confidence that this setting, between those percentages, has a higher mean transmission probability for that outlet. If "Lower" is used twice with the same text color then there is no significant difference between the two results but they are both significantly lower than the setting labeled "Higher" of the same color. If "Higher" is used twice with the same text color then there is no significant difference between the two results but they are both significantly higher than the setting labeled "Lower" of the same color. "No difference" means that there is no statistical difference between the settings of the same highlighted color. The LS Means Plot show a visual interpretation of the tables allowing for an approximation of the difference in transmission probabilities of the different parameters. A full analysis was done on outlet 1 to illustrate how to read the tables and plots. 


\subsubsection{Outlet 1}

Table 3: Outlet 1 interaction of blood pressure and particle diameter.

\begin{tabular}{|c|c|c|c|}
\hline $\begin{array}{l}\text { Particle } \\
\text { Diameter } \\
(\mathrm{mm})\end{array}$ & \multicolumn{3}{|c|}{ Blood Pressure (mmHg) } \\
\hline & 78 over 45 & 120 over 75 & 150 over 90 \\
\hline 1 & $\begin{array}{c}\text { No difference } \\
\text { Higher } \\
(0.28 \%-2.58 \%)\end{array}$ & $\begin{array}{c}\text { No difference } \\
\text { Higher } \\
(1.07 \%-3.37 \%)\end{array}$ & $\begin{array}{c}\text { No difference } \\
\text { Higher } \\
(3.21 \%-5.52 \%)\end{array}$ \\
\hline 0.5 & No difference & No difference & No difference \\
& & Lower & Lower \\
\hline 0.25 & No difference & No difference & No difference \\
& Lower & Lower & Lower \\
\hline
\end{tabular}

$\triangle$ LS Means Plot

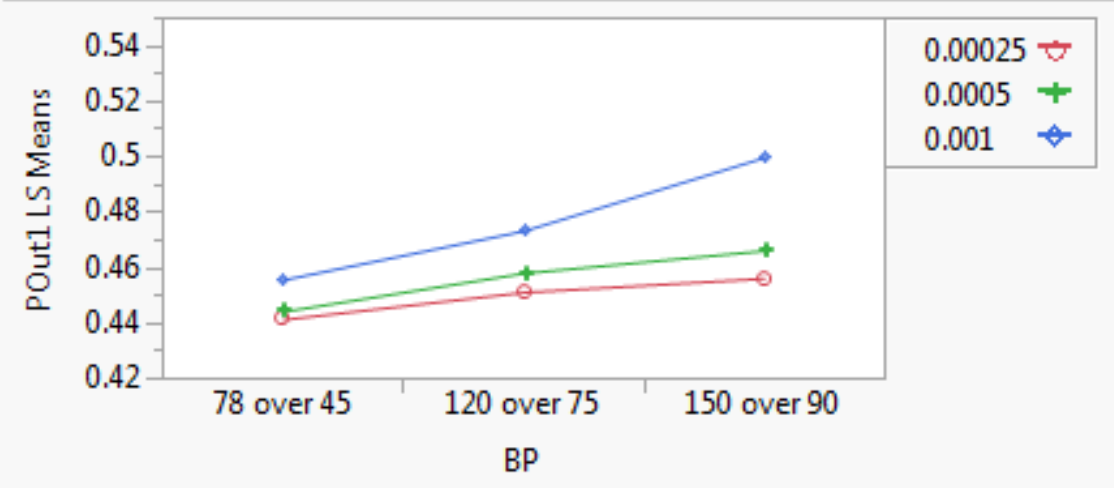

Figure 19: LS Means Plot for outlet 1 interaction of blood pressure and particle diameter.

Interpretation of Table 3 and Figure 19: The blue, red and green highlight show that there is no significant difference between having a particle diameter of $1 \mathrm{~mm}$ or $0.5 \mathrm{~mm}$ or $0.25 \mathrm{~mm}$ at any blood pressure. When the blood pressure is constant and the different particle diameters are compared a statistical difference is observed. The red colored text shows that with a blood pressure of 78 over 45 there is a significantly higher proportion of particles leaving through outlet 1 having a particle diameter of $1 \mathrm{~mm}$ versus a particle diameter of $0.25 \mathrm{~mm}$. The green colored text shows with a 
blood pressure of 120 over 75 there is a significantly higher proportion of particles leaving through outlet 1 having a particle diameter of $1 \mathrm{~mm}$ versus a particle diameter of $0.5 \mathrm{~mm}$ or $0.25 \mathrm{~mm}$. The blue text shows with a blood pressure of 150 over 90 there is a significantly higher proportion of particles leaving through outlet 1 having a particle diameter of $1 \mathrm{~mm}$ versus a particle diameter of $0.5 \mathrm{~mm}$ or $0.25 \mathrm{~mm}$. Figure 19 shows that when the partilce size is $1 \mathrm{~mm}$ it has a higher transmisson prbability then a smaller particle size at each blood presure.

The following is how to interpret the range of precentages:

There is $99 \%$ confidence that with a blood pressure of $150 / 90 \mathrm{mmHg}$ an increase in diameter size from $0.25 \mathrm{~mm}$ to $1 \mathrm{~mm}$ would lead to an increase in the mean transmission probability for outlet 1 of between $3.21 \%$ and $5.52 \%$.

There is $99 \%$ confidence that with a blood pressure of $120 / 75 \mathrm{mmHg}$ an increase in diameter size from $0.25 \mathrm{~mm}$ to $1 \mathrm{~mm}$ would lead to an increase in the mean transmission probability for outlet 1 of between $1.07 \%$ and $3.37 \%$.

There is $99 \%$ confidence that with a blood pressure of $78 / 45 \mathrm{mmHg}$ an increase in diameter size from $0.25 \mathrm{~mm}$ to $1 \mathrm{~mm}$ would lead to an increase in the mean transmission probability for outlet 1 of between $0.28 \%$ and $2.58 \%$. 
Table 4: Outlet 1 interaction of blood pressure and particle density.

\begin{tabular}{|c|c|c|c|}
\hline $\begin{array}{l}\text { Particle } \\
\text { density }\end{array}$ & \multicolumn{3}{|c|}{ Blood Pressure (mmHg) } \\
\hline & 78 over 45 & 120 over 75 & 150 over 90 \\
\hline 0.8 & $\begin{array}{l}\text { No difference } \\
\text { Lower }\end{array}$ & No difference & $\begin{array}{c}\text { No difference } \\
\text { Higher } \\
(1.52 \%-4.30 \%) \\
\text { Higher } \\
(0.95 \%-9.99 \%)\end{array}$ \\
\hline 1.066 & No difference & $\begin{array}{l}\text { No difference } \\
\text { No difference }\end{array}$ & $\begin{array}{c}\text { No difference } \\
\text { Lower } \\
\text { Higher } \\
(0.03 \%-2.81 \%)\end{array}$ \\
\hline 1.220 & No difference & $\begin{array}{l}\text { No difference } \\
\text { No difference }\end{array}$ & $\begin{array}{c}\text { No difference } \\
\text { Lower }\end{array}$ \\
\hline 1.45 & $\begin{array}{l}\text { No difference } \\
\text { No difference }\end{array}$ & $\begin{array}{l}\text { No difference } \\
\text { No difference }\end{array}$ & $\begin{array}{c}\text { Lower } \\
\text { Lower } \\
\text { No difference }\end{array}$ \\
\hline
\end{tabular}

$\triangle$ LS Means Plot

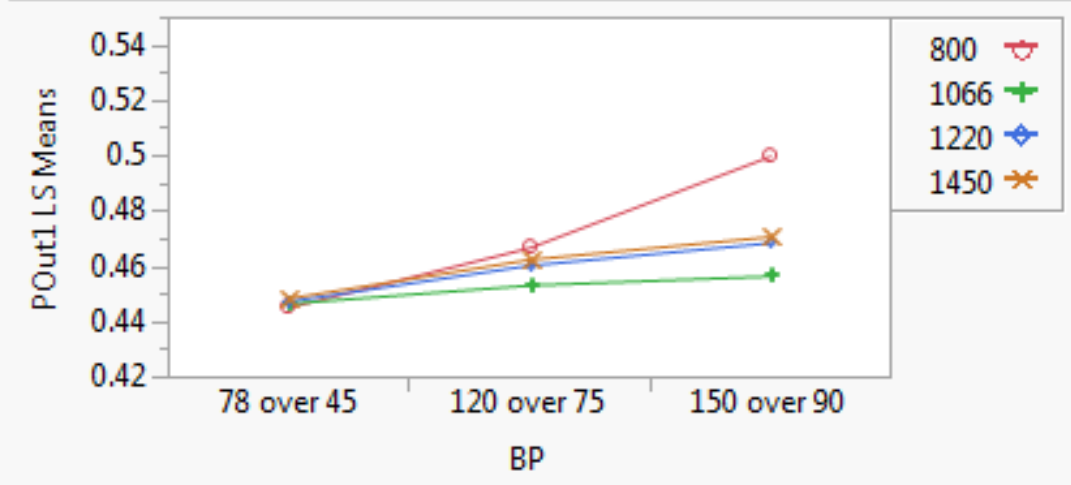

Figure 20: LS Means Plot for outlet 1 interaction of blood pressure and particle density.

Interpretation of Table 4 and Figure 20: The blue, red highlight show that there is no significant difference between having a particle density of $800 \mathrm{~g} / \mathrm{cm}^{3}, 1.066 \mathrm{~g} / \mathrm{cm}^{3}, 1.220 \mathrm{~g} / \mathrm{cm}^{3}$, or $1.45 \mathrm{~g} / \mathrm{cm}^{3}$ at blood pressures 78 over 45 and 120 over 75 . The blue highlight also shows that at a particle size of $1.066 \mathrm{~g} / \mathrm{cm}^{3}$ and $1.220 \mathrm{~g} / \mathrm{cm}^{3}$ there is no difference at any of the blood 
pressures. The green highlight shows that at a particle size of $1.45 \mathrm{~g} / \mathrm{cm}^{3}$ there is no difference at any of the blood pressures. The blue text is showing that there is a significantly higher proportion of particles leaving through Outlet 1 having a particle density of $800 \mathrm{~g} / \mathrm{cm}^{3}$ versus a particle density of $1.066 \mathrm{~g} / \mathrm{cm}^{3}$ or $1.220 \mathrm{~g} / \mathrm{cm}^{3}$ or $1.45 \mathrm{~g} / \mathrm{cm}^{3}$ with a blood pressure of 150 over 90 . The red text is showing there is a significantly higher proportion of particles leaving through Outlet 1 having a particle density of $1.066 \mathrm{~g} / \mathrm{cm}^{3}$ versus a particle density of $1.45 \mathrm{~g} / \mathrm{cm}^{3}$ with a blood pressure of 150 over 90 . The green text is showing that there is a significantly higher proportion of particles leaving through Outlet 1 having a blood pressure of 150 over 90 or 120 over 75 with a particle density of $0.8 \mathrm{~g} / \mathrm{cm}^{3}$. Figure 20 shows that when particle density is $0.8 \mathrm{~g} / \mathrm{cm}^{3}$ it has a higher transmisson prbability then the more dense particles at a blood pressure of 150 over $90 \mathrm{mmHg}$.

The following is how to interpret the range of precentages:

There is $99 \%$ confidence that with a blood pressure of $150 / 90 \mathrm{mmHg}$ a decrease in particle density from 1.45 to $1.066 \mathrm{~g} / \mathrm{cm}^{3}$ would lead to an increase in the mean transmission probability for outlet 1 of between $0.03 \%$ and $2.81 \%$.

There is $99 \%$ confidence that with a blood pressure of $150 / 90 \mathrm{mmHg}$ a decrease in particle density from 1.45 to $0.8 \mathrm{~g} / \mathrm{cm}^{3}$ would lead to an increase 
in the mean transmission probability for outlet 1 of between $1.52 \%$ and $4.30 \%$.

There is $99 \%$ confidence that with a particle density of $0.8 \mathrm{~g} / \mathrm{cm}^{3} \mathrm{a}$ change in blood pressure from $78 / 45$ to $150 / 90 \mathrm{mmHg}$ would lead to an increase in the mean transmission probability for outlet 1 of between $0.95 \%$ and $9.99 \%$.

Summary

Particle diameter, particle density and the blood pressure affect the proportion of particles that exit through outlet 1 . If the blood pressure is constant a higher proportion of particles will exit outlet 1 if the particle is larger in size. At lower blood pressures, 120 over 75 and 78 over 45, the particle density made no effect on the proportion of particles that exit though outlet 1 . At a blood pressure of 150 over 90 the lower density particles are more likely to exit through outlet 1 . 


\subsubsection{Outlet 2}

Table 5: Outlet 2 interaction of blood pressure and particle diameter.

\begin{tabular}{|c|c|c|c|}
\hline $\begin{array}{c}\text { Particle } \\
\text { Diameter } \\
(\mathrm{mm})\end{array}$ & \multicolumn{3}{|c|}{ Blood Pressure (mmHg) } \\
\hline & 78 over 45 & 120 over 75 & 150 over 90 \\
\hline & $\begin{array}{c}\text { No difference } \\
\text { Higher } \\
(0.34 \%-2.81 \%) .\end{array}$ & $\begin{array}{c}\text { No difference } \\
\text { Higher } \\
(1.38 \%-3.85 \%)\end{array}$ & $\begin{array}{c}\text { No difference } \\
\text { Higher } \\
(2.33 \%-4.80 \%)\end{array}$ \\
\hline 1 & No difference & $\begin{array}{c}\text { No difference } \\
\text { Lower }\end{array}$ & $\begin{array}{c}\text { No difference } \\
\text { Lower }\end{array}$ \\
\hline 0.5 & No difference & No difference & No difference \\
\hline 0.25 & Lower & Lower & Lower \\
\hline
\end{tabular}

$\triangle$ LS Means Plot

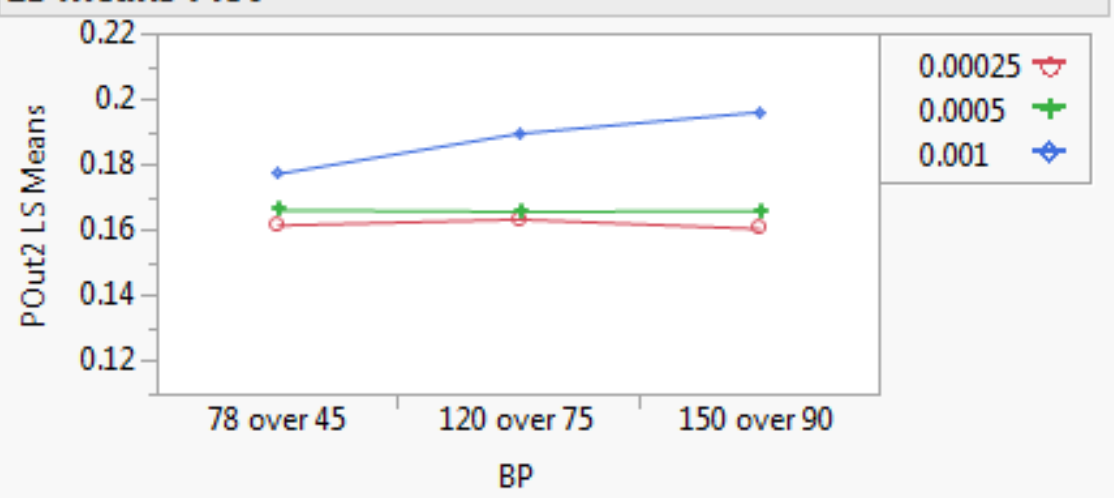

Figure 21: LS Means Plot for outlet 2 interaction of blood pressure and particle diameter.

Table 6: Outlet 2 interaction of blood pressure and particle density.

\begin{tabular}{|c|c|c|c|}
\hline $\begin{array}{c}\text { Particle } \\
\text { density } \\
\left(\mathrm{g} / \mathrm{cm}^{3}\right)\end{array}$ & \multicolumn{3}{|c|}{ Blood Pressure (mmHg) } \\
\hline 0.8 & No difference & No difference & $\begin{array}{c}\text { No difference } \\
\text { Lower }\end{array}$ \\
\hline 1.066 & No difference & No difference & $\begin{array}{c}\text { No difference } \\
\text { Higher }\end{array}$ \\
\hline 1.220 & No difference & No difference & $\begin{array}{c}\text { No difference } \\
\text { Higher }\end{array}$ \\
\hline 1.45 & No difference & No difference & $\begin{array}{c}\text { No difference } \\
\text { Higher } \\
(0.71 \%-3.69 \%)\end{array}$ \\
\hline
\end{tabular}




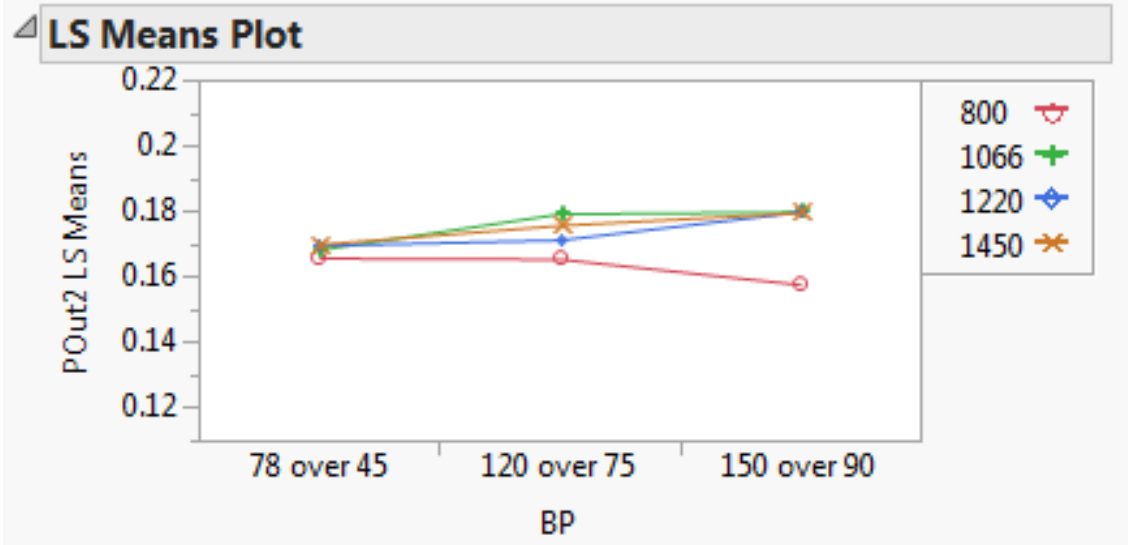

Figure 22: LS Means Plot for outlet 2 interaction of blood pressure and particle density. Summary

Particle diameter, particle density and the blood pressure affect the proportion of particles that exit through outlet 2 . At all blood pressures a particle size of $1 \mathrm{~mm}$ is significantly more likely to exit outlet 2 than a smaller particle. If the blood pressure is 150 over 90 a $0.8 \mathrm{~g} / \mathrm{cm}^{3}$ particle is significantly less likely to exit outlet 2 . 


\subsubsection{Outlet 3}

Table 7: Outlet 3 interaction of particle diameter and particle density.

\begin{tabular}{|c|c|c|c|}
\hline $\begin{array}{c}\text { Particle } \\
\text { density } \\
\left(\mathrm{g} / \mathrm{cm}^{3}\right)\end{array}$ & \multicolumn{3}{|c|}{ Particle Diameter (m) } \\
\hline & 1 & 0.5 & 0.25 \\
\hline \multirow{2}{*}{0.8} & $\begin{array}{c}\text { No difference } \\
\text { Higher } \\
(2.17 \%-5.23 \%)\end{array}$ & $\begin{array}{c}\text { No difference } \\
\text { Higher }\end{array}$ & $\begin{array}{c}\text { No difference } \\
\text { Lower }\end{array}$ \\
\hline \multirow{3}{*}{1.066} & $\begin{array}{c}\text { No difference } \\
\text { Higher } \\
(3.36 \%-6.41 \%)\end{array}$ & $\begin{array}{c}\text { No difference } \\
\text { Lower }\end{array}$ & $\begin{array}{c}\text { No difference } \\
\text { Higher }\end{array}$ \\
\hline \multirow{3}{*}{1.220} & No difference & No difference & Nower difference \\
& $\begin{array}{c}\text { Higher } \\
(2.84 \%-5.89 \%)\end{array}$ & Lower & Lower \\
\hline \multirow{3}{*}{1.45} & No difference & No difference & No difference \\
& $\begin{array}{c}\text { Higher } \\
(3.18 \%-6.24 \%)\end{array}$ & Lower & Lower \\
\hline
\end{tabular}

$\triangle$ LS Means Plot

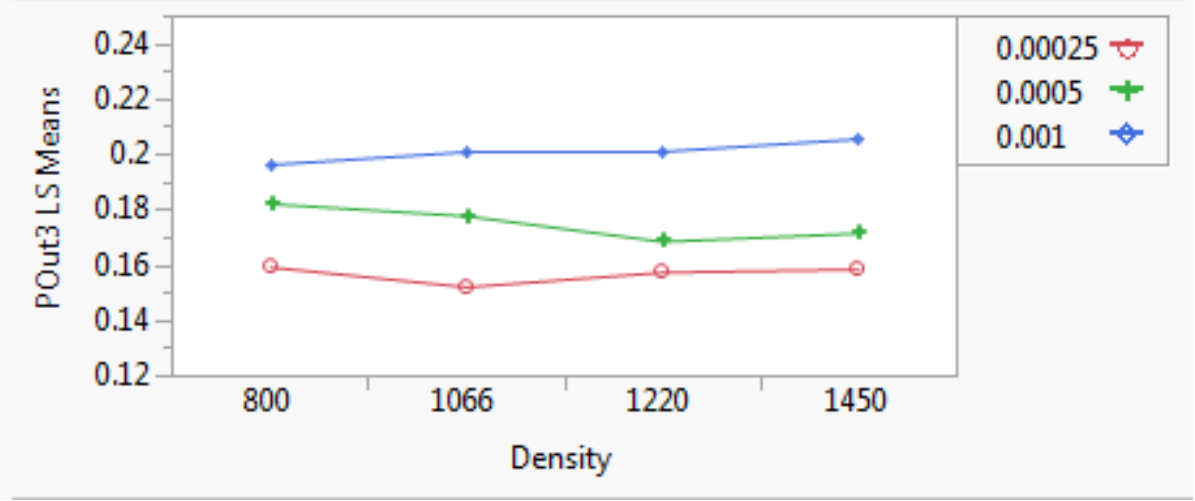

Figure 23: LS Means Plot for outlet 3 interaction of particle diameter and particle density. 
Table 8: Outlet 3 interaction of particle diameter and blood pressure.

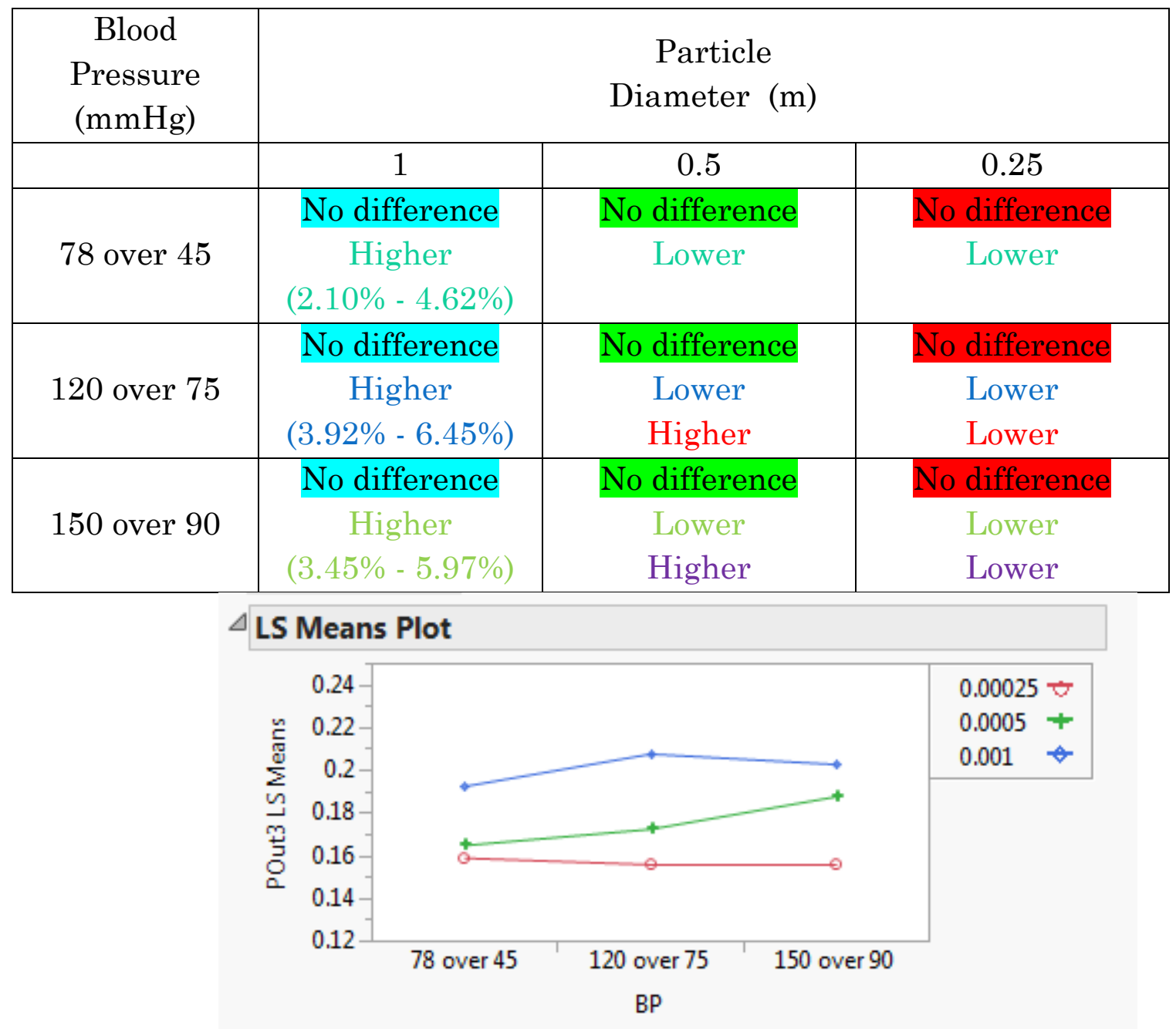

Figure 24: LS Means Plot for outlet 3 interaction of particle diameter and blood pressure.

Summary

Particle diameter, particle density and the blood pressure affect the proportion of particles that exit through outlet 3 . If the particle diameter remains constant then the particle density or the blood pressure make no difference to the outlet proportion. If the particle density or the blood pressure is the same than the larger particle is more likely to exit through outlet 3 . 


\subsubsection{Outlet 4}

Table 9: Outlet 4 interaction of particle diameter and particle density.

\begin{tabular}{|c|c|c|c|}
\hline \multirow{2}{*}{$\begin{array}{l}\text { Particle } \\
\text { density } \\
\left(\mathrm{g} / \mathrm{cm}^{3}\right) \\
\end{array}$} & \multicolumn{3}{|c|}{ Particle Diameter (m) } \\
\hline & 1 & 0.5 & 0.25 \\
\hline 0.8 & $\begin{array}{c}\text { No difference } \\
\text { Lower }\end{array}$ & $\begin{array}{c}\text { No difference } \\
\text { Higher }\end{array}$ & $\begin{array}{c}\text { Higher } \\
(5.25 \%-8.93 \%) \\
\text { Lower }\end{array}$ \\
\hline 1.066 & $\begin{array}{c}\text { No difference } \\
\text { Lower }\end{array}$ & $\begin{array}{c}\text { No difference } \\
\text { Lower } \\
\text { Lower }\end{array}$ & $\begin{array}{c}\text { Higher } \\
(7.77 \%-11.45 \%) \\
\text { Higher } \\
\text { Higher } \\
(0.17 \%-3.85 \%)\end{array}$ \\
\hline 1.220 & $\begin{array}{c}\text { No difference } \\
\text { Lower }\end{array}$ & $\begin{array}{c}\text { No difference } \\
\text { Higher }\end{array}$ & $\begin{array}{c}\text { Higher } \\
(7.32 \%-10.99 \%)\end{array}$ \\
\hline 1.45 & $\begin{array}{c}\text { No difference } \\
\text { Lower }\end{array}$ & $\begin{array}{c}\text { No difference } \\
\text { Higher }\end{array}$ & $\begin{array}{c}\text { Higher } \\
(7.94 \%-11.61 \%)\end{array}$ \\
\hline
\end{tabular}

LS Means Plot

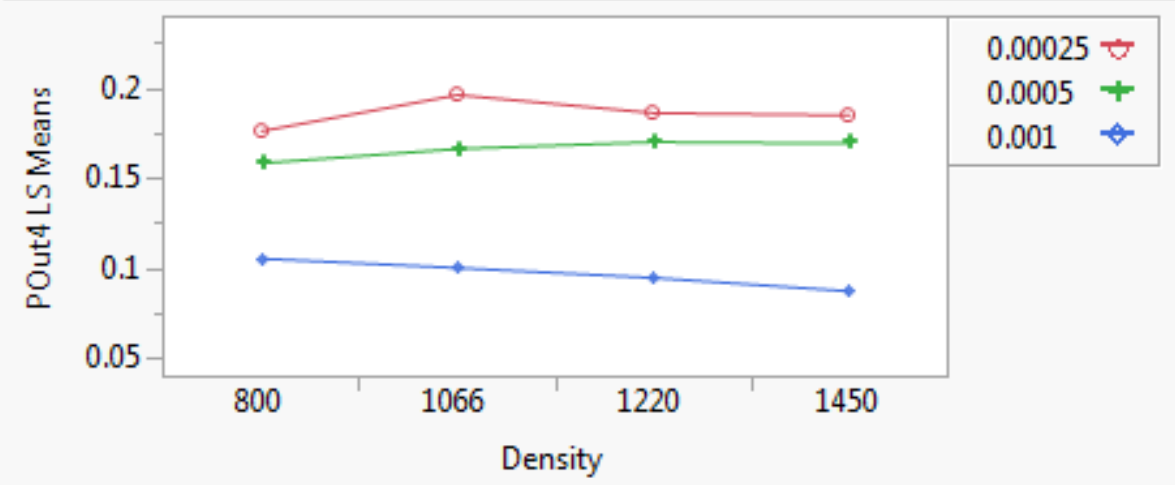

Figure 25: LS Means Plot for outlet 4 interaction of particle diameter and particle density. 
Table 10: Outlet 4 interaction of particle diameter and blood pressure.

\begin{tabular}{|c|c|c|c|}
\hline $\begin{array}{c}\text { Blood } \\
\text { Pressure } \\
(\mathrm{mmHg})\end{array}$ & \multicolumn{3}{|c|}{$\begin{array}{c}\text { Particle } \\
\text { Diameter (m) }\end{array}$} \\
\hline & 1 & 0.5 & 0.25 \\
\hline 78 over 45 & $\begin{array}{c}\text { No Difference } \\
\text { Lower }\end{array}$ & Higher & No difference \\
& & & $(2.89 \%-5.93 \%)$ \\
\hline \multirow{2}{*}{120 over 75} & $\begin{array}{c}\text { No Difference } \\
\text { Lower }\end{array}$ & Lower & No difference \\
& No Difference & Higher & $(7.91 \%-10.94 \%)$ \\
\hline 150 over 90 & Lower & Lower & No difference \\
& Lower & Higher & $(11.37 \%-14.41 \%)$ \\
\hline
\end{tabular}

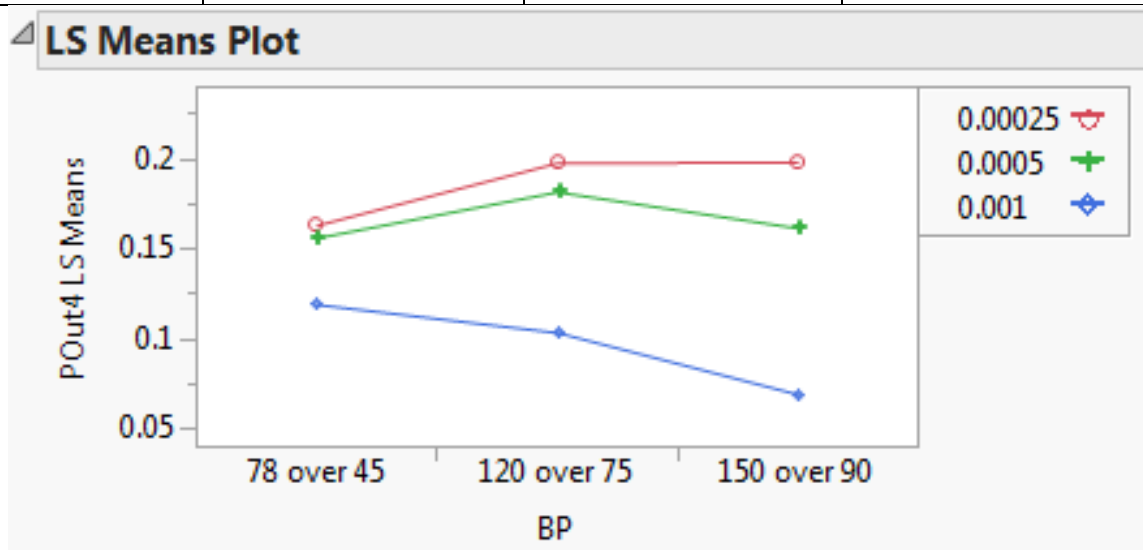

Figure 26: LS Means Plot for outlet 4 interaction of particle diameter and blood pressure. 
Table 11: Outlet 4 interaction of blood pressure and particle density.

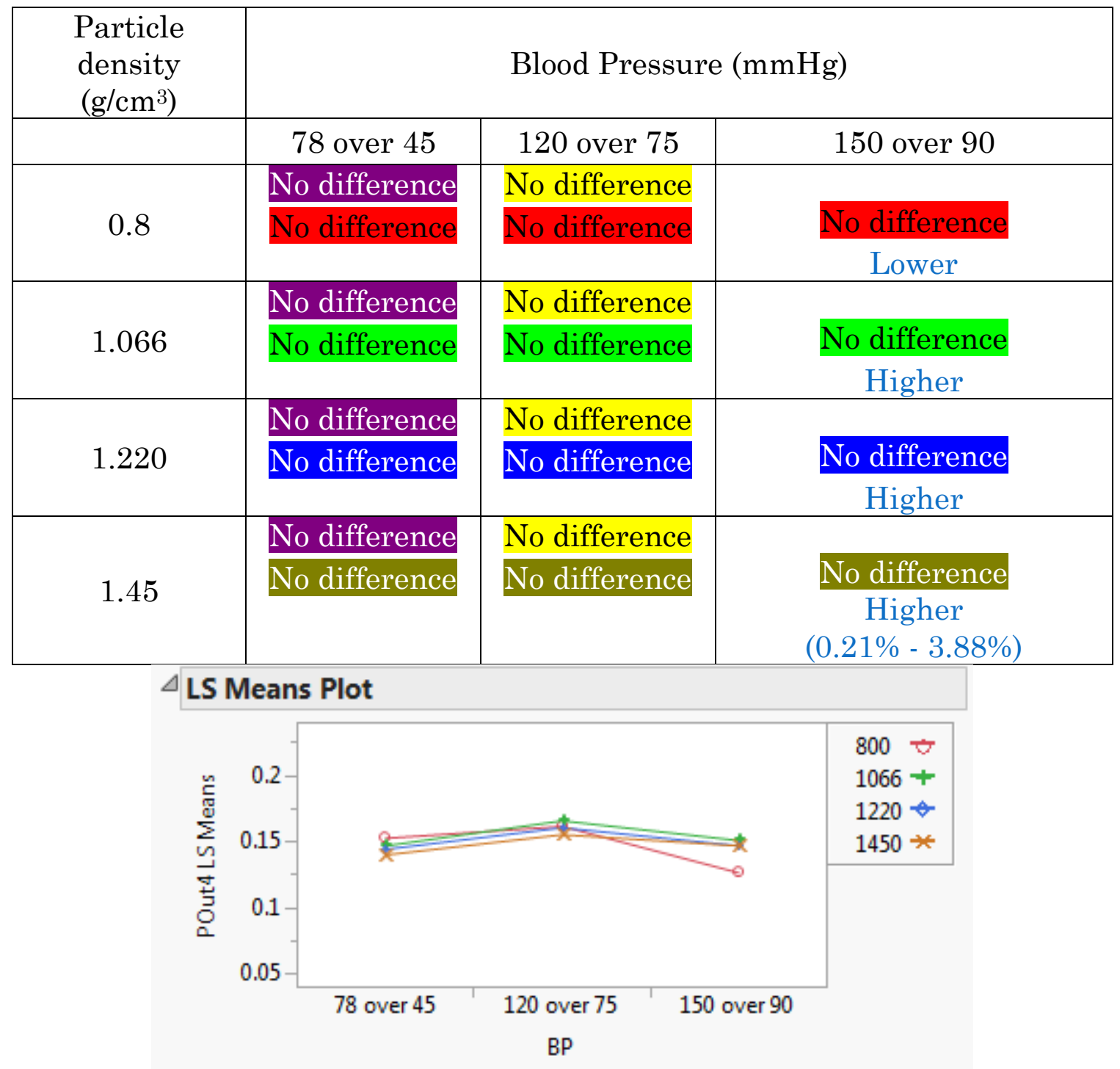

Figure 27: LS Means Plot for outlet 4 interaction of blood pressure and particle density.

\section{Summary}

Particle diameter, particle density and the blood pressure affect the percentage of particles that exit through outlet 4 . If the particle density remains constant then the smaller particle is more likely to exit outlet 4 . If the particle diameter is constant at either $1 \mathrm{~mm}$ or $0.5 \mathrm{~mm}$ then changing particle density has no effect on the proportion of particles exiting outlet 4 . If 
the particle diameter is $0.25 \mathrm{~mm}$ then the particle is more likely to exit if it has a density of $1.066 \mathrm{~g} / \mathrm{cm}^{3} \mathrm{vs} 0.8 \mathrm{~g} / \mathrm{cm}^{3}$. If the blood pressure is the same then the smaller the particle the more likely it will exit outlet 4 . At a blood pressure of 150 over $90 \mathrm{mmHg}$ a particle is more likely to exit outlet 4 if the diameter is $1.066 \mathrm{~g} / \mathrm{cm}^{3}, 1.220 \mathrm{~g} / \mathrm{cm}^{3}$, or $1.45 \mathrm{~g} / \mathrm{cm}^{3}$ versus 0.8 .

\subsubsection{Not Out}

Table 12: Not Out interaction of particle diameter and blood pressure.

\begin{tabular}{|c|c|c|c|}
\hline $\begin{array}{c}\text { Blood } \\
\text { Pressure } \\
(\mathrm{mmHg})\end{array}$ & \multicolumn{3}{|c|}{$\begin{array}{c}\text { Particle } \\
\text { Diameter }(\mathrm{m})\end{array}$} \\
\hline & 1 & 0.5 & 0.25 \\
\hline 78 over 45 & Hower & Higher & Higher \\
& Higher & Higher \\
& & $2.22 \%-7.76 \%)$ & Lower \\
\hline 120 over 75 & Lower & Lower & Higher \\
\hline 150 over 90 & Higher & Lower & Lower \\
\hline
\end{tabular}

$\triangle$ LS Means Plot

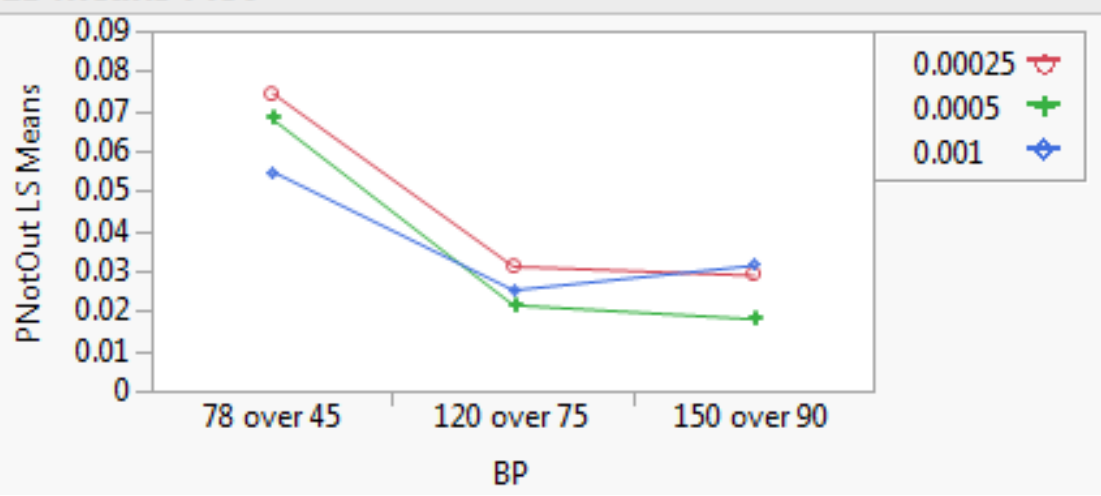

Figure 28: LS Means Plot for not out interaction of particle diameter and blood pressure. 


\section{Summary}

Particle diameter and the blood pressure affect the percentage of particles that will not exit the model. The most particle will not exit the model at low blood pressures and low values of density.

\subsubsection{Overall Summary of MANOVA}

The MANOVA has determined for every outlet the density of the particle, diameter of the particle, and the blood pressure are statistically significant in affecting the transmission probability of that outlet. It was found assuming a constant blood pressure that having a large diameter and a low density of particle would lead to a higher transmission probability for outlet 1. For outlet 2, assuming a constant blood pressure it was found that larger particles and higher density leads to a higher transmission probability. Outlet 3 showed that regardless of the blood pressure or particle diameter a larger particle would lead to a higher transmission probability. If the particle density remains constant then the smaller particle is more likely to exit outlet 4 . If the blood pressure is the same then the smaller the particle the more likely it will exit outlet 4. 


\section{DISCUSSION}

As expected the velocity of the particles increased as the blood pressure increased, Figure 15. This is easily explained using Bernoulli's equation which shows that if the diameter of the aortic arch is the same an increase in pressure would lead to an increase in fluid velocity. The large difference in velocity between outlets $1-3$ and outlet 4 can be explained because the same pressure drop was used for every outlet. In the future a larger pressure drop should be used for outlet 4 compared to outlets 1-3.

When interpreting the results it is important to remember what the different outlets physiologically represent. Outlet 1 is the brachiocephalic artery, outlet 2 is the left common carotid artery, outlet 3 is the left subclavian artery, and outlet 4 the descending aorta. The first three outlets: the brachiocephalic artery, the left common carotid artery, and the left subclavian artery have the possibility to lead into the cerebral circulatory system (CCS) and possibly cause an ischemic event. As discussed in section 2.2 the brachiocephalic artery and the left subclavian artery do not directly lead into the CCS only the left common carotid does. The brachiocephalic artery and the left subclavian artery both bifurcate and one of their branches leads into the CCS while the other does not. When analyzing the percentage of particles that would enter the CCS the transmission probability of outlets 1-3 are summed together and then reduced by $31.67 \%$. The reduction factor was chosen after looking at the results in a study performed by Carr [1]. 
In the simulation where the particle diameter was $3 \mathrm{~mm}$ the particles were getting stuck in the simulation as seen in Figure 18. The best explanation for this phenomena is that because the particle diameter is relatively large the Reynolds number is being dominated by the inertial forces show in equation 13 .

$$
N_{\text {Rep }}=\frac{u D_{p} \rho}{\mu}=\frac{\text { Inertial force }}{\text { Viscous force }}
$$

Where ' $u$ ' is the velocity of approaching stream, 'Dp' is the diameter of the particle, ' $\rho$ ' is the density of blood, and ' $\mu$ ' is the viscosity of blood.

The inertial forces are dominating the viscous forces causing the particles to leave their streamline and continue with their initial velocity and collide and stick to the walls of the simulation. This is happening when the diameter is $3 \mathrm{~mm}$ because the inertial forces are 12 time greater with a diameter of $3 \mathrm{~mm}$ compared to a diameter of $0.25 \mathrm{~mm}$. Another possible explanation for this is that the particles are getting stuck in the corners of the tetrahedral mesh generated by COMSOL. A model with a finer mesh was created to mitigate this issue. However at the halfway point of study 1 the file size was $12 \mathrm{~GB}$ and the system did not have enough memory to finish the study. 


\subsection{Statistical analysis}

The MANOVA showed that the catheter size during a Transaortic approach is not a significant predictor of particle transmission probability. The means that there is no difference in the likelihood of particles traveling to the cerebral circulatory system at catheter sizes 22,24 , or 26 French. This is understandable because the catheter was only present in the ascending aorta so it would not have a significant effect on the fluid dynamics entering the brachiocephalic artery, the left common carotid artery, the left subclavian artery, or the descending aorta.

From looking at the Table 2 roughly $80.42 \pm 19.98 \%$ of particles will exit the aortic arch through the first 3 outlets and $54.95 \pm 13.66 \%$ into the cerebral circulatory system. This is higher than the study performed by Carr which showed that $60 \pm 13 \%$ passed into the branch arteries and $41 \pm 15 \%$ passed into the CCS [1]. This is acceptable because of the large uncertainty of both numbers.

The MANOVA conclude that a larger diameter particle would lead to higher transmissions probability into the brachiocephalic artery, the left common carotid artery, and the left subclavian artery. It also concluded that a smaller diameter particle would have a higher transmission probability for the descending aorta. This is consistent with a Carr study which found that "As particle size increased, there was significant increase of particles embolic to the branch arteries for all patients" [1]. The MANOVA found that 
decreasing particle size was the most effective way of reducing the amount of particles that could enter the CCS. For example by only reducing particle size from $1 \mathrm{~mm}$ to $0.25 \mathrm{~mm}$ the transmission probability into the descending aorta increases by between $7-11 \%$ (Table 9) meaning the percentage of particles that could enter the CCS decreases $7-11 \%$.

The MANOVA found that particle density was also a statistically significant parameter. The analysis found that with a blood pressure of $150 / 90 \mathrm{mmHg}$ a more dense particle $\left(1.45 \mathrm{~g} / \mathrm{cm}^{3}\right)$ was between $0.71 \%$ and $3.69 \%$ (Table 6) more likely to exit outlet 2 and between $0.21 \%$ and $3.88 \%$ (Table 11) more likely to exit outlet 4 then a less dense particle $\left(0.8 \mathrm{~g} / \mathrm{cm}^{3}\right)$. However for outlet 1 a less dense particle $\left(0.8 \mathrm{~g} / \mathrm{cm}^{3}\right)$ is more likely to exit by between $1.52 \%$ and $4.30 \%$ (Table 5 ) when compared to a denser particle (1.45 $\left.\mathrm{g} / \mathrm{cm}^{3}\right)$. Like particle diameter, different particle densities affect the particle Reynold number's inertial force shown in equation 13 . However particle density is not in equation 13 but the density of a particle influences the velocity of the particle. The velocity changes because of the Stokes drag equation shown in equation 14.

$$
\begin{aligned}
F & =\frac{1}{t_{p}} m_{p}(u-v) \\
t_{p} & =\frac{\rho_{p} d_{p}^{2}}{18 \mu}
\end{aligned}
$$


Where ' $F$ ' is the drag force, ' $u$ ' is the velocity field, ' $t p$ ' is the particle velocity response time, ' $\rho_{d}$ ' is the particle density, ' $d_{p}$ ' is the particle diameter and, ' $\mu$ ' is the fluid viscosity.

As shown in equation 15 an increase in particle density leads to a larger particle velocity response time ' $t$,' In turn by looking at equation $14 \mathrm{a}$ larger particle velocity response time decrease the drag force ' $\mathrm{F}$ '. By reducing the drag force the velocity of the particle increases. An increase in velocity causes an increase in the Reynolds number per equation 13.

The transmission probability difference is much smaller then changes in the particle diameter because of the relative difference between the densities. The densest particle $\left(1.45 \mathrm{~g} / \mathrm{cm}^{3}\right)$ only has a relative Reynolds number of 1.55 greater than the least dense particle $\left(0.8 \mathrm{~g} / \mathrm{cm}^{3}\right)$. This explains why density is only significant with a blood pressure of $150 / 90$ mmHg. The blood pressure is higher causing a higher particle velocity. When combined with changing the densities the inertial force becomes dominate over the viscus forces.

Finally the MANOVA found that blood pressure was a statistically significant parameter. A much smaller difference is seen in the transmission probability across different blood pressures versus changes in particle diameter. The largest change is the increase between the percentages of particles remaining in the simulation at $150 / 90 \mathrm{mmHg}$ and $120 / 75 \mathrm{mmHg}$ 
versus $78 / 45 \mathrm{mmHg}$. This can be explained because at higher blood pressures the velocity of the fluid in the simulation is higher so the particles are moving through the simulation faster. 


\section{CONCLUSION}

In a small percentage of transcatheter aortic valve replacement surgeries particles can become dislodged and pass into the aortic arch. It is possible for these particles to travel out of the aortic arch, into the cerebral circulatory system and cause an ischemic event. This thesis focused on tracking these particles using a finite element analysis to determine the parameters that affect the probability or a particle entering the cerebral circulatory system. It was determined that particle diameter, particle density, and the blood pressure do affect the transmission probability of particles traveling through the aortic arch. The diameter of the particle makes the largest impact on if the particle will travel into the cerebral circulatory system and cause an ischemic event. The larger the particle up to a point, the more likely it is to flow into the cerebral circulatory system. It was also concluded that the diameter of the surgical catheter used in a transaortic approach has no impact on the transmission probabilities of the particles.

The current computer simulation is valuable because it allows for a quick implementation of new aortic arch geometries and new parameter settings for future research. The next step is to move toward the idea of creating a simulation to alert the surgeon before they begin TAVR if the patients is more prone to ischemic events. For future use based on these results, the model needs to be refined to allow for larger particle sizes, and to import and compare the results of different aortic arch geometries. A computer with more 
capabilities may be needed to handle the finer mesh needed to increase the particle size. Additionally, a larger geometric model which includes the Right Common Carotid, Right Subclavian, the left Vertebral Artery, and the Left Subclavian Artery should be tested. This would allow for a better representation of the geometry which causes the fluid to flow into the cerebral circulatory system.

In conclusion, the model answers the two hypothesis questions by determining that the particle diameter, particle density, and the blood pressure do affect the transmission probability of particles traveling through the aortic arch. Learning the exact parameters and geometries that lead to a particle traveling into the cerebral circulatory system and causing ischemia is a step in the right direction to predicting ischemia and saving thousands of lives. Additional research needs to be done to fully understand etiology and mechanisms of cerebral ischemia caused be complications of TAVR. 


\section{REFERENCES}

[1] I. A. Carr, "Size-dependent predilections of cardiogenic embolic transport," American Journal of Physiology - Heart and Circulatory Physiology, vol. 305, no. 5, 2013.

[2] S. Shadden, "TCT-842 Embolic Particles Show Surprising Size Dependent Predilection for Cerebral versus Peripheral Arteries: Results from Computational Fluid Dynamic Modeling," Journal of the American College of Cardiology, vol. 60, no. 17 supplement B, p. B244, 2012.

[3] M. Donald Lloyd-Jones, "Heart Disease and Stroke Statistics-2010 Update," American Heart Association, 2010.

[4] "U.S. Aortic Stenosis Disease Prevalence \& Treatment Statistics," University of Maryland Medical Center, 19 August 2014. [Online]. Available:

http://umm.edu/programs/heart/services/services/cardiac-surgery/valve-surgery/facts. [Accessed 26 April 2015].

[5] B. DS, "Prevalence and Characteristics of Unoperated Patients with Severe Aortic Stenosis," The Journal of Heart Valve Disease, vol. 20, pp. 284-291, 2001.

[6] B. DS, "Evaluation of patients with severe symptomatic aortic stenosis who do not undergo aortic valve replacement: the potential role of subjectively overestimated operative risk," Circulation: Cardiovascular Quality and Outcomes, vol. 2, pp. 533-539, 2009 .

[7] M. Martin B. Leon, "Transcatheter Aortic-Valve Implantation for Aortic Stenosis in Patients Who Cannot Undergo Surgery," The New England Journal of Medicine, vol. 363, no. 17, pp. 1597-1607, 2010.

[8] M. D, "Heart disease and stroke statistics—2015 update: a report from the American Heart Association," Circulstion, vol. 29, no. 322, 2015.

[9] M. LR Caplan, "New England Medical Center Posterior Circulation Stroke Registry: I. Methods, Data Base, Distribution of Brain Lesions, Stroke Mechanisms, and Outcomes," Journal of Clinical Neurology, vol. 1, pp. 14-30, 2005.

[10] M. Nicolas M. Van Mieghem, "Histopathology of Embolic Debris Captured During Transcatheter Aortic Valve Replacement," CIRCULATION, vol. 4, no. 127, pp. 21942201, 2013.

[11] A. Cheung, " Illustrated techniques for transapical aortic valve implantation," Annals of Cardiothoracic Surgery, vol. 1, no. 2, pp. 231-139, 2012. 
[12] L. Svensson, "Cleveland Clinic," March 2012. [Online]. Available:

http://my.clevelandclinic.org/services/heart/disorders/valvetreatment/aorticvalvesurger y. [Accessed 21 April 2014].

[13] "New Heart Valve," Edwards Lifesciences Corporation, 2014. [Online]. Available: http://newheartvalve.com/hcp/tavr-overview. [Accessed 21 April 2015].

[14] D. C. Miller, "Transcatheter (TAVR) versus surgical (AVR) aortic valve replacement: Occurrence, hazard, risk factors, and consequences of neurologic events in the PARTNER trial," The Journal of Thoracic and Cardiovascular Surgery, vol. 143, no. 4, pp. 832-843, 2012.

[15] K. S. Saladin, Anatomy and Physiology: The Unity of Form and Function, Boston: McGraw-Hill, 2010.

[16] H. V. Carter, Anatomy of the Human Body, London, 1918.

[17] R. TannerThies, Circulatory Hemodynamics Physiology. 4th ed, New York: SpringerVerlag, 2012.

[18] "Heart," American Heart Association, 11 March 2015. [Online]. Available: http://www.heart.org/HEARTORG/Conditions/HighBloodPressure/AboutHighBloodPre ssure/Understanding-Blood-Pressure-Readings_UCM_301764_Article.jsp. [Accessed 14 April 2015].

[19] "Arterial Pressure Waveforms," Dynapulse, [Online]. Available: http://www.dynapulse.com/educator/WebCurriculum/Chapter\%203/Arterial\%20Pressu re\%20Waveforms.htm. [Accessed 21 April 2015].

[20] C. Aram, "The Seventh Report of the Joint National Committee on Prevention, Detection, Evaluation, and Treatment of High Blood Pressure," U.S. DEPARTMENT OF HEALTH AND HUMAN SERVICES, Washington D.C, 2004.

[21] R. Erbel, "Aortic Dimensions and the Risk of Dissection," Heart, vol. 92, no. 1, p. 137$142,2006$.

[22] A. Redheuil, "Age-Related Changes in Aortic Arch Geometry: Relationship with Proximal Aortic Function and left Ventricular Mass and remodeling," NIH Public Access, pp. 1262-1270, 2013.

[23] A. Wolak, "Aortic size assessment by noncontrast cardiac computed tomography: normal limits by age, gender, and body surface area.," JACC: Cardiovascular Imaging, vol. 1, no. 2, pp. 200-209, 2008. 
[24] L. a. M. D. Cho, "Basic cerebral anatomy for the carotid interventionalist: The intracranial and extracranial vessels," Catheterization and Cardiovascular Interventions, vol. 68, no. 1, pp. 104-111, 2006.

[25] T. Brott, "2011 ASA/ACCF/AHA/AANN/AANS/ACR/ASNR/CNS/SAIP/SCAI/SIR/SNIS/SVM/SVS Guideline on the Management of Patients With Extracranial Carotid and Vertebral Artery Disease," Journal of the American College of Cardiology, vol. 57, no. 8, pp. 7-8, 2011.

[26] M. Bizzarri F, "Antegrade selective cerebral perfusion in patients with "bovine aortic arch": is it easier?," CArdiothorac Surgery, vol. 3, no. 60, 2008.

[27] H. Jilaihawi, "Meta-analysis of complications in aortic valve replacement: Comparison of Medtronic-Corevalve, Edwards-Sapien and surgical aortic valve replacement in 8,536 patients," Catheterization and Cardiovascular Interventions, vol. 80, no. 1, pp. 128-138, 2012.

[28] "euroSCORE," European System for Cardiac Operative Risk Evaluation, 3 March 2011. [Online]. Available: http://www.euroscore.org/index.htm. [Accessed 21 April 2015].

[29] S. K. Kodali, "Two-Year Outcomes after Transcatheter or Surgical Aortic-Valve Replacement," The New England Journal of Medicine, vol. 366, no. 18, pp. 1686-1695, 2012.

[30] G. Athappan, "Influence of Transatheter Aortic Valve Replacement Strategy and Valve Design on Stroke After Transcatheter Aortic Vlave Replacement," Journal of the American College of Cardiology, vol. 63, no. 20, pp. 2101-2110, 2014.

[31] P. Kahlert, "Silent and Apparent Cerebral Ischemia After Percutaneous Transfemoral Aortic Valve Implantation A Diffusion-Weighted Magnetic Resonance Imaging Study," Circulation, pp. 870-877, 2009.

[32] "Cerebral Ischemia," Columbia Neurosurgeons, [Online]. Available: http://www.columbianeurosurgery.org/conditions/cerebral-ischemia/. [Accessed 21 April 2015].

[33] L. M.C, "Annual Incidence of First Silent Stroke in the United States: A Preliminary Estimate," Cerebrovascular Diseases, vol. 16, no. 3, 2003.

[34] J. E. Wagenseil, "Elastin in Large Artery Stiffness and Hypertension," Journal of Cardiovascular Translational Research, vol. 5, no. 3, p. 264-273, 2012.

[35] J. Hauser, "System Analyze of Windkessel Models," Department of Circuit Theory, Faculty of Electrical Engineering, CTU in Prague, Prague, 2012. 
[36] M. Hlavac, "Winkessel Model Analysis in Matlab," Prague.

[37] G. Howe, "A Multiphysics Simulation of a Coronary Artery," California Polytechnic State University of California, San Luis Obispo, 2013.

[38] Z. Jones, "The Effect of Artery Bifurcation Angles on Fluid FLow and Wall Shear Stress in the Middle Cerebral Artery," California Polytechnic State University, San Luis Obispo, 2014.

[39] M. Edward R. Laskowski, "What's a normal resting heart rate?," Mayo Clinic, 29 September 2012. [Online]. Available: http://www.mayoclinic.org/healthyliving/fitness/expert-answers/heart-rate/faq-20057979. [Accessed 27 April 2015].

[40] J.-M. V. Haesdonck, "Comparison by Computerized Numeric Modeling of Energy Losses in Different Fontan Connections," Circulation, vol. 92, pp. 322-326, 1995.

[41] R. Paul, "Shear Stress Related Blood Damage in Laminar Couette Flow," Artificial Organs, vol. 27, no. 6, pp. 517-529, 2003.

[42] D. A. Rahdert, "Measurement of density and calcium in human atherosclerotic plaque and implications for arterial brachytherapy," Cardiovascular Radiation Medicine, vol. 1, no. 4, pp. 358-367, 1999.

[43] J. McLester, Applied Biomechanics: Concepts and Connections, Belmont, CA: Cengage Learning, 2007.

[44] J. I. ZWICKER, "Thrombosis and ELISA optical density values in hospitalized patients with heparin-induced thrombocytopenia," Journal of Thrombosis and Haemostasis, vol. 2, no. 12, pp. 2133-2137, 2004.

[45] B. Ramlawi, "Transcatheter Aortic Valve Replacement (TAVR): Access Planning and Strategies," Methodist DeBakey Cardiovascular Journal, vol. 8, no. 2, pp. 22-25, 2012.

[46] J.-W. L. Nico Westerhof, "The Arterial Windkessel," Medical and Biological Engineering and Computing, 2008.

[47] M. S. V. V. Marianne Catanho, "Model of Aortic Blood Flow Using the Windkessel Effect," University of California of San Diago, San Diago, 2012.

[48] N. W. Nikos Stergiopulos Berend Westerhof, "Total Arterial Inertance as the Fourth Element of the Windkessel Model," Heart and Circulatory Physiology - American Journal of Physiology, vol. 276, no. 1, pp. H81-H88, 1999.

[49] A. N. L. L. Mette Olufsen, "Dynamics of Cerebral Blood Flow Regulation Explained Using a Lumped parameter Model," American Journal of Physiology - Regulatory, Integrative and Comparative Physiology, vol. 282, pp. R611-R622, 2002. 
[50] "Underlying Cause of Death," CDC, NCHS, 2015.

[51] "Heart Disease and Stroke Statistics 2010 Update," American Heart Association, Dallas, 2010.

[52] S. Ogoh, "Middle Cerebral Artery Flow Velocity and Pulse Pressure During Dynamic Exercise in Humans," American Journal of Physiology - Heart and Circulatory Physiology, vol. 288, pp. H1526-H1531, 2005. 


\section{APPENDICES}

A: CONVERTING CT SCAN INTO COMSOL MULTIPHYSICS $®$

This guide will explain how the CT scan of the aortic arch was imported into a usable COMSOL MULTIPHYSICS® model.

Instructions:

1. Open up MeshLab click file $\rightarrow$ Import mesh and select the CT scan in .stl format (G1-07-HH arch).

2. A dialogue box will open asking to unify duplicated vertices. Select OK. The model should now be seen similar to Figure 5.

3. Click on Filters $\rightarrow$ Remeshing, Simplification and Reconstruction $\rightarrow$ Quadratic Edge Collapse Decimation.

4. The Quadratic Edge Collapse Decimation dialogue box should open up.

5. Fill out the dialogue box to match Figure 29. 


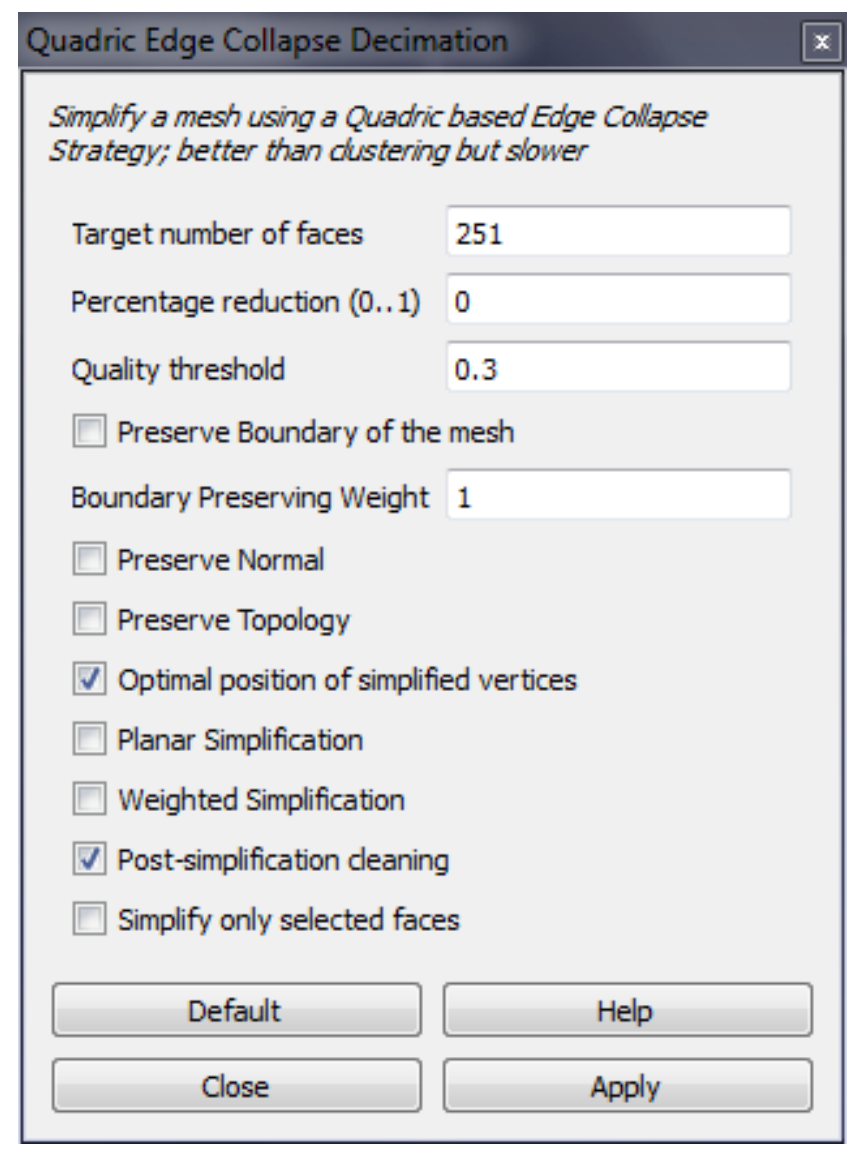

Figure 29: Quadratic Edge Collapse Decimation dialogue box.

6. Click File $\rightarrow$ Export Mesh As $\rightarrow$ Change the file type to .stl $\rightarrow$ Save the File.

7. Open SOLIDWORKS. Click File $\rightarrow$ Open $\rightarrow$ Change the file type to Mesh Files(*.NZIP;*.NXM;*.SCN;*.3DS;*.OBJ;*.STL;*.WRL;*.PLY;*.PLY2) $\rightarrow$ select your file and click OPEN.

8. The mesh should now pop up and look something like Figure 30. 


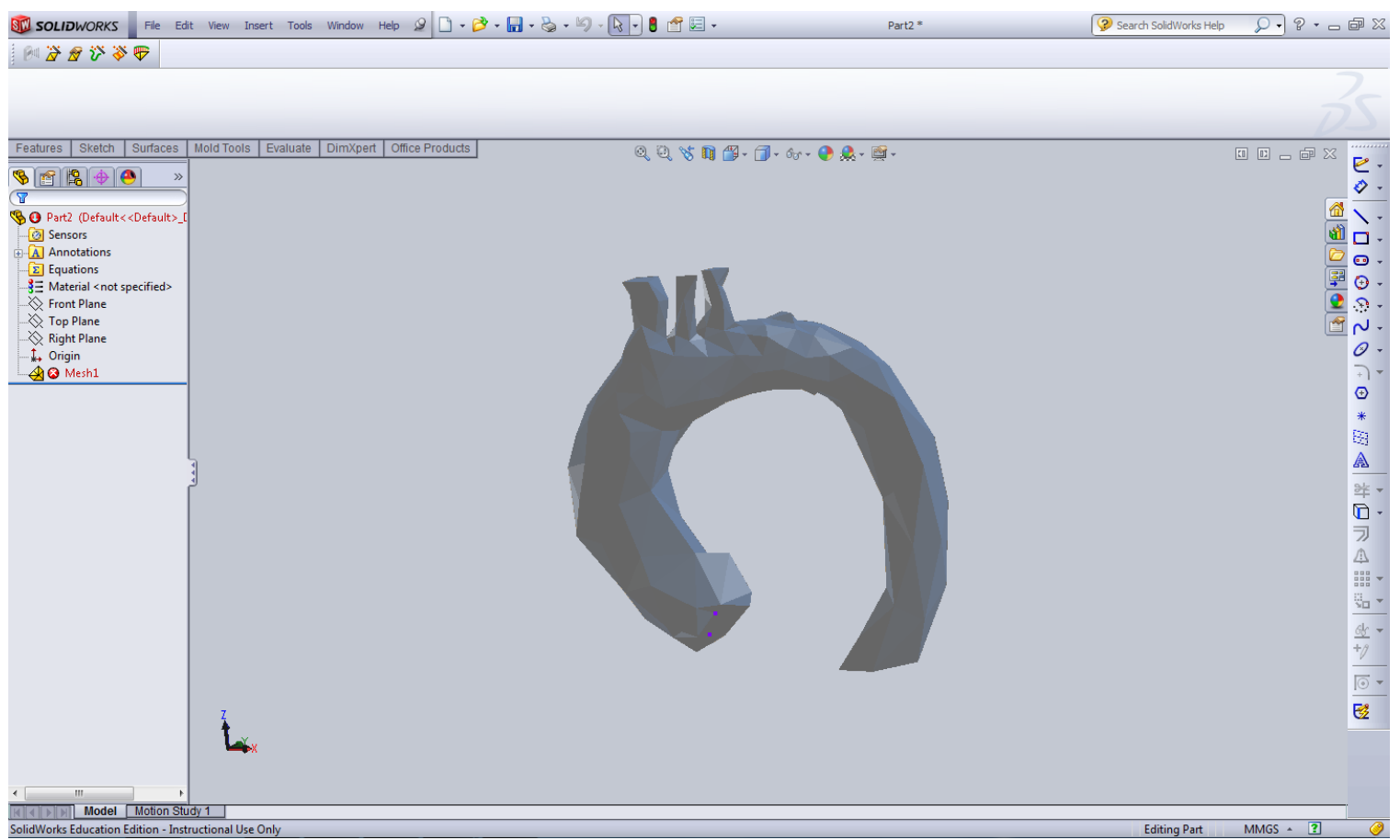

Figure 30: Mesh opened in SOLIDWORKS.

9. Now click File $\rightarrow$ Save As $\rightarrow$ Part file(*.prt;*.sldprt).

10. Next open COMSOL MULTIPHYSICS®.

11. Open an existing model or click Blank Model.

12. On the Ribbon menu click Home $\rightarrow$ Add Component $\rightarrow 3 \mathrm{D}$.

13. A Geometry should pop up under the Model Builder section.

14. Right Click On Geometry $\rightarrow$ Import.

15. Browse and select the file to open it in COMSOL. The COMSOL model is still hollow and unusable to run a fluid flow. The next steps will show how to turn the model into a solid.

16. In the Ribbon Menu select Geometry $\rightarrow$ Work Plane.

17. Change the plane type to Face Parallel. Select a face near one of the outlets that looks like it is perpendicular to the direction of the artery. 
18. If a surface cannot be found to be perpendicular to the direction of the artery then change to the face type to Quick. Create a plane that is as close to perpendicular with the artery as possible.

19. Regardless of which plane type is used right click the work plane in the model builder and add extrude.

20. Extrude from the Work Plane a short distance $(5 \mathrm{~cm})$ and check the box Unite with input objects.

21. In the geometry ribbon select difference. In the objects to add section select the imported model. In the Objects to subtract section select the extrusion made in the previous instruction. Click Build Selected.

22. Repeat steps 16-21 for all inlets and outlets.

23. Right click geometry in the model builder $\rightarrow$ Defeaturing and Repair $\rightarrow$ Cap Faces.

24. For the Bounding Edges click all edges on the model around one of the outlets as seen in Figure 31. This may involve zooming in on the corners to ensure you select every edge. Note if the edges do not connect you will receive and error in the next step. 

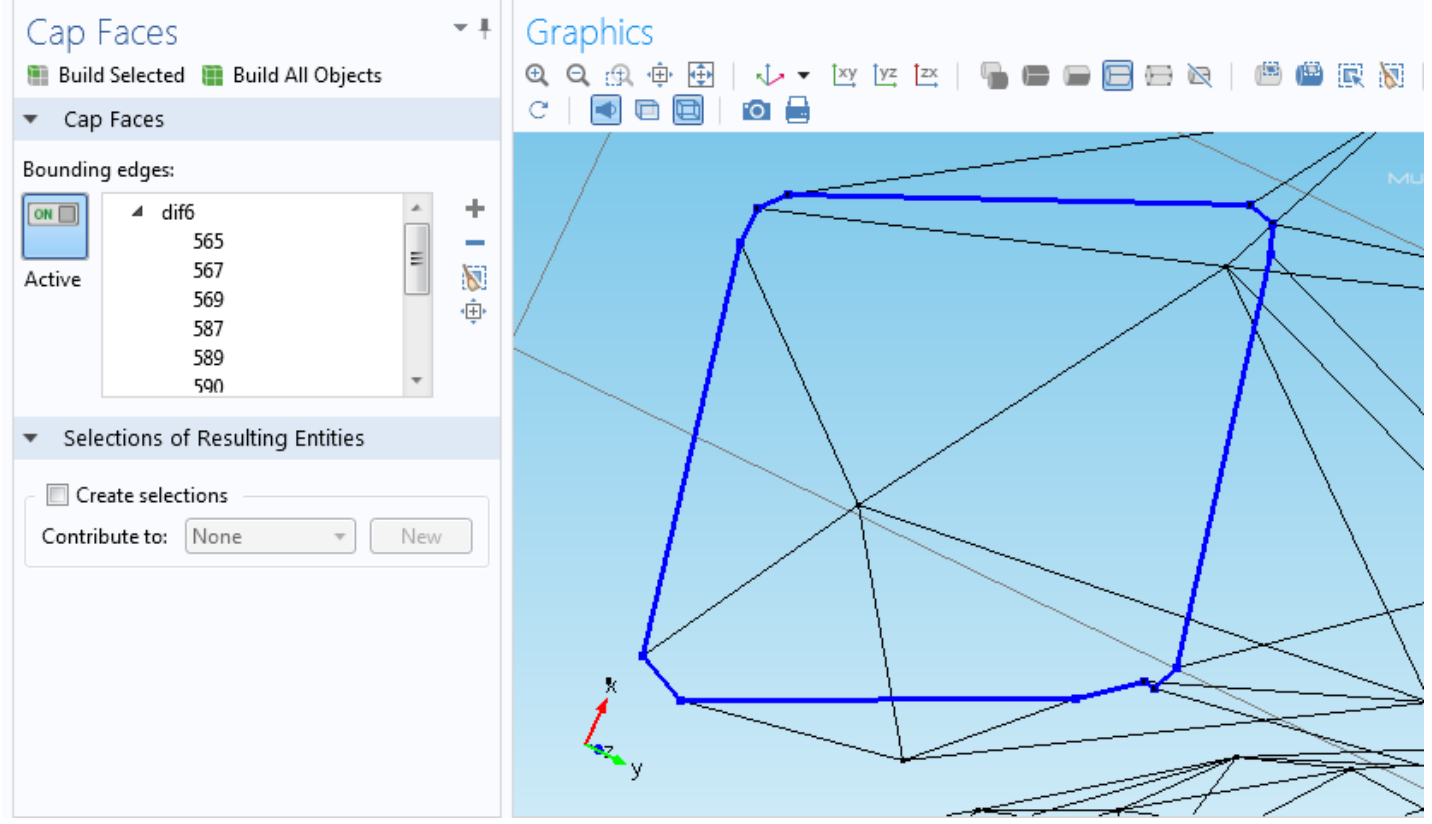

Figure 31: Cap Faces Bounding Edges.

25. Repeat steps 23-24 with all inlets and outlets.

26. Now the model is solid and fluid can flow through it. 


\title{
B: MATLAB CODE FOR WINDKESSEL MODEL
}

\author{
Windkessel.m file code: for BP 120 over 75
}

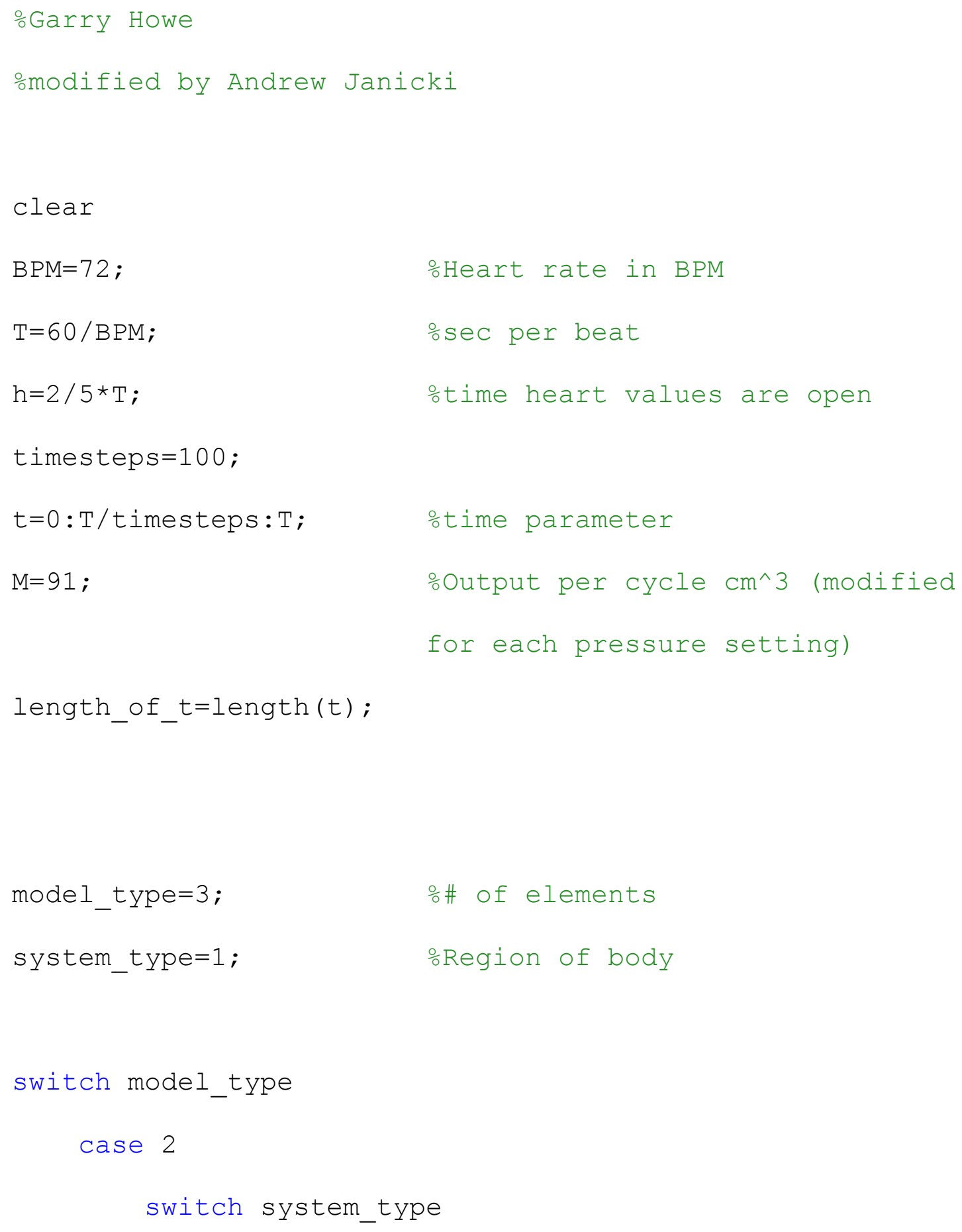


case 1

FOR SYSTEMIC 2 ELE

$\mathrm{R}=.9000 ;$ osystemic peripheral resistance in $\left(\mathrm{mmHg} / \mathrm{cm}^{\wedge} 3 / \mathrm{sec}\right)$

$\mathrm{C}=1.0666 ; \quad$ osystemic arterial compliance

in $\left(\mathrm{cm}^{\wedge} 3 / \mathrm{mmHg}\right)$

$\mathrm{p} 0=70 ; \quad$ otorr (modified for each pressure
setting)

$$
\begin{aligned}
& \mathrm{RO}=0 ; \\
& \mathrm{L}=0 ;
\end{aligned}
$$

case 2

○FOR Pulmonary 2 ELE

$\mathrm{R}=.9000 ;$ osystemic peripheral resistance in $\left(\mathrm{mmHg} / \mathrm{cm}^{\wedge} 3 / \mathrm{sec}\right)$

$\mathrm{C}=1.0666 ; \quad$ osystemic arterial compliance

in $\left(\mathrm{cm}^{\wedge} 3 / \mathrm{mmHg}\right)$

$$
\text { p0=70; } \quad \text { otorr (modified for each }
$$

pressure setting)

$$
\begin{aligned}
& \mathrm{RO}=0 ; \\
& \mathrm{L}=0 ;
\end{aligned}
$$

end

case 3

$$
\text { switch system_type }
$$




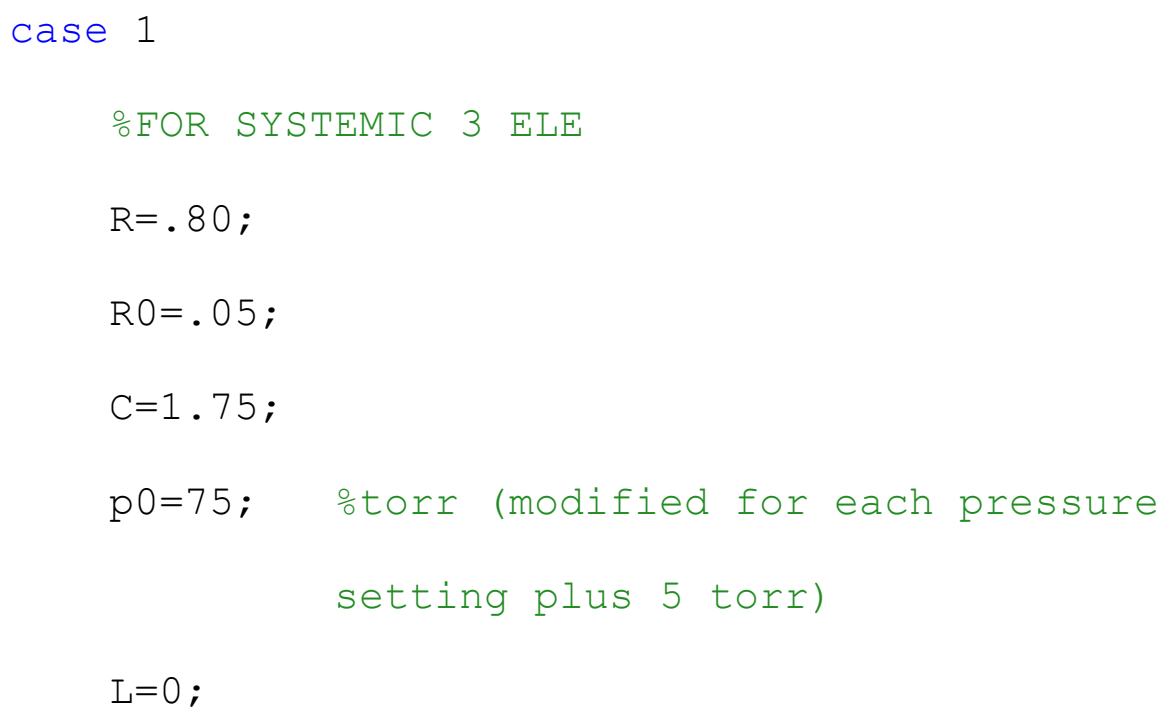




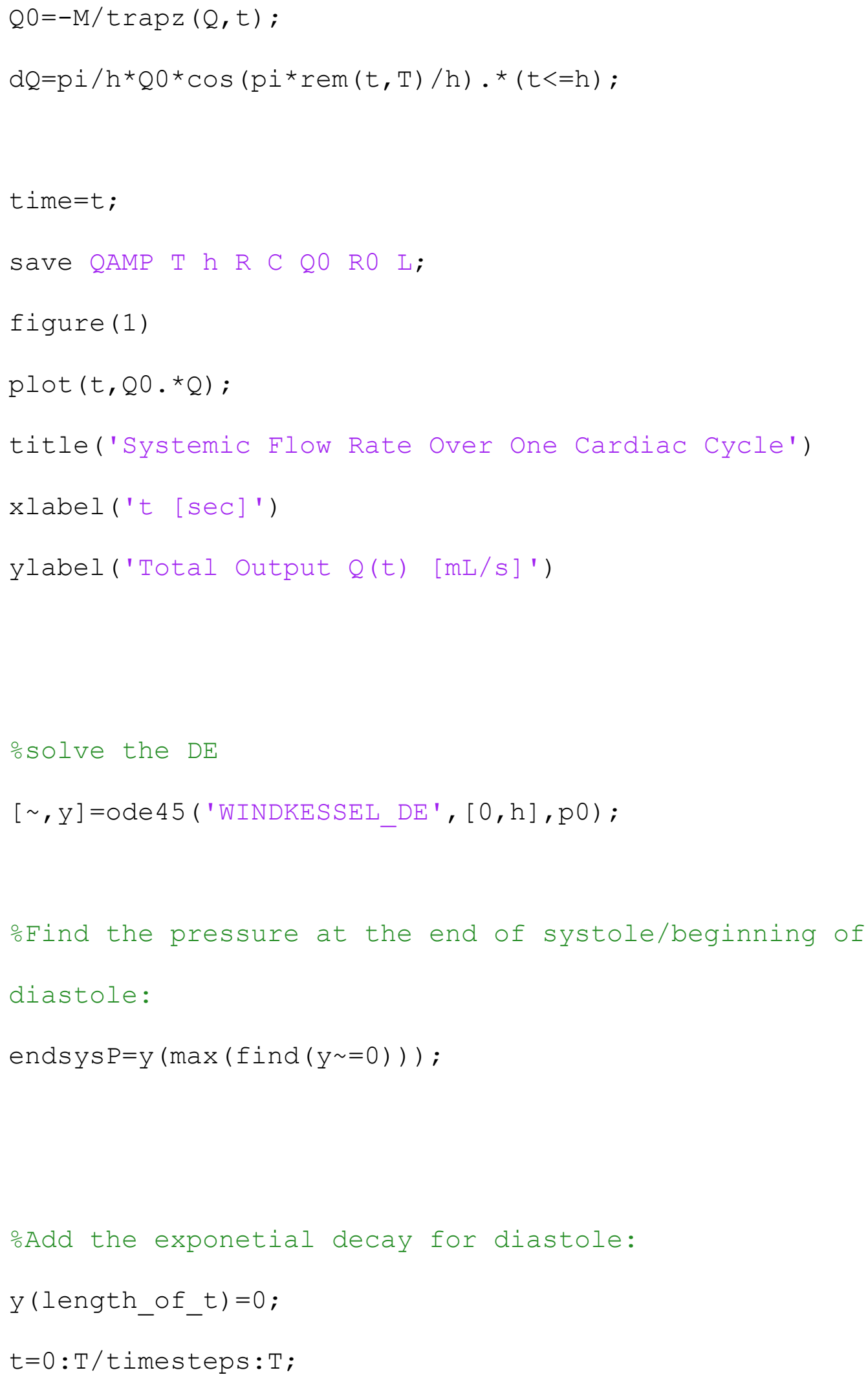




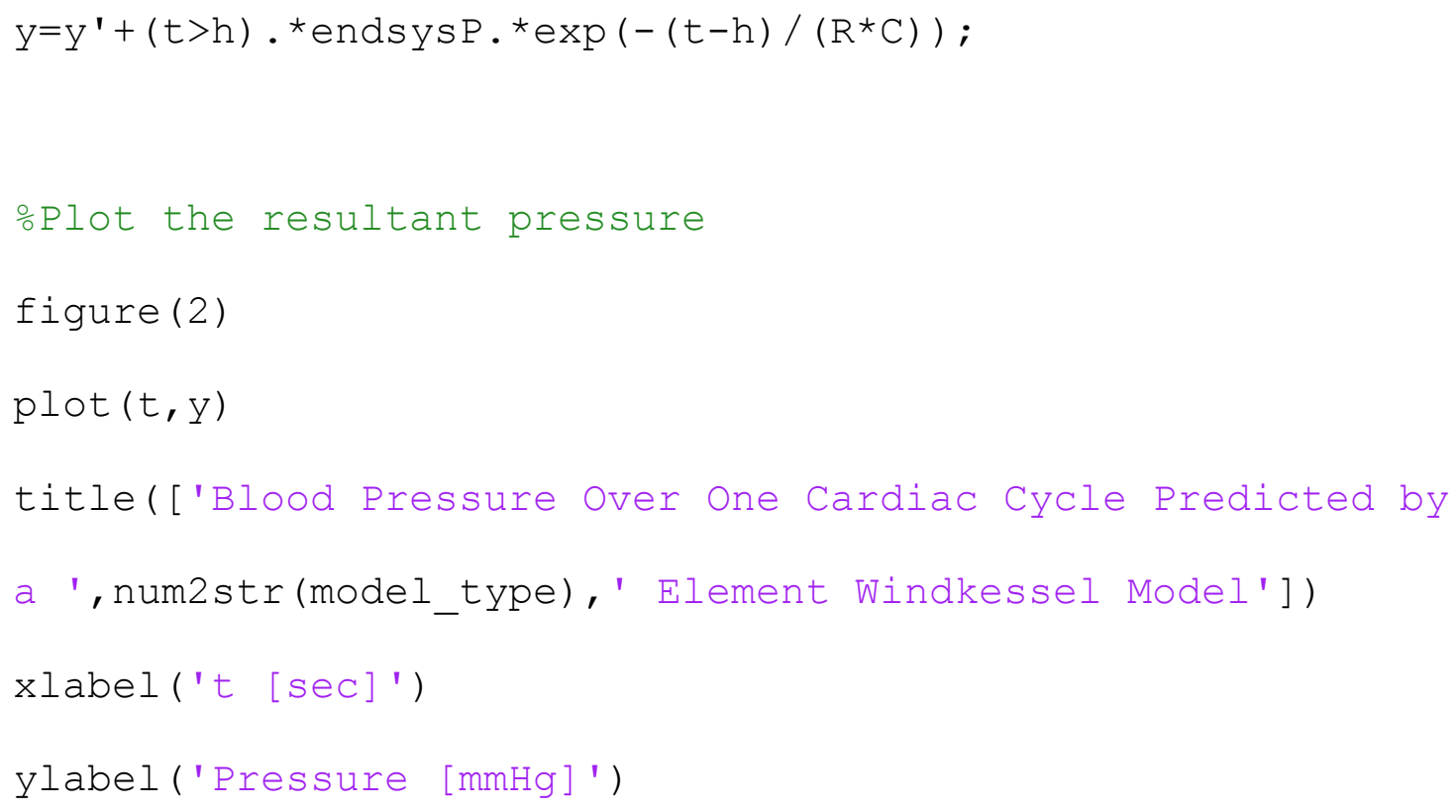

\section{Windkessel_DE.m file code:}

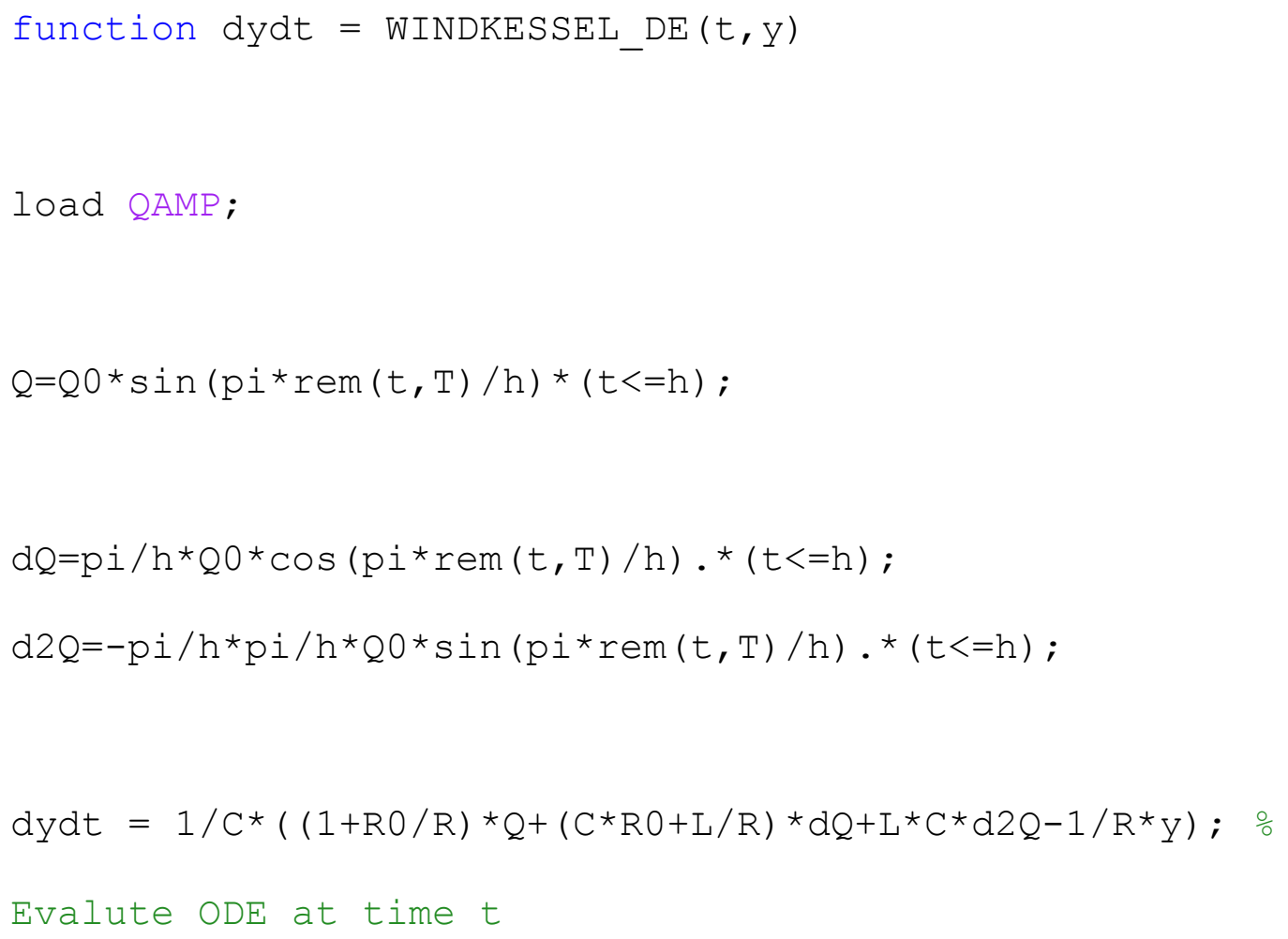


end

C: OUTPUT OF MANOVA

Outlet 1

\begin{tabular}{|c|c|c|c|c|c|}
\hline \multicolumn{6}{|l|}{$\triangle$ Fixed Effect Tests } \\
\hline Source & Nparm & DF & DFDen & F Ratio & Prob $>F$ \\
\hline Diameter & 2 & 2 & 44 & 130.8667 & $<.0001^{*}$ \\
\hline Density & 3 & 3 & 44 & 29.5921 & $<.0001^{*}$ \\
\hline $\mathrm{BP}$ & 2 & 2 & 4 & 9.7277 & $0.0291^{*}$ \\
\hline Catheter & 2 & 2 & 4 & 1.5852 & 0.3112 \\
\hline Diameter*Density & 6 & 6 & 44 & 0.7690 & 0.5984 \\
\hline Diameter ${ }^{*} \mathrm{BP}$ & 4 & 4 & 44 & 14.4418 & $<.0001^{*}$ \\
\hline Diameter ${ }^{\star}$ Catheter & 4 & 4 & 44 & 0.4483 & 0.7730 \\
\hline Density ${ }^{\star} \mathrm{BP}$ & 6 & 6 & 44 & 16.6414 & $<.0001^{*}$ \\
\hline Density ${ }^{\star}$ Catheter & 6 & 6 & 44 & 1.8261 & 0.1159 \\
\hline Diameter ${ }^{\star}$ Density ${ }^{\star} \mathrm{BP}$ & 12 & 12 & 44 & 0.6550 & 0.7834 \\
\hline Diameter ${ }^{\star}$ Density ${ }^{\star}$ Catheter & 12 & 12 & 44 & 0.3425 & 0.9760 \\
\hline
\end{tabular}

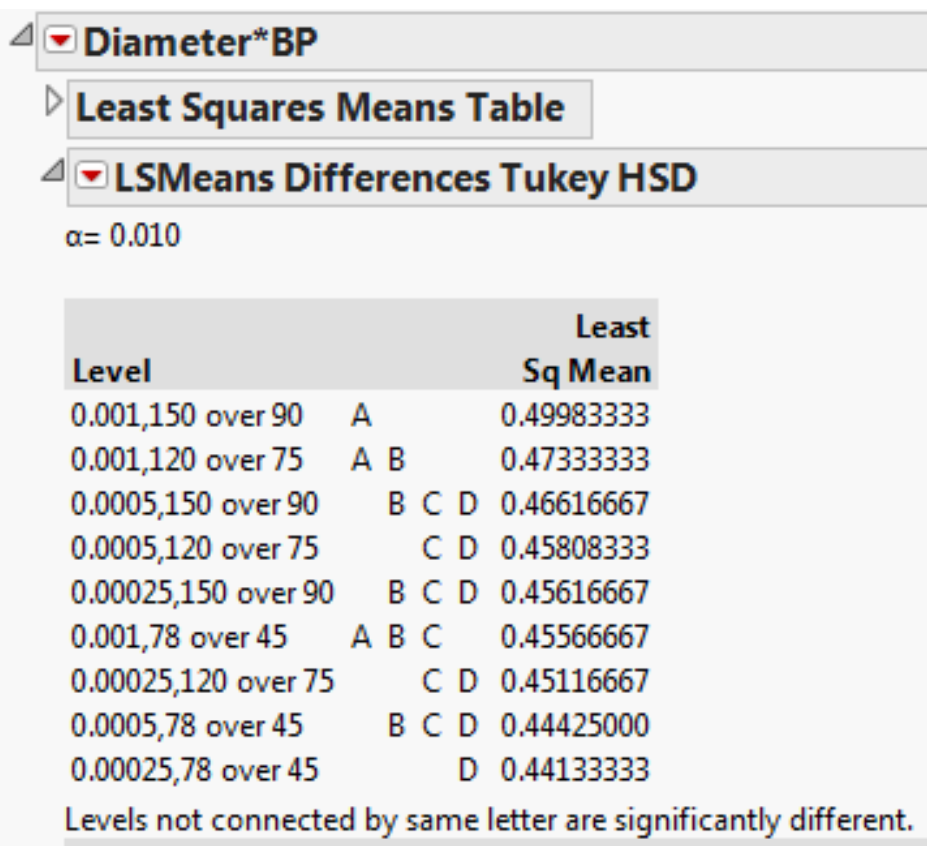




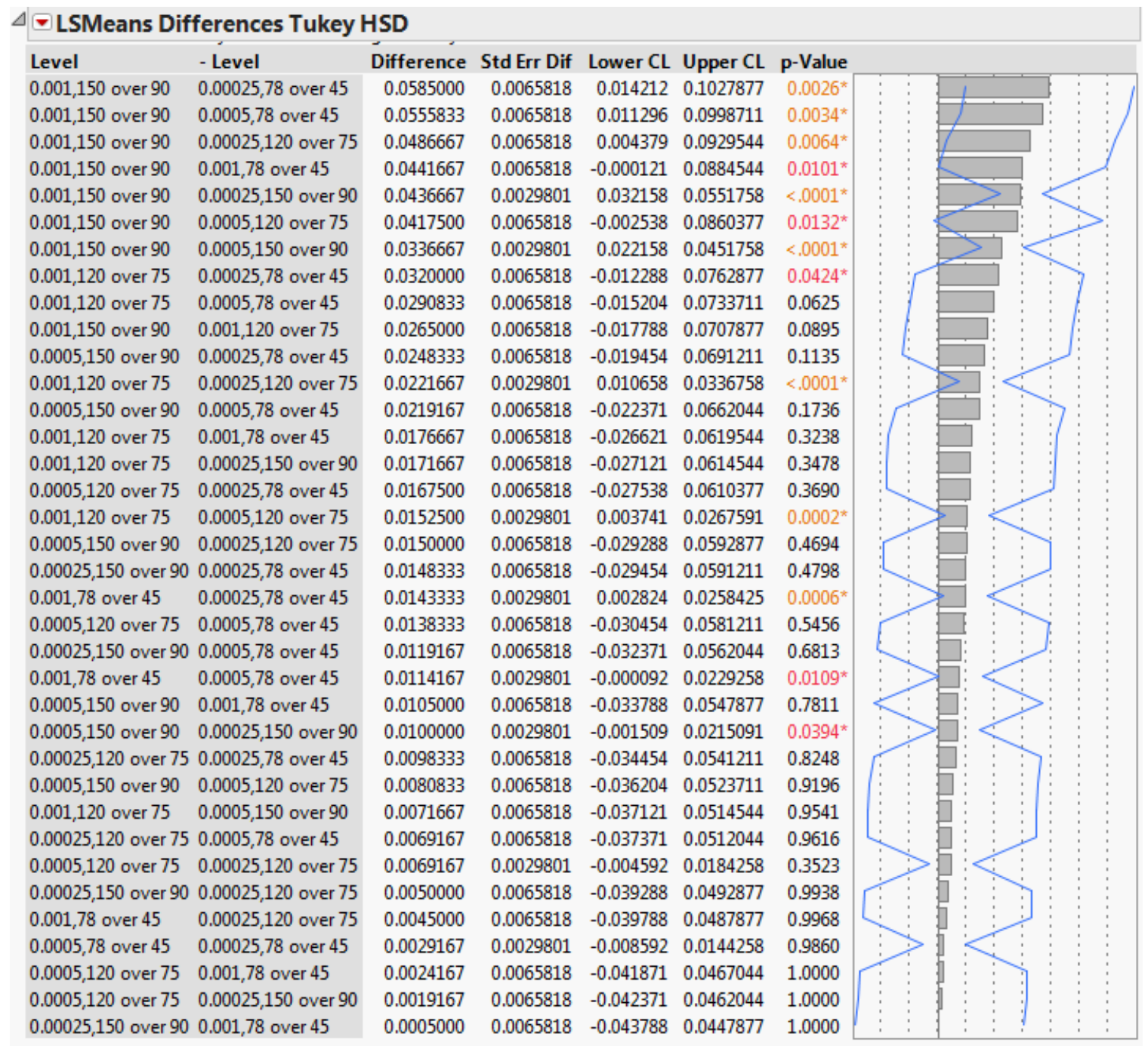




\begin{tabular}{|c|c|c|}
\hline \multicolumn{3}{|l|}{$\triangle \nabla$ Density*BP } \\
\hline \multicolumn{3}{|c|}{$D$ Least Squares Means Table } \\
\hline \multicolumn{3}{|c|}{$\Delta \nabla$ LSMeans Differences Tukey HSD } \\
\hline \multicolumn{3}{|l|}{$\alpha=0.010$} \\
\hline & & Least \\
\hline Level & & Sq Mean \\
\hline 800,150 over $90 \quad A$ & & 0.50000000 \\
\hline 1450,150 over 90 & B & 0.47088889 \\
\hline 1220,150 over 90 & $\mathrm{BC}$ & 0.46866667 \\
\hline 800,120 over $75 \quad A$ & $\mathrm{BC}$ & 0.46688889 \\
\hline 1450,120 over $75 \mathrm{~A}$ & $\mathrm{BC}$ & 0.46266667 \\
\hline 1220,120 over $75 \mathrm{~A}$ & $\mathrm{BC}$ & 0.46055556 \\
\hline 1066,150 over 90 & $\mathrm{C}$ & 0.45666667 \\
\hline 1066,120 over 75 & $\mathrm{BC}$ & 0.45333333 \\
\hline 1450,78 over 45 & $\mathrm{BC}$ & 0.44866667 \\
\hline 1220,78 over 45 & $\mathrm{BC}$ & 0.44755556 \\
\hline 1066,78 over 45 & $\mathrm{BC}$ & 0.44677778 \\
\hline 800,78 over 45 & $\mathrm{BC}$ & 0.44533333 \\
\hline
\end{tabular}




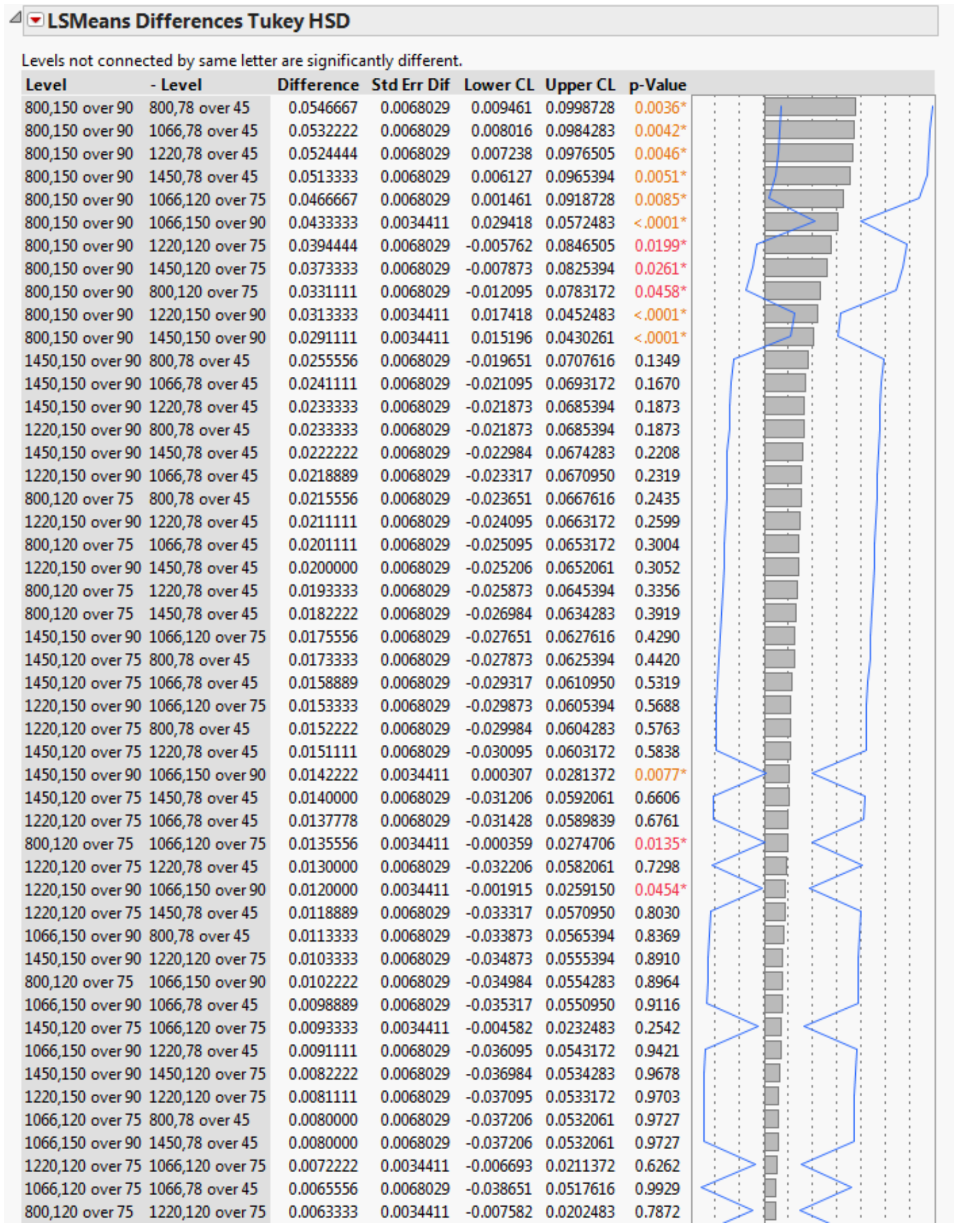




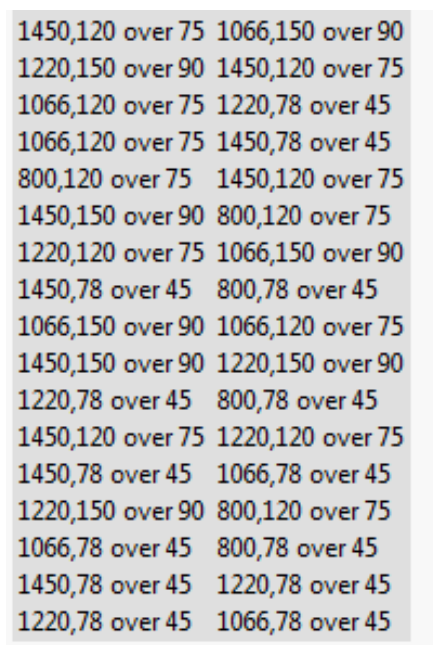

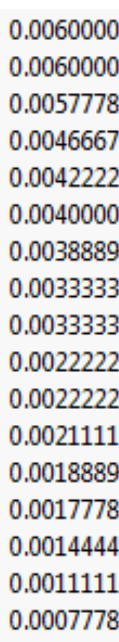

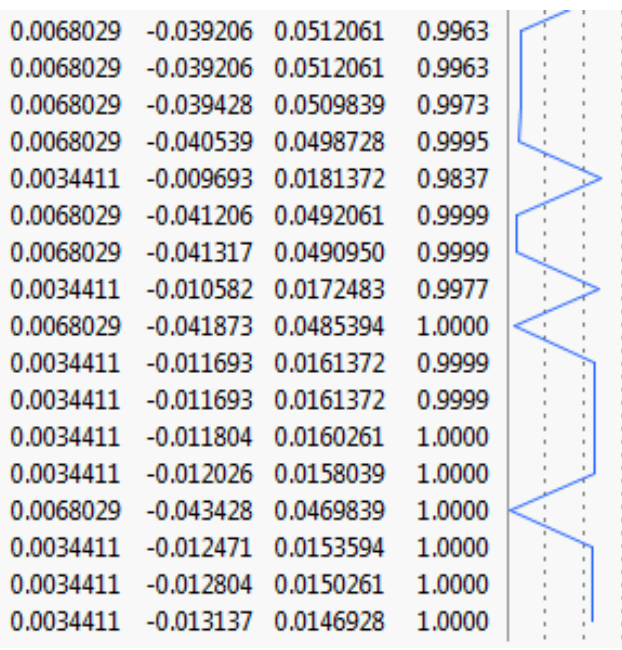

$\begin{array}{lll}0.0068029 & -0.039206 & 0.0512061\end{array}$ $\begin{array}{lll}0.0068029 & -0.039206 & 0.0512061\end{array}$ $\begin{array}{lll}0.0068029 & -0.039428 & 0.0509839\end{array}$ $\begin{array}{lll}0.0068029 & -0.040539 & 0.049872\end{array}$ $\begin{array}{lll}0.0034411 & -0.009693 & 0.0181372\end{array}$ $\begin{array}{lll}0.0068029 & -0.041206 & 0.0492061\end{array}$ $\begin{array}{lll}0.0068029 & -0.041317 & 0.049095\end{array}$ $\begin{array}{lll}0.0034411 & -0.010582 & 0.0172483\end{array}$ $\begin{array}{lll}0.0068029 & -0.041873 & 0.048539\end{array}$ $\begin{array}{lll}0.0034411 & -0.011693 & 0.016137\end{array}$ $\begin{array}{lll}0.0034411 & -0.011693 & 0.0161372\end{array}$ $\begin{array}{llll}0.0034411 & -0.011804 & 0.016026\end{array}$ $\begin{array}{llll}0.0034411 & -0.012026 & 0.0158039\end{array}$ $\begin{array}{lll}0.0068029 & -0.043428 & 0.0469839\end{array}$

$\begin{array}{lll}0.0034411 & -0.013137 & 0.0146928\end{array}$

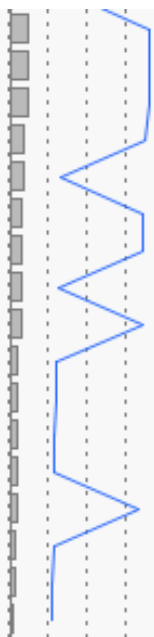

Outlet 2

\begin{tabular}{|c|c|c|c|c|c|}
\hline \multicolumn{6}{|l|}{$\triangle$ Fixed Effect Tests } \\
\hline Source & Nparm & DF & DFDen & F Ratio & Prob $>F$ \\
\hline Diameter & 2 & 2 & 44 & 113.6870 & $<.0001^{*}$ \\
\hline Density & 3 & 3 & 44 & 16.0726 & $<.0001^{*}$ \\
\hline $\mathrm{BP}$ & 2 & 2 & 4 & 0.9691 & 0.4537 \\
\hline Catheter & 2 & 2 & 4 & 1.1461 & 0.4041 \\
\hline Diameter ${ }^{\star}$ ensity & 6 & 6 & 44 & 2.7601 & $0.0230^{*}$ \\
\hline Diameter ${ }^{\star} \mathrm{BP}$ & 4 & 4 & 44 & 6.4341 & $0.0004^{*}$ \\
\hline Diameter ${ }^{\star}$ Catheter & 4 & 4 & 44 & 0.7563 & 0.5593 \\
\hline Density ${ }^{\star} \mathrm{BP}$ & 6 & 6 & 44 & 3.9206 & $0.0032^{*}$ \\
\hline Density ${ }^{\star}$ Catheter & 6 & 6 & 44 & 3.1401 & $0.0119^{*}$ \\
\hline Diameter ${ }^{\star}$ Density ${ }^{\star} \mathrm{BP}$ & 12 & 12 & 44 & 1.4808 & 0.1680 \\
\hline Diameter ${ }^{\star}$ Density ${ }^{\star}$ Catheter & 12 & 12 & 44 & 0.5015 & 0.9024 \\
\hline
\end{tabular}




\begin{tabular}{|c|c|c|}
\hline \multicolumn{3}{|l|}{$\triangle \nabla$ Diameter*BP } \\
\hline \multicolumn{3}{|c|}{$D$ Least Squares Means Table } \\
\hline \multicolumn{3}{|c|}{$\triangle \nabla$ LSMeans Differences Tukey HSD } \\
\hline \multicolumn{3}{|c|}{$\alpha=0.010$} \\
\hline Level & & $\begin{array}{r}\text { Least } \\
\text { Sq Mean }\end{array}$ \\
\hline $0.001,150$ over 90 & A & 0.19633333 \\
\hline $0.001,120$ over 75 & A B & 0.18975000 \\
\hline $0.001,78$ over 45 & $A B C$ & 0.17750000 \\
\hline $0.0005,78$ over 45 & B C D E & 0.16641667 \\
\hline $0.0005,150$ over 90 & $B C D E$ & 0.16616667 \\
\hline $0.0005,120$ over 75 & C $E$ & 0.16591667 \\
\hline $0.00025,120$ over 75 & C $E$ & 0.16358333 \\
\hline $0.00025,78$ over 45 & DE & 0.16175000 \\
\hline $0.00025,150$ over 90 & $B C D E$ & 0.160666667 \\
\hline
\end{tabular}

Levels not connected by same letter are significantly different.

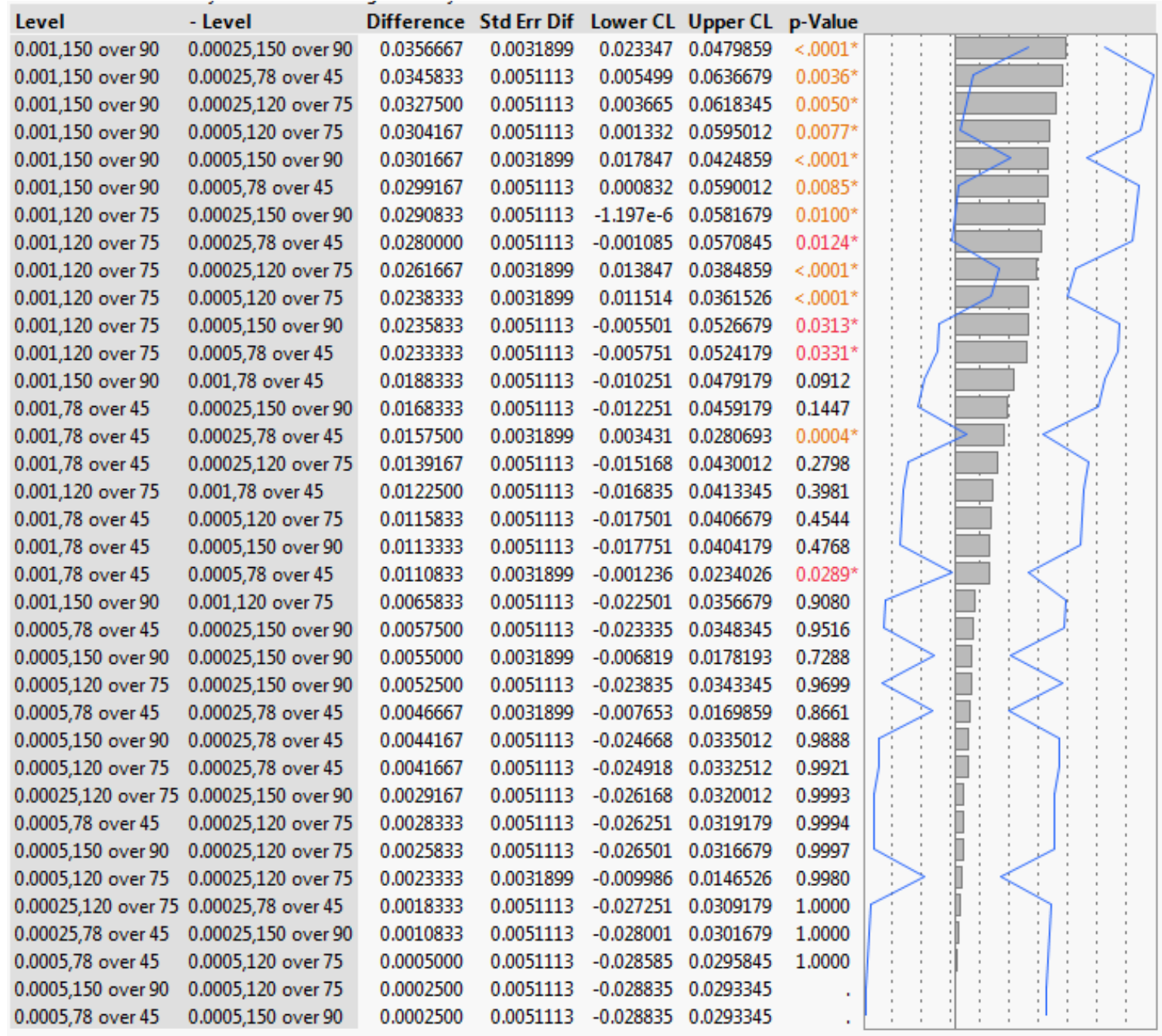




\begin{tabular}{|c|c|}
\hline \multicolumn{2}{|l|}{$\triangle \nabla$ Density*BP } \\
\hline \multicolumn{2}{|c|}{$\triangleright$ Least Squares Means Table } \\
\hline \multicolumn{2}{|c|}{$\Delta$ LSMeans Differences Tukey HSD } \\
\hline \multicolumn{2}{|l|}{$\alpha=0.010$} \\
\hline & Least \\
\hline Level & Sq Mean \\
\hline 1066,150 over $90 \mathrm{~A}$ & 0.18000000 \\
\hline 1220,150 over $90 \mathrm{~A}$ & 0.18000000 \\
\hline 1450,150 over $90 \mathrm{~A}$ & 0.17977778 \\
\hline 1066,120 over 75 A B & 0.17944444 \\
\hline 1450,120 over 75 A B & 0.17588889 \\
\hline 1220,120 over 75 A B & 0.17144444 \\
\hline 1450,78 over 45 A B & 0.17011111 \\
\hline 1220,78 over 45 A B & 0.16977778 \\
\hline 1066,78 over 45 A B & 0.16844444 \\
\hline 800,78 over 45 A B & 0.16588889 \\
\hline 800,120 over 75 A B & 0.16555556 \\
\hline 800,150 over 90 & 0.15777778 \\
\hline
\end{tabular}




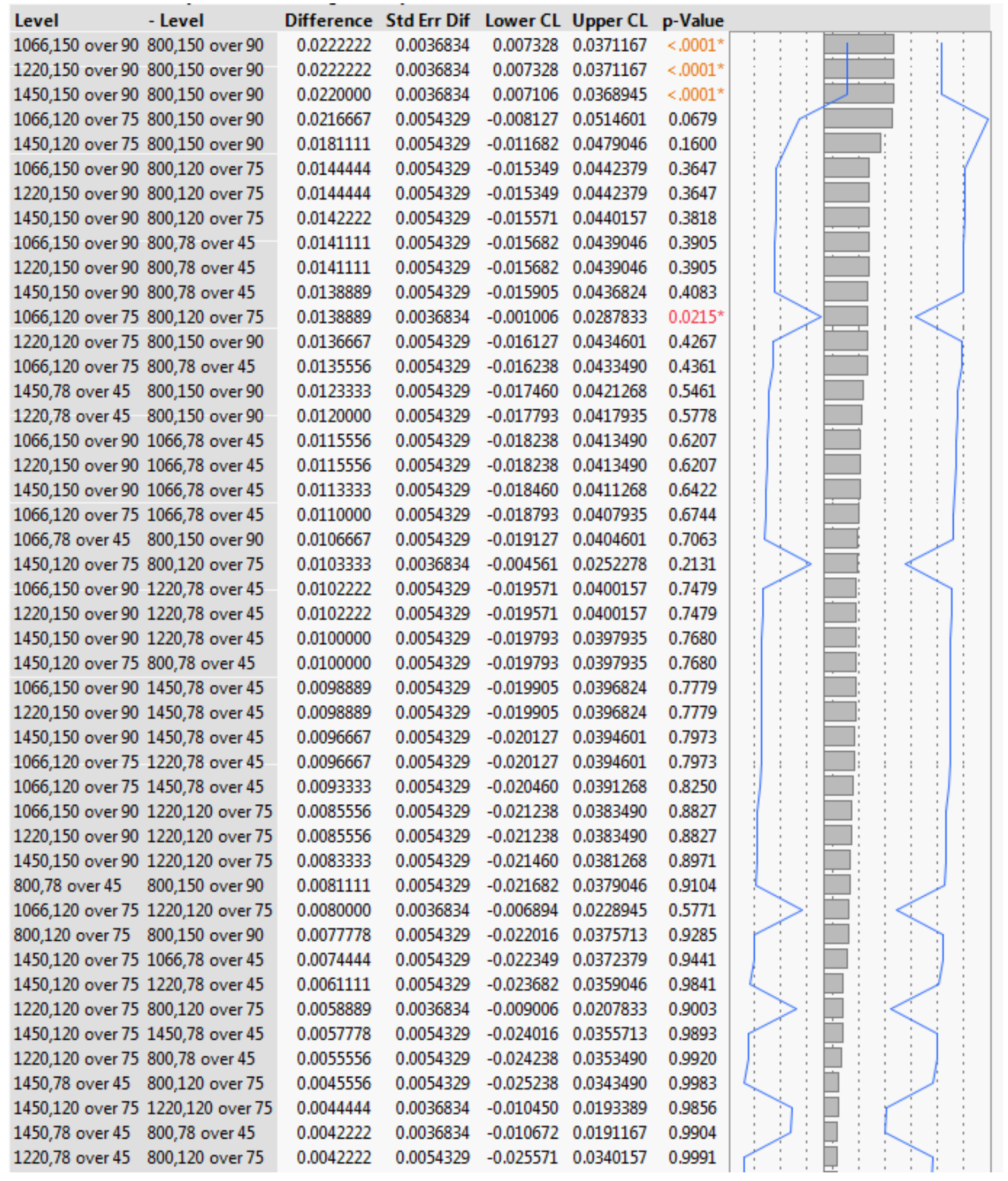




$\begin{array}{llllll}1066,150 \text { over } 90 & 1450,120 \text { over } 75 & 0.0041111 & 0.0054329 & -0.025682 & 0.0339046 \\ 1220,150 \text { over } 90 & 1450,120 \text { over } 75 & 0.0041111 & 0.0054329 & -0.025682 & 0.0339046 \\ 1450,150 \text { over } 90 & 1450,120 \text { over } 75 & 0.0038889 & 0.0054329 & -0.025905 & 0.0336824 \\ 1220,78 \text { over } 45 & 800,78 \text { over } 45 & 0.0038889 & 0.0036834 & -0.011006 & 0.0187833 \\ 1066,120 \text { over } 75 & 1450,120 \text { over } 75 & 0.0035556 & 0.0036834 & -0.011339 & 0.0184500 \\ 1220,120 \text { over } 75 & 1066,78 \text { over } 45 & 0.0030000 & 0.0054329 & -0.026793 & 0.0327935 \\ 1066,78 \text { over } 45 & 800,120 \text { over } 75 & 0.0028889 & 0.0054329 & -0.026905 & 0.0326824 \\ 1066,78 \text { over } 45 & 800,78 \text { over } 45 & 0.0025556 & 0.0036834 & -0.012339 & 0.0174500 \\ 1220,120 \text { over } 75 & 1220,78 \text { over } 45 & 0.0016667 & 0.0054329 & -0.028127 & 0.0314601 \\ 1450,78 \text { over } 45 & 1066,78 \text { over } 45 & 0.0016667 & 0.0036834 & -0.013228 & 0.0165611 \\ 1220,120 \text { over } 75 & 1450,78 \text { over } 45 & 0.0013333 & 0.0054329 & -0.028460 & 0.0311268 \\ 1220,78 \text { over } 45 & 1066,78 \text { over } 45 & 0.0013333 & 0.0036834 & -0.013561 & 0.0162278 \\ 1066,150 \text { over } 90 & 1066,120 \text { over } 75 & 0.0005556 & 0.0054329 & -0.029238 & 0.0303490 \\ 1220,150 \text { over } 90 & 1066,120 \text { over } 75 & 0.0005556 & 0.0054329 & -0.029238 & 0.0303490 \\ 1450,150 \text { over } 90 & 1066,120 \text { over } 75 & 0.0003333 & 0.0054329 & -0.029460 & 0.0301268 \\ 1450,78 \text { over } 45 & 1220,78 \text { over } 45 & 0.0003333 & 0.0036834 & -0.014561 & 0.0152278 \\ 800,78 \text { over } 45 & 800,120 \text { over } 75 & 0.0003333 & 0.0054329 & -0.029460 & 0.0301268 \\ 1066,150 \text { over } 90 & 1450,150 \text { over } 90 & 0.0002222 & 0.0036834 & -0.014672 & 0.0151167 \\ 1220,150 \text { over } 90 & 1450,150 \text { over } 90 & 0.0002222 & 0.0036834 & -0.014672 & 0.0151167 \\ 1066,150 \text { over } 90 & 1220,150 \text { over } 90 & 2.776 e-17 & 0.0036834 & -0.014894 & 0.0148945\end{array}$

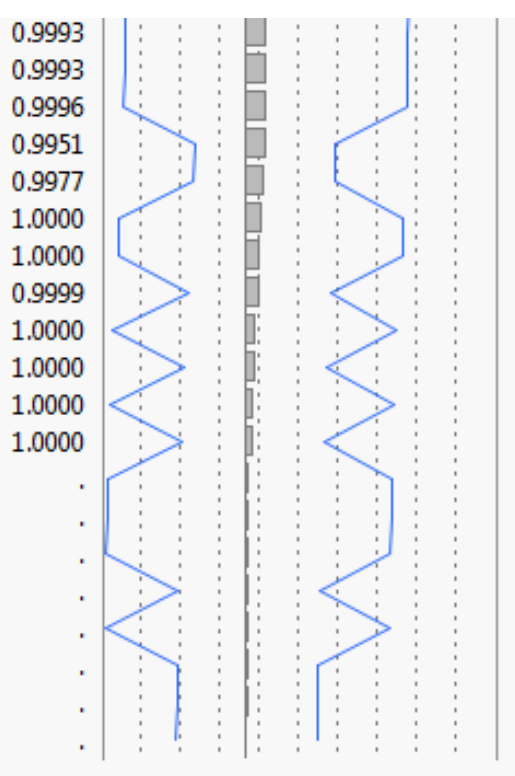

Outlet 3

\begin{tabular}{|c|c|c|c|c|c|}
\hline \multicolumn{6}{|l|}{$\triangle$ Fixed Effect Tests } \\
\hline Source & Nparm & DF & DFDen & F Ratio & Prob $>F$ \\
\hline Diameter & 2 & 2 & 44 & 276.3911 & $<.0001^{*}$ \\
\hline Density & 3 & 3 & 44 & 1.1019 & 0.3585 \\
\hline $\mathrm{BP}$ & 2 & 2 & 4 & 2.9364 & 0.1641 \\
\hline Catheter & 2 & 2 & 4 & 0.4644 & 0.6586 \\
\hline Diameter*Density & 6 & 6 & 44 & 3.8594 & $0.0035^{*}$ \\
\hline Diameter ${ }^{*} \mathrm{BP}$ & 4 & 4 & 44 & 11.3847 & $<.0001^{*}$ \\
\hline Diameter ${ }^{\star}$ Catheter & 4 & 4 & 44 & 2.1907 & 0.0856 \\
\hline Density ${ }^{*} \mathrm{BP}$ & 6 & 6 & 44 & 3.1675 & $0.0114^{*}$ \\
\hline Density ${ }^{\star}$ Catheter & 6 & 6 & 44 & 1.7886 & 0.1236 \\
\hline Diameter*Density ${ }^{\star} \mathrm{BP}$ & 12 & 12 & 44 & 2.3068 & $0.0219^{*}$ \\
\hline Diameter ${ }^{\star}$ Density ${ }^{\star}$ Catheter & 12 & 12 & 44 & 1.4249 & 0.1911 \\
\hline
\end{tabular}




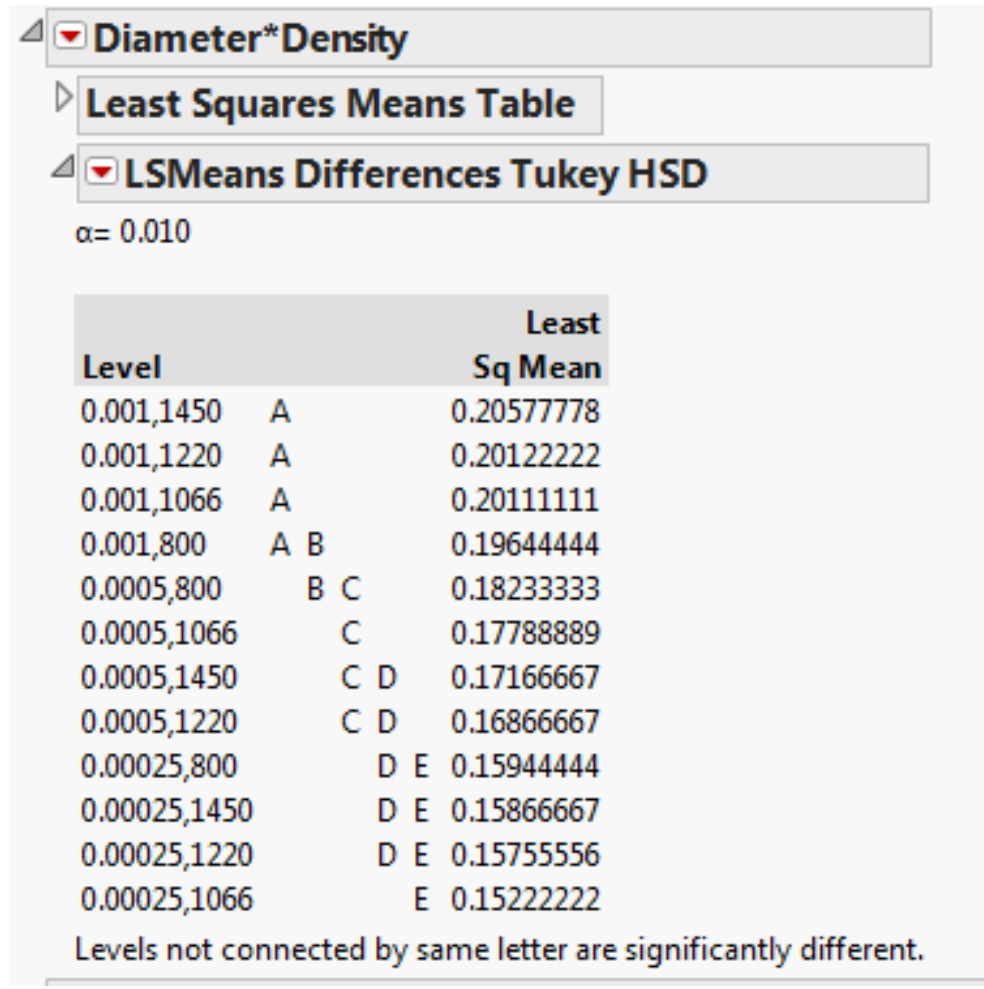




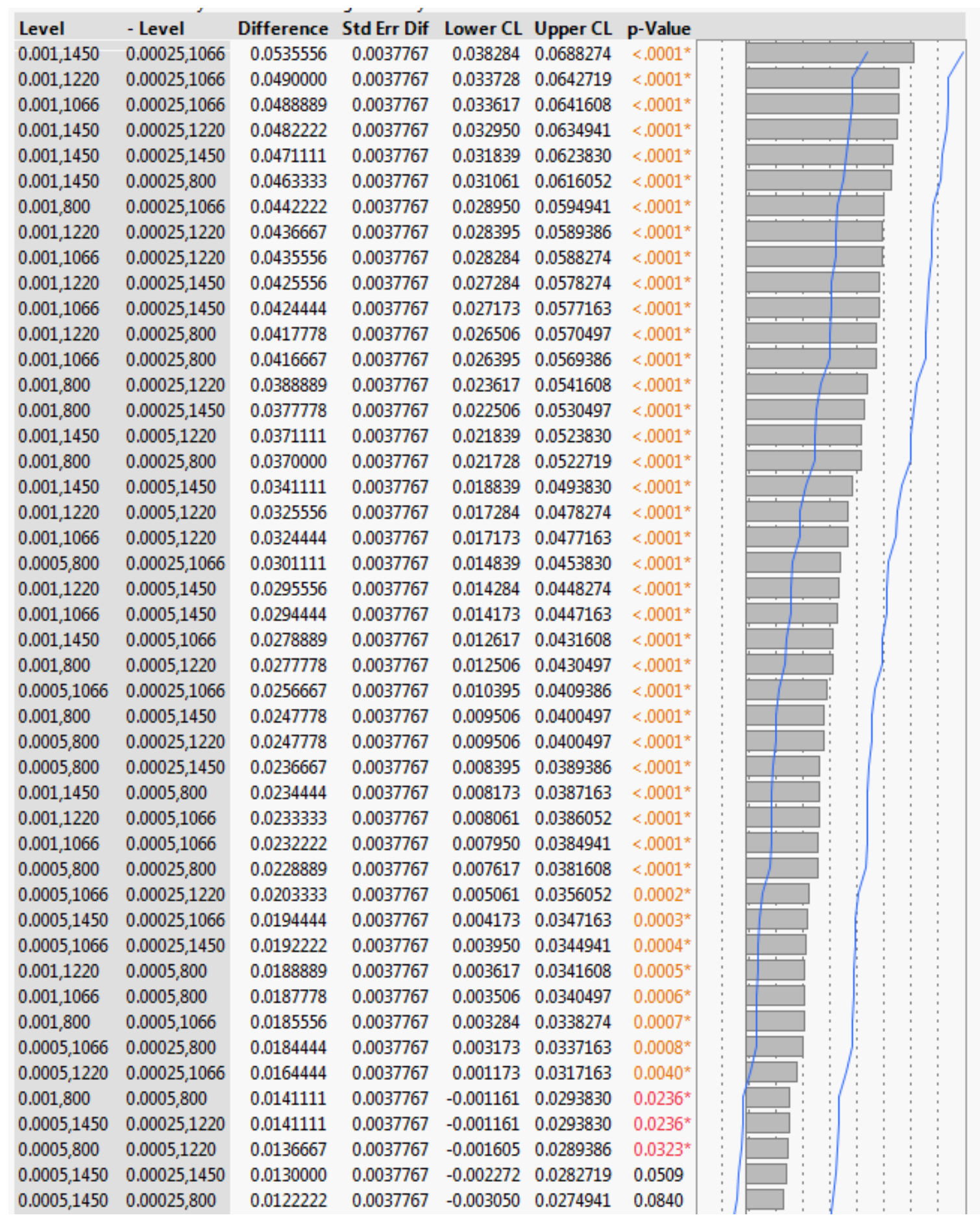




$\begin{array}{ll}0.0005,1220 & 0.00025,1220 \\ 0.0005,800 & 0.0005,1450 \\ 0.0005,1220 & 0.00025,1450 \\ 0.001,1450 & 0.001,800 \\ 0.0005,1220 & 0.00025,800 \\ 0.0005,1066 & 0.0005,1220 \\ 0.00025,800 & 0.00025,1066 \\ 0.00025,1450 & 0.00025,1066 \\ 0.0005,1066 & 0.0005,1450 \\ 0.00025,1220 & 0.00025,1066 \\ 0.001,1220 & 0.001,800 \\ 0.001,1066 & 0.001,800 \\ 0.001,1450 & 0.001,1066 \\ 0.001,1450 & 0.001,1220 \\ 0.0005,800 & 0.0005,1066 \\ 0.0005,1450 & 0.0005,1220 \\ 0.00025,800 & 0.00025,1220 \\ 0.00025,1450 & 0.00025,1220 \\ 0.00025,800 & 0.00025,1450 \\ 0.001,1220 & 0.001,1066\end{array}$

$\begin{array}{lllll}0.0111111 & 0.0037767 & -0.004161 & 0.0263830 & 0.1617 \\ 0.0106667 & 0.0037767 & -0.004605 & 0.0259386 & 0.2053 \\ 0.0100000 & 0.0037767 & -0.005272 & 0.0252719 & 0.2857 \\ 0.0093333 & 0.0037767 & -0.005939 & 0.0246052 & 0.3835 \\ 0.0092222 & 0.0037767 & -0.006050 & 0.0244941 & 0.4013 \\ 0.0092222 & 0.0037767 & -0.006050 & 0.0244941 & 0.4013 \\ 0.0072222 & 0.0037767 & -0.008050 & 0.0224941 & 0.7454 \\ 0.0064444 & 0.0037767 & -0.008827 & 0.0217163 & 0.8557 \\ 0.0062222 & 0.0037767 & -0.009050 & 0.0214941 & 0.8813 \\ 0.0053333 & 0.0037767 & -0.009939 & 0.0206052 & 0.9548 \\ 0.0047778 & 0.0037767 & -0.010494 & 0.0200497 & 0.9794 \\ 0.0046667 & 0.0037767 & -0.010605 & 0.0199386 & 0.9828 \\ 0.0046667 & 0.0037767 & -0.010605 & 0.0199386 & 0.9828 \\ 0.0045556 & 0.0037767 & -0.010716 & 0.0198274 & 0.9857 \\ 0.0044444 & 0.0037767 & -0.010827 & 0.0197163 & 0.9882 \\ 0.0030000 & 0.0037767 & -0.012272 & 0.0182719 & 0.9996 \\ 0.0018889 & 0.0037767 & -0.013383 & 0.0171608 & 1.0000 \\ 0.0011111 & 0.0037767 & -0.014161 & 0.0163830 & 1.0000 \\ 0.0007778 & 0.0037767 & -0.014494 & 0.0160497 & 1.0000 \\ 0.0001111 & 0.0037767 & -0.015161 & 0.0153830 & .\end{array}$

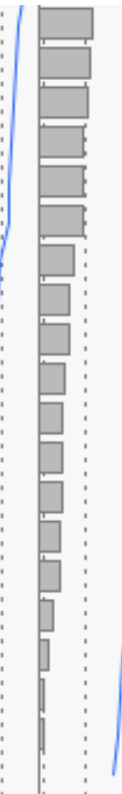
$\triangle$ Diameter*BP
$\nabla$ Least Squares Means Table
$\triangle \nabla$ LSMeans Differences Tukey HSD $\alpha=0.010$

$\begin{array}{lllr}\text { Level } & & \begin{array}{r}\text { Least } \\ \text { Sq Mean }\end{array} \\ 0.001,120 \text { over } 75 & \text { A B } & & 0.20783333 \\ 0.001,150 \text { over } 90 & \text { A } & & 0.20291667 \\ 0.001,78 \text { over } 45 & \text { A B C } & 0.19266667 \\ 0.0005,150 \text { over } 90 & \text { B C D } & 0.18783333 \\ 0.0005,120 \text { over } 75 & \text { C D E } & 0.17258333 \\ 0.0005,78 \text { over } 45 & \text { D E F } & 0.16500000 \\ 0.00025,78 \text { over } 45 & & \text { E F } & 0.15908333 \\ 0.00025,120 \text { over } 75 & & \text { F } 0.15600000 \\ 0.00025,150 \text { over } 90 & \text { E F } 0.15583333\end{array}$

Levels not connected by same letter are significantly different. 


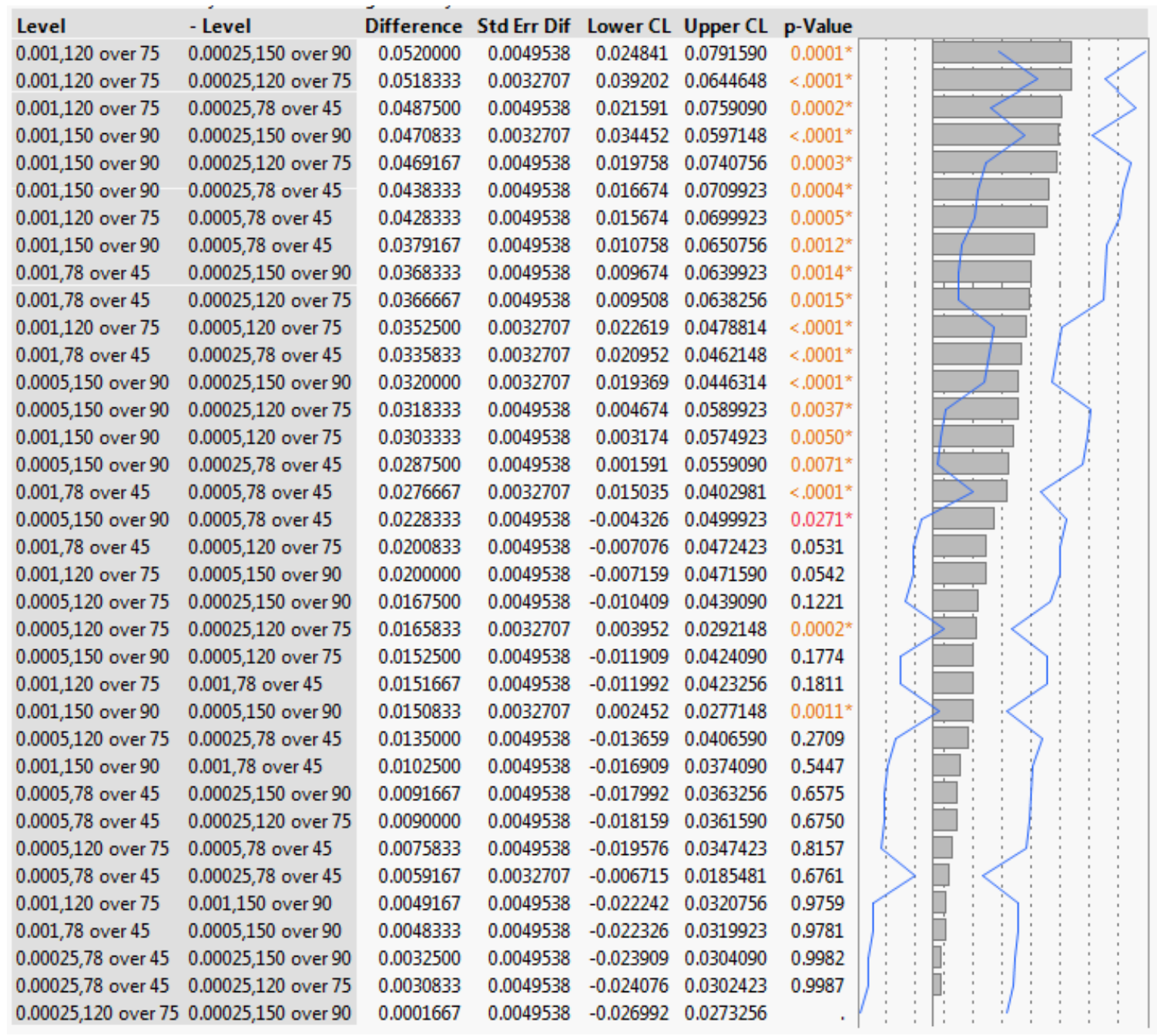

Outlet 4

\begin{tabular}{|c|c|c|c|c|c|}
\hline \multicolumn{6}{|l|}{ Fixed Effect Tests } \\
\hline Source & Nparm & DF & DFDen & F Ratio & Prob $>F$ \\
\hline Diameter & 2 & 2 & 44 & 847.6209 & $<.0001^{*}$ \\
\hline Density & 3 & 3 & 44 & 3.6105 & $0.0204^{*}$ \\
\hline $\mathrm{BP}$ & 2 & 2 & 4 & 2.0994 & 0.2380 \\
\hline Catheter & 2 & 2 & 4 & 0.5810 & 0.6005 \\
\hline Diameter ${ }^{\star}$ Density & 6 & 6 & 44 & 5.8059 & $0.0002^{*}$ \\
\hline Diameter ${ }^{*} \mathrm{BP}$ & 4 & 4 & 44 & 61.8501 & $<.0001^{*}$ \\
\hline Diameter ${ }^{*}$ Catheter & 4 & 4 & 44 & 1.6631 & 0.1756 \\
\hline Density $\mathrm{BP}$ & 6 & 6 & 44 & 6.3462 & $<.0001^{*}$ \\
\hline Density ${ }^{\star}$ Catheter & 6 & 6 & 44 & 1.4541 & 0.2162 \\
\hline Diameter ${ }^{\star}$ Density ${ }^{\star} \mathrm{BP}$ & 12 & 12 & 44 & 0.9612 & 0.4986 \\
\hline Diameter ${ }^{*}$ Density ${ }^{*}$ Catheter & 12 & 12 & 44 & 0.5785 & 0.8474 \\
\hline
\end{tabular}




\begin{tabular}{|c|c|c|}
\hline \multicolumn{3}{|c|}{$\Delta \nabla$ Diameter*Density } \\
\hline \multicolumn{3}{|c|}{$D$ Least Squares Means Table } \\
\hline \multicolumn{3}{|c|}{$\Delta \nabla$ LSMeans Differences Tukey HSD } \\
\hline \multicolumn{3}{|l|}{$\alpha=0.010$} \\
\hline & & Least \\
\hline Level & & Sq Mean \\
\hline $0.00025,1066$ & & 0.19677778 \\
\hline $0.00025,1220$ & $A B$ & 0.18666667 \\
\hline $0.00025,1450$ & $A B$ & 0.18544444 \\
\hline $0.00025,800$ & B C & 0.17666667 \\
\hline $0.0005,1220$ & B C & 0.17055556 \\
\hline $0.0005,1450$ & B C & 0.16977778 \\
\hline $0.0005,1066$ & $\mathrm{C}$ & 0.16677778 \\
\hline $0.0005,800$ & $\mathrm{C}$ & 0.15877778 \\
\hline $0.001,800$ & D & 0.10577778 \\
\hline $0.001,1066$ & D & 0.10066667 \\
\hline $0.001,1220$ & D & 0.09511111 \\
\hline $0.001,1450$ & $\mathrm{D}$ & 0.08766667 \\
\hline
\end{tabular}




\begin{tabular}{|c|c|c|c|c|c|c|c|}
\hline Level & - Level & Difference & Std Err Dif & Lower CL & Upper CL & p-Value & \\
\hline $0.00025,1066$ & $0.001,1450$ & 0.1091111 & 0.0045423 & 0.090743 & 0.1274790 & $<.0001^{*}$ & \\
\hline $0.00025,1066$ & $0.001,1220$ & 0.1016667 & 0.0045423 & 0.083299 & 0.1200345 & $<.0001^{*}$ & \\
\hline $0.00025,1220$ & $0.001,1450$ & 0.0990000 & 0.0045423 & 0.080632 & 0.1173679 & $<.0001^{*}$ & \\
\hline $0.00025,1450$ & $0.001,1450$ & 0.0977778 & 0.0045423 & 0.079410 & 0.1161456 & $<.0001^{*}$ & \\
\hline $0.00025,1066$ & $0.001,1066$ & 0.0961111 & 0.0045423 & 0.077743 & 0.1144790 & $<.0001^{\star}$ & \\
\hline $0.00025,1220$ & $0.001,1220$ & 0.0915556 & 0.0045423 & 0.073188 & 0.1099234 & $<.0001^{\star}$ & \\
\hline $0.00025,1066$ & $0.001,800$ & 0.0910000 & 0.0045423 & 0.072632 & 0.1093679 & $<.0001^{\star}$ & \\
\hline $0.00025,1450$ & $0.001,1220$ & 0.0903333 & 0.0045423 & 0.071965 & 0.1087012 & $<, 0001^{\star}$ & \\
\hline $0.00025,800$ & $0.001,1450$ & 0.0890000 & 0.0045423 & 0.070632 & 0.1073679 & $<.0001^{*}$ & \\
\hline $0.00025,1220$ & $0.001,1066$ & 0.0860000 & 0.0045423 & 0.067632 & 0.1043679 & $<.0001^{\star}$ & \\
\hline $0.00025,1450$ & $0.001,1066$ & 0.0847778 & 0.0045423 & 0.066410 & 0.1031456 & $<.0001^{\star}$ & \\
\hline $0.0005,1220$ & $0.001,1450$ & 0.0828889 & 0.0045423 & 0.064521 & 0.1012567 & $<.0001^{*}$ & \\
\hline $0.0005,1450$ & $0.001,1450$ & 0.0821111 & 0.0045423 & 0.063743 & 0.1004790 & $<.0001^{\star}$ & \\
\hline $0.00025,800$ & $0.001,1220$ & 0.0815556 & 0.0045423 & 0.063188 & 0.0999234 & $<.0001^{\star}$ & \\
\hline $0.00025,1220$ & $0.001,800$ & 0.0808889 & 0.0045423 & 0.062521 & 0.0992567 & $<.0001^{\star}$ & \\
\hline $0.00025,1450$ & $0.001,800$ & 0.0796667 & 0.0045423 & 0.061299 & 0.0980345 & $<.0001^{\star}$ & \\
\hline $0.0005,1066$ & $0.001,1450$ & 0.0791111 & 0.0045423 & 0.060743 & 0.0974790 & $<.0001^{\star}$ & \\
\hline $0.00025,800$ & $0.001,1066$ & 0.0760000 & 0.0045423 & 0.057632 & $\begin{array}{l}0.0943679 \\
0.0938123\end{array}$ & $\begin{array}{l}<.0001^{*} \\
<0001^{*}\end{array}$ & \\
\hline $\begin{array}{l}0.0005,1220 \\
0.0005,1450\end{array}$ & $\begin{array}{l}0.001,1220 \\
0.001,1220\end{array}$ & $\begin{array}{l}0.0754444 \\
0.0746667\end{array}$ & $\begin{array}{l}0.0045423 \\
0.0045423\end{array}$ & $\begin{array}{l}0.057077 \\
0.056299\end{array}$ & $\begin{array}{l}0.0938123 \\
0.0930345\end{array}$ & $\begin{array}{l}<.0001^{\star} \\
<.0001^{\star}\end{array}$ & \\
\hline $0.0005,1066$ & $0.001,1220$ & 0.0716667 & 0.0045423 & 0.053299 & 0.0900345 & $<.0001^{\star}$ & \\
\hline $0.0005,800$ & $0.001,1450$ & 0.0711111 & 0.0045423 & 0.052743 & 0.0894790 & $<.0001^{*}$ & \\
\hline $0.00025,800$ & $0.001,800$ & 0.0708889 & 0.0045423 & 0.052521 & 0.0892567 & $<.0001^{*}$ & \\
\hline $0.0005,1220$ & $0.001,1066$ & 0.0698889 & 0.0045423 & 0.051521 & 0.0882567 & $<.0001^{*}$ & \\
\hline $0.0005,1450$ & $0.001,1066$ & 0.0691111 & 0.0045423 & 0.050743 & 0.0874790 & $<.0001^{\star}$ & \\
\hline $0.0005,1066$ & $0.001,1066$ & 0.0661111 & 0.0045423 & 0.047743 & 0.0844790 & $<.0001^{\star}$ & \\
\hline $0.0005,1220$ & $0.001,800$ & 0.0647778 & 0.0045423 & 0.046410 & 0.0831456 & $<.0001^{\star}$ & \\
\hline $0.0005,1450$ & $0.001,800$ & 0.0640000 & 0.0045423 & 0.045632 & 0.0823679 & $<.0001^{*}$ & \\
\hline $0.0005,800$ & $0.001,1220$ & 0.0636667 & 0.0045423 & 0.045299 & 0.0820345 & $<.0001^{\star}$ & \\
\hline $0.0005,1066$ & $0.001,800$ & 0.0610000 & 0.0045423 & 0.042632 & 0.0793679 & $<.0001^{*}$ & \\
\hline $\begin{array}{l}0.0005,800 \\
0.0005,800\end{array}$ & $\begin{array}{l}0.001,1066 \\
0.001,800\end{array}$ & $\begin{array}{l}0.0581111 \\
0.0530000\end{array}$ & $\begin{array}{l}0.0045423 \\
0.0045423\end{array}$ & $\begin{array}{l}0.039743 \\
0.034632\end{array}$ & $\begin{array}{l}0.0764790 \\
0.0713670\end{array}$ & $\begin{array}{l}<.0001^{\star} \\
<.0001^{\star}\end{array} \mid$ & \\
\hline $0.00025,1066$ & $0.0005,800$ & 0.0380000 & 0.0045423 & 0.019632 & 0.0563679 & $<.0001^{\star}$ & \\
\hline $0.00025,1066$ & $0.0005,1066$ & 0.0300000 & 0.0045423 & 0.011632 & 0.0483679 & $<.0001^{*}$ & \\
\hline $0.00025,1220$ & $0.0005,800$ & 0.0278889 & 0.0045423 & 0.009521 & 0.0462567 & $<.0001^{*}$ & \\
\hline $0.00025,1066$ & $0.0005,1450$ & 0.0270000 & 0.0045423 & 0.008632 & 0.0453679 & $<.0001^{*}$ & \\
\hline $0.00025,1450$ & $0.0005,800$ & 0.0266667 & 0.0045423 & 0.008299 & 0.0450345 & $<.0001^{*}$ & \\
\hline $0.00025,1066$ & $0.0005,1220$ & 0.0262222 & 0.0045423 & 0.007854 & 0.0445901 & $<.0001^{\star}$ & \\
\hline $0.00025,1066$ & $0.00025,800$ & 0.0201111 & 0.0045423 & 0.001743 & 0.0384790 & $0.0032^{*}$ & \\
\hline & $0.0005,1066$ & 0.0198889 & 0.0045423 & 0.001521 & 0.0382567 & $0.0037^{\star}$ & \\
\hline $0.00025,1450$ & $0.0005,1066$ & 0.0186667 & 0.0045423 & 0.000299 & 0.0370345 & $0.0083^{*}$ & \\
\hline
\end{tabular}




$\begin{array}{ll}0.001,1066 & 0.001,1450 \\ 0.0005,1220 & 0.0005,800 \\ 0.00025,1066 & 0.00025,1450 \\ 0.0005,1450 & 0.0005,800 \\ 0.001,800 & 0.001,1220 \\ 0.00025,1066 & 0.00025,1220 \\ 0.00025,1220 & 0.00025,800 \\ 0.00025,800 & 0.0005,1066 \\ 0.00025,1450 & 0.00025,800 \\ 0.0005,1066 & 0.0005,800 \\ 0.001,1220 & 0.001,1450 \\ 0.00025,800 & 0.0005,1450 \\ 0.00025,800 & 0.0005,1220 \\ 0.001,1066 & 0.001,1220 \\ 0.001,800 & 0.001,1066 \\ 0.0005,1220 & 0.0005,1066 \\ 0.0005,1450 & 0.0005,1066 \\ 0.00025,1220 & 0.00025,1450 \\ 0.0005,1220 & 0.0005,1450\end{array}$

$\begin{array}{lllll}0.0130000 & 0.0045423 & -0.005368 & 0.0313679 & 0.1905 \\ 0.0117778 & 0.0045423 & -0.006590 & 0.0301456 & 0.3144 \\ 0.0113333 & 0.0045423 & -0.007035 & 0.0297012 & 0.3694 \\ 0.0110000 & 0.0045423 & -0.007368 & 0.0293679 & 0.4137 \\ 0.0106667 & 0.0045423 & -0.007701 & 0.0290345 & 0.4602 \\ 0.0101111 & 0.0045423 & -0.008257 & 0.0284790 & 0.5408 \\ 0.0100000 & 0.0045423 & -0.008368 & 0.0283679 & 0.5573 \\ 0.0098889 & 0.0045423 & -0.008479 & 0.0282567 & 0.5737 \\ 0.0087778 & 0.0045423 & -0.009590 & 0.0271456 & 0.7332 \\ 0.0080000 & 0.0045423 & -0.010368 & 0.0263679 & 0.8293 \\ 0.0074444 & 0.0045423 & -0.010923 & 0.0258123 & 0.8848 \\ 0.0068889 & 0.0045423 & -0.011479 & 0.0252567 & 0.9279 \\ 0.0061111 & 0.0045423 & -0.012257 & 0.0244790 & 0.9677 \\ 0.0055556 & 0.0045423 & -0.012812 & 0.0239234 & 0.9841 \\ 0.0051111 & 0.0045423 & -0.013257 & 0.0234790 & 0.9917 \\ 0.0037778 & 0.0045423 & -0.014590 & 0.0221456 & 0.9994 \\ 0.0030000 & 0.0045423 & -0.015368 & 0.0213679 & 0.9999 \\ 0.0012222 & 0.0045423 & -0.017146 & 0.0195901 & 1.0000 \\ 0.0007778 & 0.0045423 & -0.017590 & 0.0191456 & \end{array}$

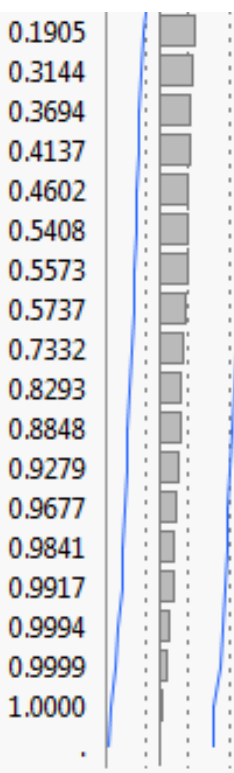

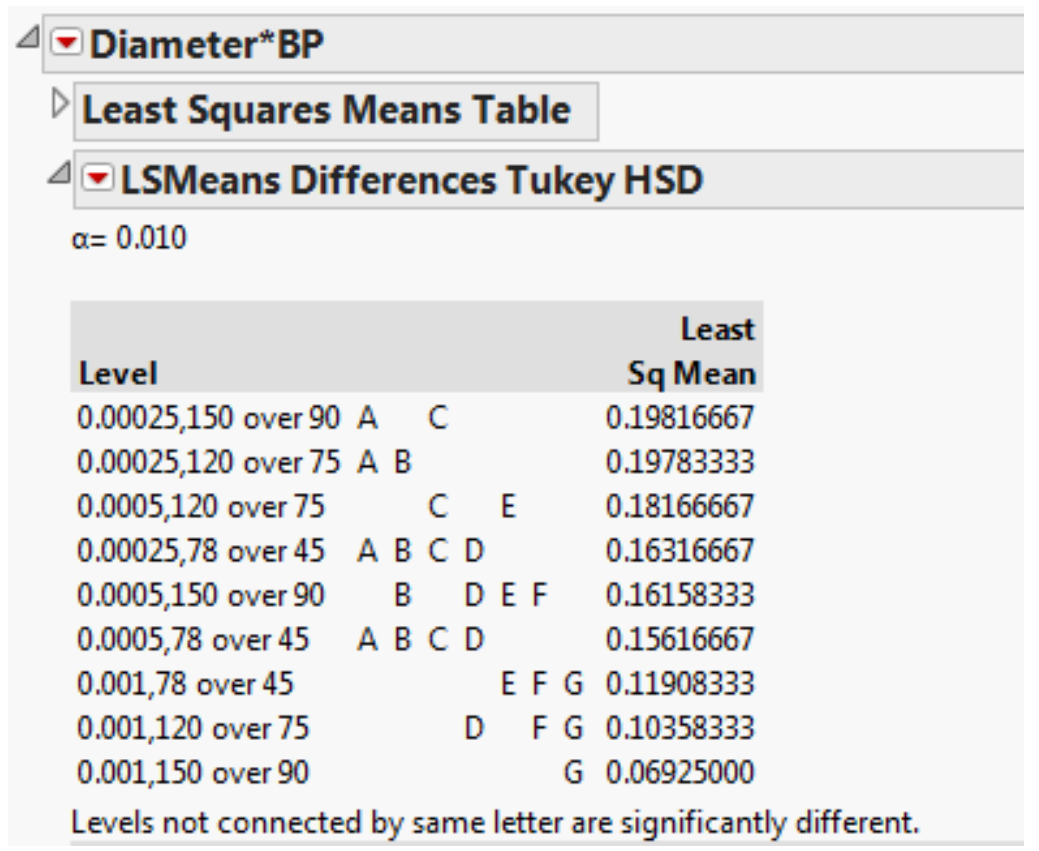




\begin{tabular}{|c|c|}
\hline Level & - Level \\
\hline $0.00025,150$ over 90 & $0.001,150$ over 90 \\
\hline $0.00025,120$ over 75 & $0.001,150$ over 90 \\
\hline $0.0005,120$ over 75 & $0.001,150$ over 90 \\
\hline $0.00025,150$ over 90 & $0.001,120$ over 75 \\
\hline $0.00025,120$ over 75 & $0.001,120$ over 75 \\
\hline $0.00025,78$ over 45 & $0.001,150$ over 90 \\
\hline $0.0005,150$ over 90 & $0.001,150$ over 90 \\
\hline $0.0005,78$ over 45 & $0.001,150$ over 90 \\
\hline $0.00025,150$ over 90 & $0.001,78$ over 45 \\
\hline $0.00025,120$ over 75 & $0.001,78$ over 45 \\
\hline $0.0005,120$ over 75 & $0.001,120$ over 75 \\
\hline $0.0005,120$ over 75 & $0.001,78$ over 45 \\
\hline $0.00025,78$ over 45 & $0.001,120$ over 75 \\
\hline $0.0005,150$ over 90 & $0.001,120$ over 75 \\
\hline $0.0005,78$ over 45 & $0.001,120$ over 75 \\
\hline $0.001,78$ over 45 & $0.001,150$ over 90 \\
\hline $0.00025,78$ over 45 & $0.001,78$ over 45 \\
\hline $0.0005,150$ over 90 & $0.001,78$ over 45 \\
\hline $0.00025,150$ over 90 & $0.0005,78$ over 45 \\
\hline $0.00025,120$ over 75 & $0.0005,78$ over 45 \\
\hline $0.0005,78$ over 45 & $0.001,78$ over 45 \\
\hline $0.00025,150$ over 90 & $0.0005,150$ over 90 \\
\hline $0.00025,120$ over 75 & $0.0005,150$ over 90 \\
\hline $0.00025,150$ over 90 & $0.00025,78$ over 45 \\
\hline $0.00025,120$ over 75 & $0.00025,78$ over 45 \\
\hline $0.001,120$ over 75 & $0.001,150$ over 90 \\
\hline $0.0005,120$ over 75 & $0.0005,78$ over 45 \\
\hline $0.0005,120$ over 75 & $0.0005,150$ over 90 \\
\hline $0.0005,120$ over 75 & $0.00025,78$ over 45 \\
\hline $0.00025,150$ over 90 & $0.0005,120$ over 75 \\
\hline $0.00025,120$ over 75 & $0.0005,120$ over 75 \\
\hline $0.001,78$ over 45 & $0.001,120$ over 75 \\
\hline $0.00025,78$ over 45 & $0.0005,78$ over 45 \\
\hline $0.0005,150$ over 90 & $0.0005,78$ over 45 \\
\hline $0.00025,78$ over 45 & $0.0005,150$ over 90 \\
\hline $0.00025,150$ over 90 & $0.00025,120$ over 7 \\
\hline
\end{tabular}

Difference Std Err Dif Lower CL Upper CL p-Value

$\begin{array}{llllll}0.1289167 & 0.0039338 & 0.113725 & 0.1441088 & <.0001\end{array}$

$\begin{array}{llllll}0.1285833 & 0.0099338 & 0.058366 & 0.1988008 & 0.0006 *\end{array}$

$\begin{array}{llllll}0.1124167 & 0.0099338 & 0.042199 & 0.1826341 & 0.0011\end{array}$

$\begin{array}{llllll}0.0945833 & 0.0099338 & 0.024366 & 0.1648008 & 0.0026^{*}\end{array}$

$\begin{array}{llllll}0.0942500 & 0.0039338 & 0.079058 & 0.1094421 & <.0001\end{array}$

$\begin{array}{llllll}0.0939167 & 0.0099338 & 0.023699 & 0.1641341 & 0.0027^{*}\end{array}$

$\begin{array}{llllll}0.0923333 & 0.0039338 & 0.077141 & 0.1075255 & <.0001 *\end{array}$

$\begin{array}{llllll}0.0869167 & 0.0099338 & 0.016699 & 0.1571341 & 0.0038 *\end{array}$

$\begin{array}{llllll}0.0790833 & 0.0099338 & 0.008866 & 0.1493008 & 0.0059\end{array}$

$\begin{array}{llllll}0.0787500 & 0.0099338 & 0.008533 & 0.1489674 & 0.0060^{*}\end{array}$

$\begin{array}{llllll}0.0780833 & 0.0039338 & 0.062891 & 0.0932755 & <.0001 *\end{array}$

$\begin{array}{llllll}0.0625833 & 0.0099338 & -0.007634 & 0.1328008 & 0.0165^{*}\end{array}$

$\begin{array}{llllll}0.0595833 & 0.0099338 & -0.010634 & 0.1298008 & 0.0204^{*}\end{array}$

$\begin{array}{llllll}0.0580000 & 0.0099338 & -0.012217 & 0.1282174 & 0.0229 *\end{array}$

$\begin{array}{llllll}0.0525833 & 0.0099338 & -0.017634 & 0.1228008 & 0.0343 *\end{array}$

$\begin{array}{llllll}0.0498333 & 0.0099338 & -0.020384 & 0.1200508 & 0.0426^{*}\end{array}$

$\begin{array}{llllll}0.0440833 & 0.0039338 & 0.028891 & 0.0592755 & <.0001^{*}\end{array}$

$\begin{array}{llllll}0.0425000 & 0.0099338 & -0.027717 & 0.1127174 & 0.0784\end{array}$

$\begin{array}{llllll}0.0420000 & 0.0099338 & -0.028217 & 0.1122174 & 0.0819\end{array}$

$\begin{array}{llllll}0.0416667 & 0.0099338 & -0.028551 & 0.1118841 & 0.0843\end{array}$

$\begin{array}{llllll}0.0370833 & 0.0039338 & 0.021891 & 0.0522755 & <.0001 *\end{array}$

$\begin{array}{llllll}0.0365833 & 0.0039338 & 0.021391 & 0.0517755 & <.0001^{*}\end{array}$

$\begin{array}{llllll}0.0362500 & 0.0099338 & -0.033967 & 0.1064674 & 0.1367\end{array}$

$\begin{array}{llllll}0.0350000 & 0.0099338 & -0.035217 & 0.1052174 & 0.1533\end{array}$

$\begin{array}{llllll}0.0346667 & 0.0099338 & -0.035551 & 0.1048841 & 0.1581\end{array}$

$\begin{array}{llllll}0.0343333 & 0.0099338 & -0.035884 & 0.1045508 & 0.1630\end{array}$

$\begin{array}{llllll}0.0255000 & 0.0099338 & -0.044717 & 0.0957174 & 0.3691\end{array}$

$\begin{array}{llllll}0.0200833 & 0.0099338 & -0.050134 & 0.0903008 & 0.5849\end{array}$

$\begin{array}{llllll}0.0185000 & 0.0099338 & -0.051717 & 0.0887174 & 0.6580\end{array}$

$\begin{array}{llllll}0.0165000 & 0.0099338 & -0.053717 & 0.0867174 & 0.7509\end{array}$

$\begin{array}{llllll}0.0161667 & 0.0039338 & 0.000975 & 0.0313588 & 0.0049 *\end{array}$

$\begin{array}{llllll}0.0155000 & 0.0099338 & -0.054717 & 0.0857174 & 0.7955\end{array}$

$\begin{array}{llllll}0.0070000 & 0.0039338 & -0.008192 & 0.0221921 & 0.6948\end{array}$

$\begin{array}{llllll}0.0054167 & 0.0099338 & -0.064801 & 0.0756341 & 0.9993\end{array}$

$\begin{array}{llllll}0.0015833 & 0.0099338 & -0.068634 & 0.0718008 & 1.0000\end{array}$ 0.0003333

0.0099338

$-0.0698840 .0705508$

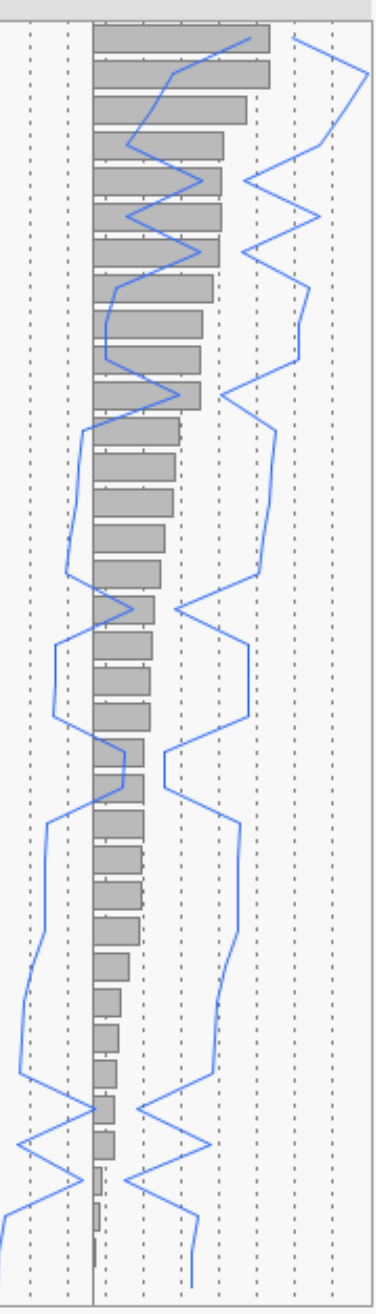




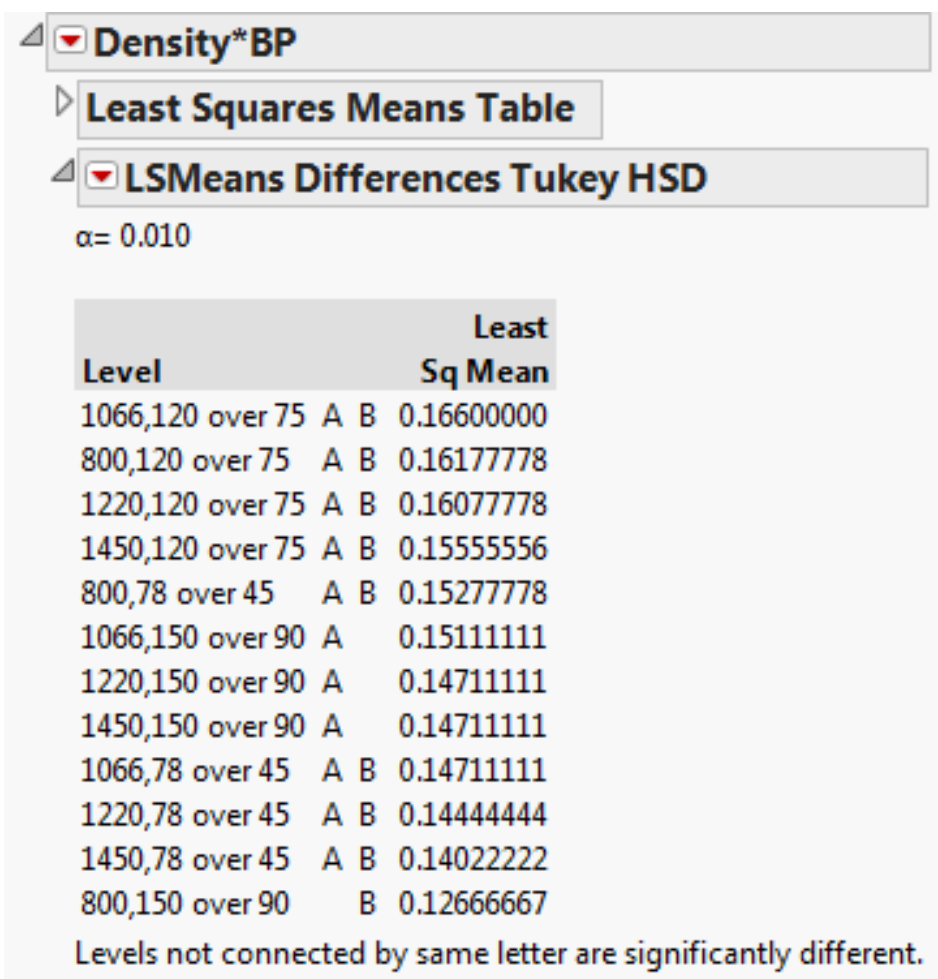




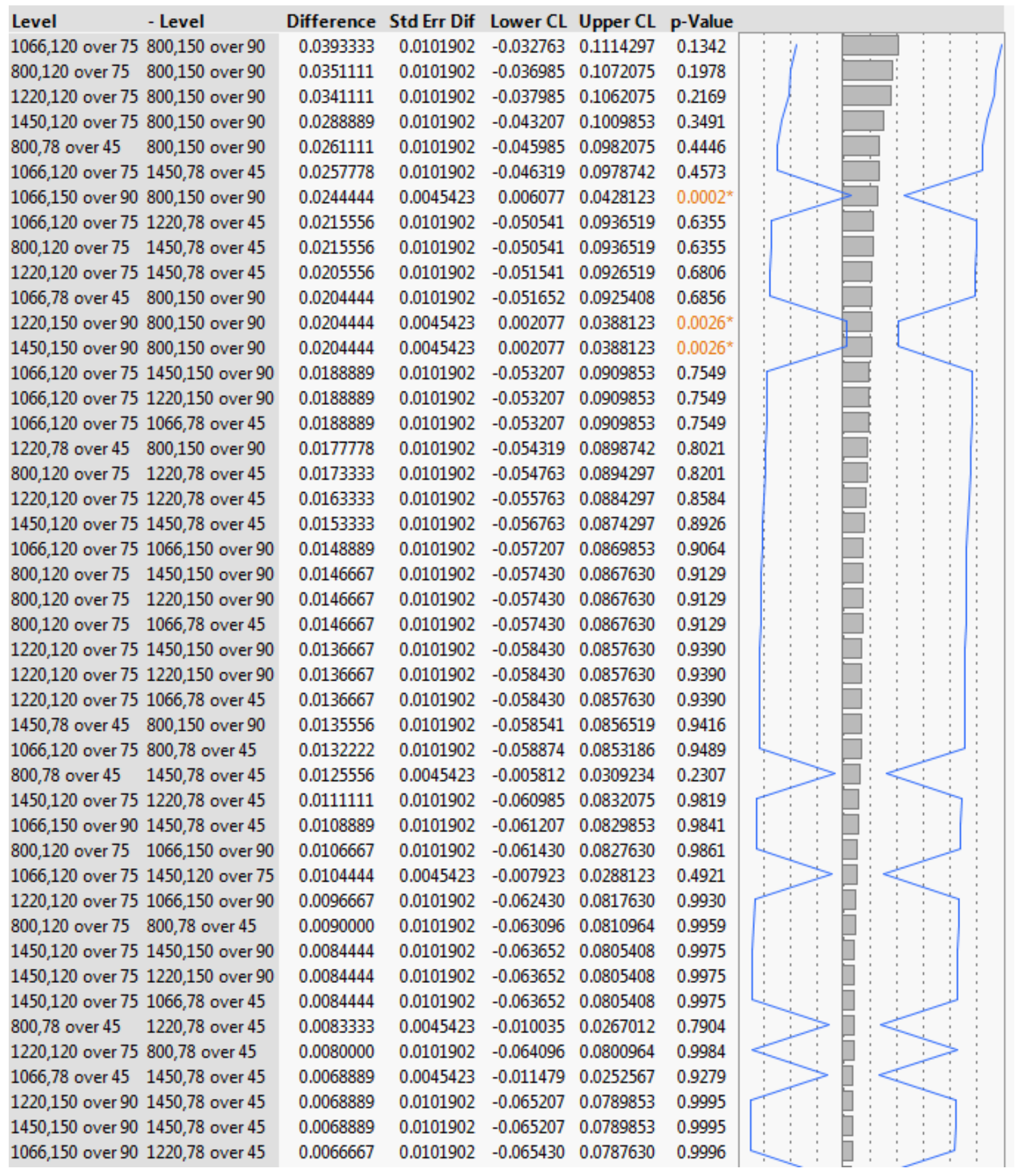




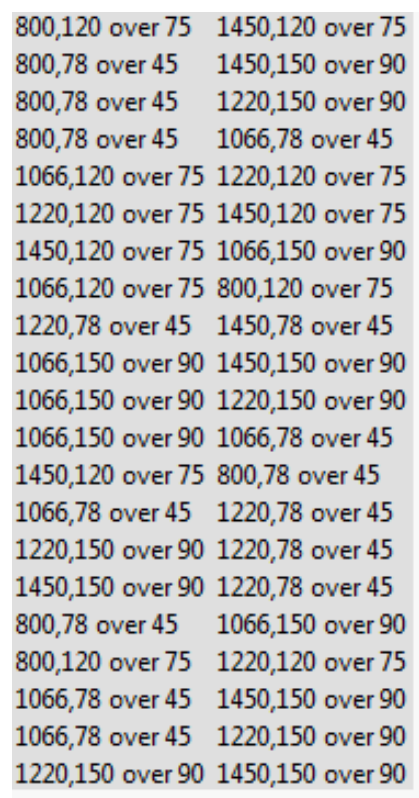

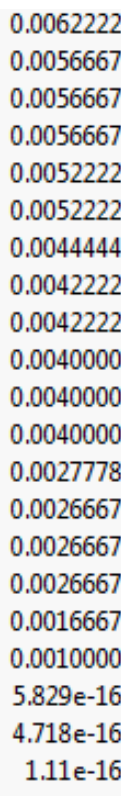

0.0062222 0.0056667

0.0056667

0.0056667

0.0052222

0.0052222

.0044444

0.0042222

0.0040000

0.0040000

0.0040000

0.0027778

0.0026667

0.0026667

0.0026667

0.0016667

.

$4.718 \mathrm{e}-16$

$1.11 \mathrm{e}-16$

\begin{abstract}
$\begin{array}{lll}0.0045423 & -0.012146 & 0.0245901\end{array}$
$\begin{array}{llll}0.0101902 & -0.066430 & 0.0777630\end{array}$

$\begin{array}{llll}0.0101902 & -0.066430 & 0.0777630\end{array}$

$\begin{array}{lll}0.0045423 & -0.012701 & 0.0240345\end{array}$

$\begin{array}{lll}0.0045423 & -0.013146 & 0.0235901\end{array}$

$\begin{array}{lll}0.0045423 & -0.013146 & 0.0235901\end{array}$

$\begin{array}{llll}0.0101902 & -0.067652 & 0.0765408\end{array}$

$\begin{array}{lll}0.0045423 & -0.014146 & 0.0225901\end{array}$

$\begin{array}{llll}0.0045423 & -0.014146 & 0.0225901\end{array}$

$\begin{array}{llll}0.0045423 & -0.014368 & 0.0223679\end{array}$

$\begin{array}{llll}0.0045423 & -0.014368 & 0.0223679\end{array}$

$\begin{array}{llll}0.0101902 & -0.068096 & 0.0760964\end{array}$

$\begin{array}{lll}0.0101902 & -0.069319 & 0.0748742\end{array}$

$\begin{array}{llll}0.0045423 & -0.015701 & 0.0210345\end{array}$

$\begin{array}{lll}0.0101902 & -0.069430 & 0.0747630\end{array}$

$\begin{array}{llll}0.0101902 & -0.069430 & 0.0747630\end{array}$

$\begin{array}{lll}0.0101902 & -0.070430 & 0.0737630\end{array}$

$\begin{array}{llll}0.0045423 & -0.017368 & 0.0193679\end{array}$

$\begin{array}{llll}0.0101902 & -0.072096 & 0.0720964\end{array}$

$\begin{array}{llll}0.0101902 & -0.072096 & 0.0720964\end{array}$

$\begin{array}{llll}0.0045423 & -0.018368 & 0.0183679\end{array}$
\end{abstract}
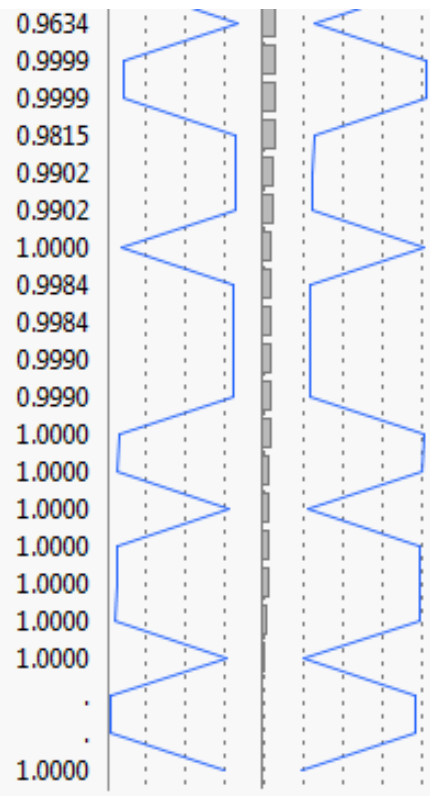

Not Out

\begin{tabular}{|c|c|c|c|c|c|}
\hline \multicolumn{6}{|l|}{$\Delta$ Fixed Effect Tests } \\
\hline Source & Nparm & DF & DFDen & F Ratio & Prob $>F$ \\
\hline Diameter & 2 & 2 & 44 & 35.6823 & $<.0001^{*}$ \\
\hline Density & 3 & 3 & 44 & 1.9413 & 0.1368 \\
\hline $\mathrm{BP}$ & 2 & 2 & 4 & 70.0827 & $0.0008^{*}$ \\
\hline Catheter & 2 & 2 & 4 & 1.6034 & 0.3081 \\
\hline Diameter ${ }^{*}$ Density & 6 & 6 & 44 & 2.8095 & $0.0211^{*}$ \\
\hline Diameter ${ }^{*} \mathrm{BP}$ & 4 & 4 & 44 & 25.8785 & $<.0001^{*}$ \\
\hline Diameter ${ }^{\star}$ Catheter & 4 & 4 & 44 & 1.2551 & 0.3020 \\
\hline Density ${ }^{\star B P}$ & 6 & 6 & 44 & 1.6139 & 0.1660 \\
\hline Density ${ }^{\star}$ Catheter & 6 & 6 & 44 & 2.3903 & $0.0437^{\star}$ \\
\hline Diameter ${ }^{\star}$ Density ${ }^{\star} \mathrm{BP}$ & 12 & 12 & 44 & 1.2826 & 0.2626 \\
\hline Diameter ${ }^{\star}$ Density ${ }^{\star}$ Catheter & 12 & 12 & 44 & 1.0787 & 0.4005 \\
\hline
\end{tabular}




\begin{tabular}{|c|c|c|}
\hline \multicolumn{3}{|l|}{ Diameter ${ }^{*}$ BP } \\
\hline \multicolumn{3}{|c|}{$D$ Least Squares Means Table } \\
\hline \multicolumn{3}{|c|}{$\triangle \nabla$ LSMeans Differences Tukey HSD } \\
\hline \multicolumn{3}{|c|}{$\alpha=0.010$} \\
\hline Level & & $\begin{array}{r}\text { Leas } \\
\text { Sq Meal }\end{array}$ \\
\hline $0.00025,78$ over 45 & A & 0.0746666 \\
\hline $0.0005,78$ over 45 & A & 0.0681666 \\
\hline $0.001,78$ over 45 & B & 0.0550833 \\
\hline $0.001,150$ over 90 & $B C \quad E$ & 0.0316666 \\
\hline $0.00025,120$ over 75 & $B C D$ & 0.0314166 \\
\hline $0.00025,150$ over 90 & $B C \quad E$ & 0.0291666 \\
\hline $0.001,120$ over 75 & CDEF & 0.0255000 \\
\hline $0.0005,120$ over 75 & E F & 0.0217500 \\
\hline $0.0005,150$ over 90 & D F & 0.0182500 \\
\hline
\end{tabular}

Levels not connected by same letter are significantly different.

$\begin{array}{ll}\text { Level } & - \text { Level } \\ 0.00025,78 \text { over } 45 & 0.0005,150 \text { over } 90 \\ 0.00025,78 \text { over } 45 & 0.0005,120 \text { over } 75 \\ 0.0005,78 \text { over } 45 & 0.0005,150 \text { over } 90 \\ 0.00025,78 \text { over } 45 & 0.001,120 \text { over } 75 \\ 0.0005,78 \text { over } 45 & 0.0005,120 \text { over } 75 \\ 0.00025,78 \text { over } 45 & 0.00025,150 \text { over } 90 \\ 0.00025,78 \text { over } 45 & 0.00025,120 \text { over } 75 \\ 0.00025,78 \text { over } 45 & 0.001,150 \text { over } 90 \\ 0.0005,78 \text { over } 45 & 0.001,120 \text { over } 75 \\ 0.0005,78 \text { over } 45 & 0.00025,150 \text { over } 90 \\ 0.001,78 \text { over } 45 & 0.0005,150 \text { over } 90 \\ 0.0005,78 \text { over } 45 & 0.00025,120 \text { over } 75 \\ 0.0005,78 \text { over } 45 & 0.001,150 \text { over } 90 \\ 0.001,78 \text { over } 45 & 0.0005,120 \text { over } 75 \\ 0.001,78 \text { over } 45 & 0.001,120 \text { over } 75 \\ 0.001,78 \text { over } 45 & 0.00025,150 \text { over } 90 \\ 0.001,78 \text { over } 45 & 0.00025,120 \text { over } 75 \\ 0.001,78 \text { over } 45 & 0.001,150 \text { over } 90 \\ 0.00025,78 \text { over } 45 & 0.001,78 \text { over } 45 \\ 0.001,150 \text { over } 90 & 0.0005,150 \text { over } 90 \\ 0.00025,120 \text { over } 75 & 0.0005,150 \text { over } 90 \\ 0.0005,78 \text { over } 45 & 0.001,78 \text { over } 45 \\ 0.00025,150 \text { over } 90 & 0.0005,150 \text { over } 90 \\ 0.001,150 \text { over } 90 & 0.0005,120 \text { over } 75 \\ 0.00025,120 \text { over } 75 & 0.0005,120 \text { over } 75 \\ 0.00025,150 \text { over } 90 & 0.0005,120 \text { over } 75 \\ 0.001,120 \text { over } 75 & 0.0005,150 \text { over } 90 \\ 0.00025,78 \text { over } 45 & 0.0005,78 \text { over } 45 \\ 0.001,150 \text { over } 90 & 0.001,120 \text { over } 75 \\ 0.00025,120 \text { over } 75 & 0.001,120 \text { over } 75 \\ 0.001,120 \text { over } 75 & 0.0005,120 \text { over } 75 \\ 0.00025,150 \text { over } 90 & 0.001,120 \text { over } 75 \\ 0.0005,120 \text { over } 75 & 0.0005,150 \text { over } 90 \\ 0.001,150 \text { over } 90 & 0.00025,150 \text { over } 90 \\ 0.00025,120 \text { over } 75 & 0.00025,150 \text { over } 90 \\ 0.001,150 \text { over } 90 & 0.00025,120 \text { over } 75 \\ & \end{array}$

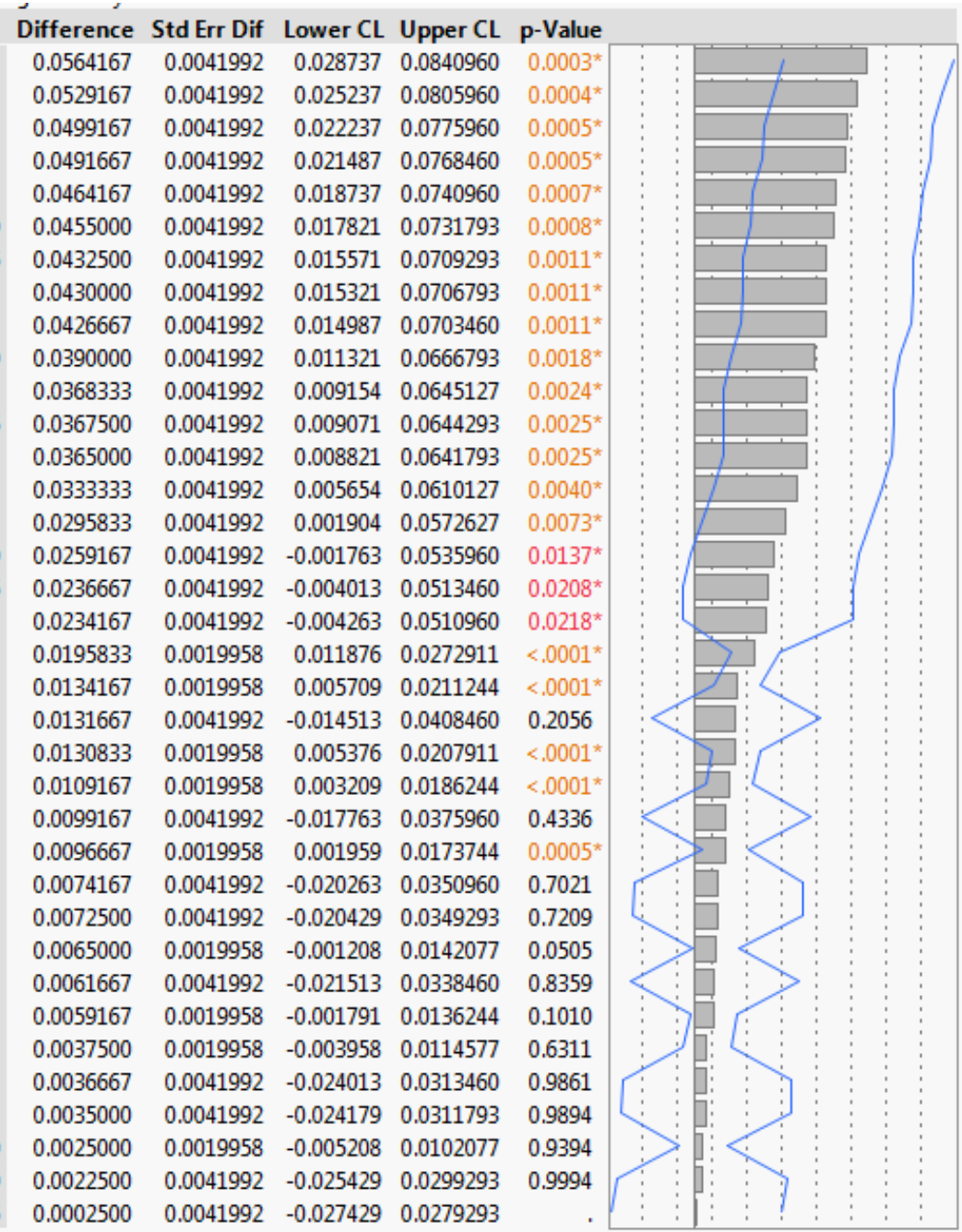

